IS HAPPINESS U-SHAPED EVERYWHERE? AGE AND SUBJECTIVE WELL-BEING IN 132 COUNTRIES

David G. Blanchflower

WORKING PAPER 26641 


\title{
IS HAPPINESS U-SHAPED EVERYWHERE? AGE AND SUBJECTIVE WELL-BEING IN 132 COUNTRIES
}

David G. Blanchflower

Working Paper 26641

http://www.nber.org/papers/w26641

\author{
NATIONAL BUREAU OF ECONOMIC RESEARCH \\ 1050 Massachusetts Avenue \\ Cambridge, MA 02138 \\ January 2020
}

The views expressed herein are those of the author and do not necessarily reflect the views of the National Bureau of Economic Research.

NBER working papers are circulated for discussion and comment purposes. They have not been peer-reviewed or been subject to the review by the NBER Board of Directors that accompanies official NBER publications.

(C) 2020 by David G. Blanchflower. All rights reserved. Short sections of text, not to exceed two paragraphs, may be quoted without explicit permission provided that full credit, including () notice, is given to the source. 
Is Happiness U-shaped Everywhere? Age and Subjective Well-being in 132 Countries

David G. Blanchflower

NBER Working Paper No. 26641

January 2020

JEL No. I31,J01

\begin{abstract}
$\underline{\text { ABSTRACT }}$
I draw systematic comparisons across 109 data files and 132 countries of the relationship between well-being, variously defined, and age. I produce 444 significant country estimates with controls, so these are ceteris paribus effects, and find evidence of a well-being U-shape in age in one hundred and thirty-two countries, including ninety-five developing countries, controlling for education, marital and labor force status. I also frequently find it without any controls at all. There is additional evidence from an array of attitudinal questions that were worded slightly differently than standard happiness or life satisfaction questions such as satisfaction with an individual's financial situation. Averaging across the 257 individual country estimates from developing countries gives an age minimum of 48.2 for well-being and doing the same across the 187 country estimates for advanced countries gives a similar minimum of 47.2. The happiness curve is everywhere.
\end{abstract}

David G. Blanchflower

Bruce V. Rauner Professor of Economics

6106 Rockefeller Hall

Dartmouth College

Hanover, NH 03755-3514

and NBER

David.G.Blanchflower@Dartmouth.EDU 
In this paper I identify U-shapes in age in well-being data, variously defined, in one hundred and twenty-eight advanced and developing countries. I find the happiness curve (Rauch, 2019) for ninety-five developing countries ${ }^{1}$ and thirty-seven advanced including controls for gender, education, marital and labor force status, and year when pooled year surveys are used . $^{2}$ I report 444 separate country level estimates across countries from a number of data files from around the world, 187 from advanced countries and 257 from developing countries. The age minima appear to center in midlife around age fifty for both.

\section{Previous Evidence on the Happiness Curve}

The background literature is large and, there is some disagreement over whether U-shapes exist at all, see, for example, Baird et al. (2010), Blanchflower (2009a), Blanchflower and Oswald (2008a, 2009, 2011), Carstensen et al. (2011), Charles et al. (2001), Easterlin (2003, 2006), Frey and Stutzer (2002), Frijters and Beaton (2012), Glenn (2009), Graham and Pozuelo (2017), Hellevik (2017), Hudson et al. (2016), Lachman (2015), Leland (2018), Mroczek and Kolanz (1998), Mroczek and Spiro (2005), Rauch (2018) Shields and Wheatley Price (2005), Stone et al. 2010, Steptoe et al. (2015), Wunder et al. (2013), Schwandt (2016).

Easterlin (2006) is a particularly important paper. Controlling for year of birth, it finds evidence of a hill-shape in well-being over the life cycle. His paper used pooled General Social Survey data from the United States. A recent review by Ulloa et al. (2013) goes as far as to draw the conclusion that "extant studies ... show either a U-shaped, inverted U-shaped or linear relation between ageing and subjective well-being." Other studies, such as Lachman (2015), come close to arguing that there may be a midlife dip but that it is too small to be significant. I disagree.

An early psychology literature suggested there was no age-happiness relationship (Cantril, 1965, and Palmore and Luikart, 1972). Myers (2000, p. 58) argued that "Although many people believe there are unhappy times of life- times of adolescent stress, midlife crisis, or old age decline repeated surveys across the industrialized world reveal that no time in life is notably happiest and most satisfying". In contrast, Michael Argyle, concluded that studies of life satisfaction found that it increased with age (Argyle, 1999, 2001). A survey by Diener et al (1999, p. 291) concluded that "recent studies converge to show that life satisfaction often increases, or at least does not drop, with age”.

\footnotetext{
${ }^{1}$ Albania; Algeria; Argentina; Armenia; Azerbaijan; Bangladesh; Belarus; Benin; Bolivia; Bosnia; Botswana; Brazil; Burkina Faso; Burundi; Cameroon; Cape Verde; Chile; China; Columbia; Costa Rica; Cote d'Ivoire; Dominican Republic; Ecuador; Egypt; El Salvador; eSwatini; Gabon; Georgia; Ghana; Honduras; India; Indonesia; Iran; Iraq; Israel; Jordan; Kenya; Kosovo; Kuwait; Kyrgyzstan; Laos; Lebanon; Lesotho; Liberia; Libya; Macedonia; Madagascar; Malawi; Malaysia; Maldives; Mali; Mauritius; Mexico; Moldova; Mongolia; Montenegro; Morocco; Mozambique; Myanmar; Namibia; Niger; Nigeria; Panama; Paraguay; Peru; Philippines; Puerto Rico; Russia; São Tomé; Senegal; Serbia; Singapore; South Africa; South Korea; Sri Lanka; Surinam; Swaziland; Taiwan; Tajikistan; Tanzania; Thailand; Togo; Trinidad; Tunisia; Turkey; Turkish Cyprus; Uganda; Ukraine; Uruguay; Uzbekistan; Venezuela; Vietnam; Yemen; Zambia and Zimbabwe.

${ }^{2}$ Australia; Austria; Belgium; Bulgaria; Canada; Croatia; Cyprus; Czech Republic; Denmark; Estonia; Finland; France; Germany; Greece; Hungary; Iceland; Ireland; Italy; Japan; Latvia; Lithuania; Luxembourg; Malta; Netherlands; New Zealand; Norway; Poland; Portugal; Romania; Slovakia; Slovenia; Spain; Sweden; Switzerland; United Kingdom and the United States.
} 
More recently Whitbourne (2018) has gone so far as to argue that the U-shape curve is a 'myth' despite based on no serious analysis. Whitbourne complains, without any evidence, about possible sample selection bias in relation to who is able to answer the survey questions in the later adult decades. Clearly, not the people who are either no longer alive, or are in a life situation where they cannot answer questions. It's the survivors whom researchers can test. They may have been happy and non-depressed for their entire lives. If the data analyses were based only on survivors, the picture that emerges might be completely different. Instead of a dip, you would see a straight line or even an increase." The U-shape I identify is taken from large random samples of the population. Dead people don't answer the surveys that is true. I illustrate that the U-shape exists between ages sixteen and seventy in the vast majority of countries that I have data for, developed or developing.

Whitbourne also suggests that you can redraw the U-shapes we identify with a smaller scale which makes them look as if they are a straight line rather than a U-shape. She specifically criticizes the results in Blanchflower and Oswald (2019). "The 'dip' involves a difference between 7.2 and 7.8. No statistical analyses are provided in the paper, because, as the authors claim, the large sample size would ensure this finding would achieve statistical significance. However, if you redraw the graph, which I was able to do from the format in which I received it, the curve turns into a wobbly line in which a dip is just barely discernible." It turns out the dip is neither small quantitatively nor is it statistically insignificant.

I update and extend results in an earlier paper, (Blanchflower and Oswald, 2008a), where it was shown that a U-shape in age existed in well-being data across a number of countries. Using data on 500,000 randomly sampled Americans and West Europeans, the paper found that holding other factors constant, a typical individual's happiness reaches its minimum on both sides of the Atlantic for both males and females in middle age. ${ }^{3}$ The minimum in age was broadly similar between advanced, East European and developing nations. The function minimized on average in mid-life. For example, in Europe for both men and women it minimized at around 47 with controls including education, marital and labor force status. For developing countries from the WVS, sweeps 1-4, minima were 43 for men and 44 for women. A maximum in age in unhappiness data for Europe was found at around age 47. Some apparent exceptions, particularly in twenty developing nations along with a few western countries, mostly where there are small numbers of observations, to the U-shape were noted. ${ }^{4}$

\footnotetext{
${ }^{3}$ Evidence for a U-shape was found in twenty-two advanced countries (Australia; Belgium; Canada; Denmark; Finland; France; Germany; Greece; Iceland; Ireland; Italy; Japan; Luxembourg; Malta; Netherlands; Norway; Portugal; Spain; Sweden; Switzerland; UK and USA). Second, evidence was provided for the existence of a similar U-shape through the life-course in East European, Latin American and Asian nations. Evidence was found in fourteen ex-Soviet Republics (Albania; Bosnia; Bulgaria; Croatia; Czech Republic; Estonia; Hungary; Latvia; Lithuania; Macedonia; Poland; Romania; Serbia; Slovakia) and thirty-eight developing countries (Argentina; Azerbaijan; Belarus; Brazil; Brunei; Brazil; Brunei; Cambodia; Chile; China; Colombia; Costa Rica; Dominican Republic; Ecuador; El Salvador; Iraq; Israel; Honduras; Kyrgyzstan; Laos; Mexico; Myanmar; Nicaragua; Nigeria; Paraguay; Peru; Puerto Rico; Philippines; Russia; Singapore; South Africa; South Korea Tanzania; Turkey; Ukraine; Uruguay; Uzbekistan; and Zimbabwe. I find evidence of a U-shape in all of these countries also.

${ }^{4}$ That included Algeria, Armenia; Austria; Bangladesh; Chile; Colombia; Egypt; Greece; India; Indonesia; Iran; Jordan; Luxembourg; Moldova; Morocco; New Zealand; Pakistan; Saudi Arabia; Singapore; Slovenia; Taiwan; Uganda; Venezuela and Vietnam. In this paper I report U-shapes for all but three of them - Bangladesh; Pakistan and Saudi Arabia.
} 
Subsequently, Glenn (2009) argued that it was inappropriate to include controls and what mattered was the raw data; Blanchflower and Oswald (2009) disagreed. Glenn claimed that: "the appearance of this U-shaped curve of well-being is the result of the use of inappropriate and questionable control variables" and especially marital status. It is worth rehearsing the arguments we used there again. In many countries around the world, and especially in Europe, as I illustrate in detail below, the U-shape can be found without any control variables, and a major problem with Glenn's analysis was that he focused too heavily on the United States.

Second, we disagreed with Glenn's methodological position, which seems to be that social scientists should not hold constant other factors when they study the relationship between wellbeing and age. Ultimately in social science, the control variables that are included in multiple regression equations we noted, have to be chosen with an eye on the intellectual or policy question being answered. The summary of our argument went as follows. If the aim is to describe the data, it is reasonable to leave out most or all control variables. 'Smokers die at rate Z' is an acceptable statement to make. But that is not the same as 'smoking changes your risk by Z', which requires other confounding variables to be controlled for such as diet, education, income and exercise. We argued "it would likely be an error to use an equation without controls to tell the public what impact ageing has on happiness without separating out the effects of other variables such as, say, education, marriage or unemployment. If the aim is to understand relationships", we argued, "it will rarely be desirable to stop at bivariate patterns." That seems right and I don't stop at bivariate patterns in this paper, but I present results with and without controls which even then give Ushapes.

Blanchflower and Oswald (2019) examined the issue of differences between the well-being and age relationship with and without controls using seven pooled cross-country data sets, covering 51 countries and 1.3 million randomly sampled people, the paper examines the cross-sectional pattern of psychological well-being from approximately age 20 to age $90 .^{5}$ The paper described the two conceptual approaches. One studies raw numbers on well-being and age which we termed the descriptive approach. The second studies the patterns in regression equations for well-being (that is, adjusting for other influences). This we termed the ceteris-paribus analytical approach. The paper applied each and compared the patterns of life-satisfaction and happiness. Using the first method, evidence of a midlife low was found in five of the seven data sets; the two that didn't were both for the United States. Using the second method, all seven data sets produced evidence consistent with a midlife low.

As a validation of the happiness data Blanchflower and Oswald (2016) examined the use of antidepressants in randomized samples from 27 European countries and show that the probability of taking antidepressants follows an inverted U-shaped curve that peaks in people's late 40s. Additionally, and remarkably, Weiss et al. (2012) find a similar U shape exists among chimpanzees and orangutans. Raters familiar with the individual apes assessed cheerfulness among 508 great apes. The U-shaped pattern or midlife crisis emerges with or without use of parametric methods.

\footnotetext{
5 The data sets were a) LFS survey for the UK, 2011-2015; b) BRFSS for the USA, 2010 c) Eurobarometer, 2016; d) European Social Survey 2002-2014; e) ISSP 2012; f) GSS for the USA, 1972-2014 g) Latinobarometer 2013 and 2015.
} 
The results imply that human wellbeing's curved shape is not uniquely human and that, although it may be partly explained by aspects of human life and society, its origins may lie partly in the biology we share with great apes.

Graham and Pozuelo (2017) analyzed the happiness curve within 46 individual countries, including controls for gender, education, marital and employment status and household income and found U-shapes. They also looked at how the happiness curve varied depending on where in the well-being distribution individuals. They also extended the analysis to stress with the same controls and showed an inverted U. The U-shaped relationship between age and happiness was measured using data from the Gallup World Poll from 2005-2014 with the dependent variable, the so-called Cantril ladder, based on an individual's reports on the where they would put themselves on an eleven-point ladder in which their lives compare to the best possible life they can imagine, held in 44 of the 46 countries, and a reverse $U$ held for stress in almost as many. ${ }^{6}$ Fortin et al (2015) using the same Gallup World Poll data also find evidence of an inverse U-shape in age for stress and also find the same for worry and anger in the raw data, without controls.

All of the patterns identified there are statistically significant as will be confirmed below, given the large sample sizes. As Blanchflower and Oswald (2019) note the claim that the size of the dip is tiny does not appear to be correct. In the seven data sets, they studied the size of the drop, in well-being to the low point in the late 40s is equivalent in magnitude to the influence of a major life event like unemployment or marital separation.

Deaton (2018) uses data from the Gallup World Poll and plots Cantril's ladder without controls and finds an the (unconditional) U-shape in the English speaking countries (U.K., U.S., Canada, Ireland, New Zealand and Australia), to a lesser extent in East and in South Asia and perhaps in Latin America and Caribbean-though only in the last age group, and in Europe-more for men than women-but not elsewhere. The World as a whole shows the U-shape. In the two poorest regions, Africa and South Asia, life evaluation is low throughout life and, in Africa, it falls with age. In the ex-Communist countries of Asia and in the two poorest regions, Africa and South Asia, life evaluation is low throughout life and, in Africa, it falls with age. In the ex-Communist countries of Asia and Eastern Europe, life-evaluation is markedly lower among the elderly. Steptoe et al. (2015), who use an earlier version of the Gallup data, do not find any consistent pattern.

Deaton (2018) reported only unadjusted estimates in part he argued because of the difficult to apply consistent controls to the Gallup data, not because the questions do not exist, but because their meaning varies so much across the globe, with different patterns of education, work,

\footnotetext{
${ }^{6}$ Graham and Pozuelo (2017) found U-shapes for eighteen ex-Soviet countries (Albania; Bosnia Herzegovina; Bulgaria; Czech Republic; Croatia; Estonia; Hungary; Kosovo; Latvia; Lithuania; Macedonia; Montenegro; Poland; Portugal; Romania; Serbia, Slovakia; Slovenia), seventeen advanced countries (Australia; Austria; Belgium; Cyprus; Canada; Denmark; Finland; France; Germany; Greece; Ireland; Italy; Netherlands; Spain; Sweden; UK and USA) and nine developing countries (Argentina; Brazil; Chile; China; Colombia; India; Peru; Russia and Venezuela). The authors did not find a U-shape in age for Mexico or South Africa. They also examined data from the World Values Surveys (WVS) used in Blanchflower and Oswald (2008a) and here and found U-shapes for all but five of their sample of forty-six countries - Brazil, Chile; Columbia; India and Montenegro were the exceptions but they did find them in the WVS for Mexico and Argentina.
} 
retirement, and health systems. Deaton also suggested that a weightier argument is that many possible and potentially important controls are age dependent, including income and the presence of children but especially health, disability and marital status.

Deaton notes that "different authors use different countries and different data sets with different SWB questions, so it is possible that the age patterns in the Gallup data are different from those that come from other questions and different survey protocols; it would be an important (if daunting) task to make systematic comparisons." This is what I try to do here. ${ }^{7}$

Helliwell, Norton et al (2019) found U-shapes in data for the US using the Gallup World Healthways data for happiness yesterday as well as Cantril's ladder plus for Canada (Canadian General Social Survey and Canadian Community Health Survey) and the UK (Annual Population Survey), for happiness with and without controls. They found that the U- shape in age is significantly flatter, and well-being in the middle of the age range higher, for those living as couples, and for those who have lived for longer in their communities. A strong sense of community belonging, the authors found, is associated with greater life satisfaction at all ages, but especially so at ages 60 and above, in some samples deepening the U-shape in age by increasing the size of the life satisfaction gains following the mid-life low.

Some have further argued that no U-shape exists in longitudinal data (Frijters and Beatton, 2012; Kassenboehmer and Haisken-DeNew, 2012). In contrast Cheng et al (2017) drawing on four data sets, and only within-person changes in well-being, build on the work of Van Landeghem (2012) and document powerful support for a $U$ shape in longitudinal data. Three of the data sets are nationally representative household surveys, namely the British Household Panel Survey (BHPS, 1991- 2008), the Household Income and Labour Dynamics in Australia (HILDA, 2001- 10) and the German Socio-Economic Panel (SOEP, 1984- 2008). The fourth data set comprises a relatively more homogenous sample of medical doctors from the Medicine in Australia Balancing Employment and Life (MABEL) longitudinal study. They measure the change in well-being of randomly selected individuals each year and then plot that against individuals' ages. On average, they find people's well-being gradually drops until individuals reach midlife. From then on, it picks up smoothly as people go on, in each of three countries and four data sets, to approach the age of 70 .

Wunder et al. (2013) and Ranjbar and Sperlich (2019) both use semi-parametric methods on German SOEP panel data to examine the relation between age and well-being. They both get the same results; Ranjbar and Sperlich conclude "we find a clear, deep valley between the ages of 45 and 50, typically interpreted as a midlife crisis." Piper (2015) uses GMM dynamic panel estimation with 16 waves of the British Household Panel Study on youngsters age 16-30 and found that happiness declined over that age range, a result found by comparing the coefficients of the age dummies: a result in line with the overall U-shape. Furthermore, tests of the individual age group coefficients demonstrate that they are, in many cases, significantly different from each other. Additionally, because the preferred model controls for the individual waves in the sample, this decline of life satisfaction with age is a lifecycle effect. The life satisfaction of young people

\footnotetext{
${ }^{7}$ In private communications Angus Deaton suggested that he didn’t have quite this in mind. He suggested, more just a look at the questions they ask, their response rates, and whether they are even grossly consistent.
} 
between 16 and 30 falls, and this seems to be something that everyone, on average, experiences. Overall, his findings, Piper argues, "are in line with the common U-shape finding." Clark (2019) also finds, using the same data source and panel data methods controlling for fixed effects that the data "continues to produce a U-shaped relationship between well-being and age".

Morgan and O’Connor (2017) examined Eurobarometer data for 17 countries $^{8}$ for the years 19732016 and argued that there is in fact an M-shape in age rather than a U-shape after controlling for cohort and education effects. They argue there is a local maximum in life satisfaction around age 30, declining life satisfaction until around age 50 followed by rising life satisfaction, and declining life satisfaction after age $75 .^{9}$ It turns out that their results are driven by the inclusion of four education variables they created that seem unusual. This M-shape is not there though in their raw data. It is also not there when their education variable is dropped and only survey, country, gender, cohort and age controls are included, and is also not there when the standard education variable included in the data file is used. More on this below.

Other commentators have expressed skepticism that the curve's trajectory holds true mainly in countries where the median wage is high and people tend to live longer or, alternatively, where the poor feel resentment more keenly during middle age and don't mind saying so. John Briley in a recent op-ed argued that 'the curve is not universal - data from economically struggling countries, for example, don't show the happiness rebound". ${ }^{10}$ Arthur Krystal ${ }^{11}$, for example, has suggested that there may be a simpler explanation: "perhaps the people who participate in such surveys are those whose lives tend to follow the curve, while people who feel miserable at seventy or eighty, whose ennui is offset only by brooding over unrealized expectations, don't even bother to open such questionnaires". This critique of course could apply to any research based on surveys with a bias having nothing to do with age.

There is zero evidence that the U-shape has anything to do with differential response bias by age. I have the U-shape in many data sets with various happiness measures including happiness itself and life satisfaction and Cantril's ladder. It makes no difference if the dependent variable is scored, from 1-4 say or from 1-10, the results are essentially the same. The smaller numbers of observations for older age groups is an issue but that simply reflects the overall demographics in the country - there are fewer people age eighty than age thirty and especially so in countries with shorter life expectancy. ${ }^{12}$ Helliwell (2019) recently argued that "to use a single life satisfaction

\footnotetext{
${ }^{8}$ The countries included in their study are France, Belgium, the Netherlands, West Germany, Italy, Luxembourg, Denmark, Ireland, Great Britain, Northern Ireland, Greece, Spain, Portugal, East Germany, Finland, Sweden, and Austria.

${ }^{9}$ Thanks to the authors who kindly provided me with their data.

${ }^{10}$ John Briley, 'Does happiness in your 50s signal the end of ambition?", The Washington Post, December $18^{\text {th }}$, 2019.

${ }^{11}$ Arthur Krystal, 'Why we can't tell the truth about aging? A long life is a gift. But will we really be grateful for it?', The New Yorker, October 28, 2019.

${ }^{12}$ According to the Census Bureau's International Population database in 2018 there were 4,675, 612 age thirty versus 1,483,523 age eighty. In LDCs the ratio is smaller - in Venezuela for example the numbers are 65,319 and 519,040 respectively.
} 
question in large population-based samples might represent the best use of survey resources." Following Helliwell's advice, where feasible I use life satisfaction as my well-being measure.

I examine the happiness curve using a total of one hundred and nine distinct micro data sets - 33 sweeps of the General Social Survey (GSS) from 1972-2018; the 2010 Behavioral Re (BRFSS), both for the United States; 3 sweeps of the Annual Population Survey for the UK, 2016-2018; the 2012 and 2017 sweeps of the International Social Survey Program (ISSP); sweeps 1-9 of the European Social Surveys (ESS); forty-two sweeps of the Eurobarometer from 2009-2018 (EB); four sweeps of the European Quality of Life Survey: sweeps 2-6 of the World Values Survey (WVS); the Latino Barometers of 2016 and 2017 (LB); the Afro Barometer Surveys of 2016 and 2019 (AB) and the Asia Barometers of 2003-2007 (AS). ${ }^{13}$ The ISSP and WVS both contain data from four large non-European English speaking advanced nations - Australia; Canada; New Zealand and the United States. They all give U-shapes in happiness with and without controls.

\section{U-shapes in Happiness and Life Satisfaction in Advanced and Developing Countries}

It is worth pursuing the possibility that a) the U-shape doesn't apply to poorer countries, where residents have shorter life expectancies, noting that Blanchflower and Oswald (2008a) did find it for 39 developing countries in WVS sweeps $1-4^{14}$ averaging out at around age 43 with a set of control variables and b) if it does, the minimum would be different and likely lower given the shorter life expectancy. In this paper I explore that issue and find evidence that there are U-shapes in age in developing countries with similar minima to those in advanced countries however wellbeing is measured. I do this for groups of developing and advanced countries as well as for countries individually. The minima without controls are much higher and often there is a steady decline by age in developing countries and no minima in the raw data by age. I do find it though in many country level equations for developing countries.

I use three methods to identify the U-shape. First, I run an OLS regression with the dependent variable a measure of well-being, on a pooled sample of countries across all ages, with age and age squared, without any controls although I do include country dummies and if there are multiple survey years, then I also include sweep dummies. I then repeat and include, as far as is feasible a consistent set of personal control variables across all studies of gender, marital status, education and labor force status to estimate ceteris paribus effects.

Second, I then re-estimate for individual countries including the gender, education, marital and labor force status control variables with the age of respondents limited to those under the age of

https://www.census.gov/data-tools/demo/idb/region.php?T=10\&RT=0\&A=both\&Y=2019\&C=US\&R=

${ }^{13}$ We pooled forty-two recent sweeps of the Eurobarometer surveys on thirty-five European countries including the EU28 plus Turkey, Turkish Cyprus; Macedonia; Montenegro; Serbia; Albania and Iceland for the years 2009-2019 2009 (71.1 and 71.3); 2010 (73.4 and 74.2); 2011 (75.3; 75.4 and 76.3); 2012 (77.4 and 78.1); 2013 (79.3; $79.4 ; 80.1$ and 80.2); 2014 (81.1; 81.4; 81.5; 82.3 and 82.4); 2015 (83.1; 83.2; 83.3; 83.4; 84.2; 84.3 and 84.4); 2016 (85.2; 86.1; 86.2; 86.3); 2017 (87.1; 87.3; 88.3 and 88.4 and 2018 (89.1; 89.2; 89.3; 90.1; 90.2; 90.4 ) and 2019 (91.2)

${ }^{14}$ Countries were Albania; Algeria; Argentina; Bangladesh; Belarus; Brazil; Chile; China; Colombia; Dominican Republic; Egypt; India; Indonesia; Iran; Iraq; Jordan; Kyrgyzstan; Mexico; Moldova; Morocco; Nigeria; Peru; Philippines; Puerto Rico; Russia; Saudi Arabia; Singapore; South Africa; Taiwan; Tanzania; Turkey; Uganda; Ukraine; Uruguay; Venezuela; Vietnam and Zimbabwe. 
seventy. I do this for simplicity given very different life expectancies across countries and hence much smaller sample sizes for older age groups and likely variability at older ages. Sample sizes are often quite small for these individual country regressions and on average many are only around 1000 observations. I find for several advanced countries that there are insignificant results using, for example ISSP data, but when using EB or ESS when the samples are much larger the significance of both age terms appears. I assume that there is a significant U-shape if there is a negative sign on the age coefficient and a positive sign on the square with the T-statistic of both above 1.5 .

Finally, I re-estimate the well-being equation and replace the age and age squared term with a complete set of single year of age variables which I then plot in a series of charts. This is to ensure that the quadratic I fitted is not an inappropriate functional form. This way the form is freely estimated and then plotted, with the individual coefficients added to the constant.

The well-being variables are always coded from low to high, so a positive coefficient means happier. Sometimes I use happiness data and sometimes life satisfaction and the number of options available varies by survey and year. Mostly there are four options, that I call 4-step, of eleven options from 0-10 that I call 11-step, 7-step and 10-step. It doesn't seem that this makes much of a difference. Sample size does seem to matter although it is surprising how many U-shapes are identified even with sample size of under a thousand.

I am also able to identify U-shapes in age in both European and African nations using a broader set of attitudinal questions on living standards as well as on an individual's financial conditions as well as the state of the national economy. I focus in particular on questions about financial situations individuals find themselves in as well as on the general state of the economy. These questions are widely used in consumer confidence surveys. Respondents are asked such questions in the Eurobarometers, as well as in the monthly consumer surveys run by the European Commission in every EU country since the 1980s. I compare results of asking similar questions in Europe and Africa. It seems the U-shape in age is more general than just in happiness and life satisfaction equations and applies to other attitudinal economic variables. This suggests the happiness curve has broader applicability to other attitudinal variables about the person and the economy.

\section{Empirical Analysis of Quadratics in Age}

In this section I report the results of estimating a series of linear well-being regressions. In each case I report coefficients and T-statistics for the age and the age squared variables with and without controls for education, gender, marital and labor force status, country and where appropriate where there are multiple survey years used a set of year dummies. the without controls equations include year and country dummies. I calculate the minimum of the quadratic in age by differentiating with respect to age and solving which means dividing the age coefficient by the Age $^{2}$ coefficient multiplied by two. Hence on row 1 of Table 1a the age coefficient is -.01771 and Age $^{2}$ is -.00014 so the minimum is $-1 * .01771 /(2 * .00014)=63.25$.

I turn first for the two countries that have micro data files with thousands of observations - the United States and the United Kingdom. 


\section{i) The United States}

I need to make clear at the outset that the United States does look different in the raw data. There are two main sources of well-being data in the USA - the General Social Survey which has happiness data from 1972-2018, with an average of around 2000 observations a year and the Behavioral Risk Factor Surveillance System (BRFSS) which has life satisfaction available for the years 2005-2010, with over four million observations, but this question has not been included in subsequent years. In the GSS the question asked is "Taken all together, how would you say things are these days? would you say that you are very happy=3, pretty happy=2, or not too happy=1?" In the BRFSS respondents are asked "In general, how satisfied are you with your life? Very satisfied=4; Satisfied=3; Dissatisfied=2 and Very dissatisfied=1." (All my codes).

If I run OLS regressions and include and an age and an age squared term I get the following for ages 18 and over (t-statistics in parentheses). All equations include year dummies.

\begin{tabular}{lllll} 
& \multicolumn{1}{c}{ Age } & \multicolumn{1}{c}{ Age $^{2}$} & Minimum & N \\
BRFSS (life satisfaction) & & & & \\
Without controls & $-.00253(2.44)$ & $+.000013(13.63)$ & 97 & $4,283,544$ \\
With controls & $-.00531(47.70)$ & $+.000062(59.30)$ & 43 & $4,283,544$ \\
& & & & \\
GSS (happiness) & & & 71 (max) & 59,860 \\
Without controls & $+.00427(5.13)$ & $-.00003(3.89)$ & 59,707
\end{tabular}

In the case of the BRFSS, without controls the age term is negative and the square term positive but the minimum is close to 100. For the GSS the signs are reversed but are both significant suggesting an inverted U-shape. In both cases when I add controls there is a significant U-shape with a minimum of 43 and 40 respectively.

It is important to look at the raw data to determine the appropriateness of fitting a quadratic to the two sets of data. As can be seen from Chart 1a for the BRFSS, 2005-2010 which reports scatter plots of the coefficients of single year of age dummy variables in a life satisfaction equation a) without any controls except year dummies, and then $b$ ) adding controls for marital and labor force status, gender and education. In each case the individual coefficients are added to the constant. It is clear that there is an M-shape in the raw data, with an initial decline and then a rise through the early thirties and then the mod-life drop and subsequent pick-up. Adding controls takes away the $\mathrm{M}$ and produces a clean and highly significant U-shape.

Chart 1b does the same exercise for the happiness data from GSS. As with the BRFSS without controls the function rises through around age thirty and also doesn't have an initial dip. There is then a dip in midlife. With controls the U-shape becomes apparent.

It turns out that there are very different patterns without controls by marital status and education, but in all cases, there is a U-shape with controls. Chart 1c plots the married that are $55 \%$ of the total, there is an M-shape without controls and a U-shape with them. Chart 1d reports it for the non-married, which includes never married (11\%), divorced (14\%), separated (2\%), widowed (15\%) and living together (2\%). It shows an obvious U-shape both with and without controls. IN 
contrast Chart 1e and Chart 1f for both college and non-college have U-shapes with and without controls.

Graham and Pozuelo (2017) also found marked differences for the married and unmarried using the Gallup Healthways data for the US, in sharp contrast to Europe. They found that there were U-shapes for both groups in Europe and argued that there is a major difference in the levels of happiness across married and unmarried cohorts in the US, with those of the married significantly higher than those of the unmarried. In addition, they found that "the unmarried experience a much steeper dip than do the married as beginning in the late 20s and then closing the gap with the married in the late 50s. The married, meanwhile, have a slight upward bump in the U curve in the late 20s to the mid-40s and then a drop again at that point." 15

The authors note rightly that it is hard to explain why there are such large differences in the happiness of the married versus unmarried in the USA and not in Europe. They go on to argue, which seems right, that "in theory, selection bias could be an issue, as happier people are more likely to marry each other. Yet this is not the whole story and does not explain the differences between these two contexts, which are otherwise very similar in terms of per capita income, education levels, and other traits." Differences between married and unmarried subsamples are clearly worth exploring but are not pursued here for lack of space across other countries. One issue is that marriage versus cohabiting is much more the norm in the US than it is in the UK which may impact the happiness of those who are unmarried by middle age.

\section{ii) The United Kingdom}

Charts 2a and $2 \mathrm{~b}$ examine the data, for people under age 70, from the other major large crosssection survey of well-being from the most recent sweeps available for 2016-2018 from the Annual Population Surveys for the United Kingdom. Earlier sweeps were used in Bell and Blanchflower (2019) to examine the well-being of the underemployed and the unemployed. These surveys contain data on four well-being measures and overall there are about 270,000 observations on each. The question used is as follows.

SATIS - 'Overall, how satisfied are you with your life nowadays? where nought is 'not at all satisfied' and 10 is 'completely satisfied'.

Chart 2a plots the single year of age coefficients with the dependent variable life satisfaction (satis) with age and its square without any other controls except for two, year dummies. Then I add controls for education, marital status and labor force status and plot again. There is a clear Ushape in both cases, with a small up-tick at around thirty in the data without controls, which disappears with controls.

Grover and Helliwell (2019) examined happiness data for the UK using earlier sweeps of these data and found that the U-shape in the relationship between life satisfaction and age exists for both the married and unmarried but is deeper for the unmarried, and the difference between married and unmarried is greatest when people are in their late 40s and 50s. I

\footnotetext{
15 See especially their Figure 50a, p257.
} 
confirm that in Chart 2b, with a U-shape for both the married and unmarried with and without controls. It is clear that the married are happier than the unmarried.

The broad picture though is a, ceteris paribus, U-shape in well-being. A quadratic in age, it turns out is likely a reasonable first order approximation to these data across many countries, recognizing there may be individual nuances hidden by using the same functional form across countries.

\section{iii) Multiple Countries}

I start out using data from the Eurobarometer surveys (EB). Concern has recently been expressed over response rates to these surveys especially in relation to the questions on respondent's views on the EU, with the concern that Eurosceptics do not respond to the surveys which then suggest higher levels of support than they should. The Eurobarometer surveys differ from other surveys that use the mail or the telephone, the EU Commission only conducts interviews with members of the public face-to-face at home. This makes it even more difficult to achieve high response rates.

The EU Commission on $5^{\text {th }}$ December 2019 defended the methods of its public opinion surveys in response to criticism that the low rate of responses could lead to bias towards the EU. In the most recent Eurobarometer survey for which response rates have been calculated, and obtained by the Danish newspaper, the rate was 14 percent in Finland, 15 percent in Germany, 20 percent in Luxembourg, 22 percent in Italy, 27 percent in the UK, 28 percent in Denmark, 31 percent in Greece and France, 33 percent in Ireland, 34 percent in Spain, 38 percent in Latvia and 40 percent in Portugal. Erik Gahner Larsen from the University of Kent in a blog ${ }^{16}$ noted rightly, that the response rate is informative but not sufficient or even necessary in order to obtain representative samples. He finds no evidence that countries with lower response rates are much more positive towards the EU in Eurobarometer compared to the European Social Survey. Of note is that there seems very little evidence that responses to questions on life satisfaction in the EB have been impacted over time by a rise in non-response rates/

Table 1a uses data on 4-step life satisfaction for over 1.2 million Europeans from forty-two sweeps of the EB for the years 2009-2019. ${ }^{17}$ The question asked is "On the whole, are you very satisfied, fairly satisfied, not very satisfied or not at all satisfied with the life you lead? Not at all satisfied $(=1)$; not very satisfied (=2); fairly satisfied $(=3)$ and very satisfied $(=4) "$. It establishes the facts in European countries, by which I mean the EU28 plus seven other countries (Iceland, Norway, Turkey, Turkish Cyprus, Albania; Macedonia and Montenegro). There are seventeen western EU member countries, plus Iceland and Norway, and twelve East European countries that are currently EU members. There are six developing countries including four ex-Soviet (Albania; Macedonia, Montenegro and Serbia) that are not EU members plus Turkey and Turkish Cyprus in that group, all of which are so-called candidate countries.

\footnotetext{
16 'Eurobarometer and Euroscepticism' https://erikgahner.dk/2019/eurobarometer-and-euroscepticism/

${ }^{17}$ Information, 'New data reveals serious problems with the EU's official public opinion polls', $3^{\text {rd }}$ December 2019. https://www.information.dk/udland/2019/12/new-data-reveals-serious-problems-with-the-eus-official-publicopinion-polls and Eszter Zalan, 'EU Commission defends Eurobarometer methodology,' EU Observer, December $5^{\text {th }}$ 2019.
} 
First, eight estimates are provided for pooled samples across all age groups, with and without controls overall and then separately for Western and Eastern Europe, and for developing countries, with and without controls for gender, education, marital and labor force status. In all four cases with and without controls there is a minimum in midlife in the early fifties and the minima are a little higher without controls. There is also a U-shape with controls when a set of eight cohort dummies are included for each ten-year period for birth from 1930. To add these cohort controls there needs to be a long time run of data which there is in the EB and GSS surveys.

Second, separate estimates are provided by country with controls with age restricted to be under seventy years. In all thirty-seven cases the age term is significant and negative and the squared term significantly positive. There is some variation with a low of 29 in Luxembourg and a high of 80 for Montenegro but mostly are in the forties and fifties.

There are significant U-shapes for the pooled sample overall and separately for the Western Europe, Eastern European and developing country samples with and without controls.

Table 1b reports results for all Western and Eastern European countries without controls and there are U-shapes in three of the six developing countries. In a couple of cases (Bulgaria and Romania), the minimum is nearer to 100 than to fifty. But overall the minima are slightly higher than without controls, but not in all. In the UK the minimum is age 43 in both.

Table 1c estimates life satisfaction equations using the 1973-2002 Manheim Eurobarometer Trend file used by Blanchflower and Oswald (2008a) for a smaller group of eighteen EU countries plus Norway and there are U-shapes with and without controls in the overall sample and in every one of the 19 countries with controls for those under age 70. Somewhat surprisingly the U-shape looks broadly similar in the years before and after the Great Recession which hit in 2008. Adding cohort dummies does lower the minimum sharply.

Chart 3a uses single year of age plots with and without controls using the EB files from 20092019, and both show U-shapes. Chart 3b adds cohort dummies to the list of controls and the Ushape remains. Chart 3c reports single year of age estimates with and without controls from the Mannheim Trend Files for 1973-2002 and there are U-shapes again with and without controls. Chart 3d adds cohort dummies again and the U-shape remains.

There is an issue raised by Morgan and O'Connor (2017), henceforth MO, over whether there is an M-shape rather than a U-shape in EB data. MO kindly sent me their data and it turns out that in contrast to the United States there is no evidence of the M-shape either in the raw data or when they add cohort dummies. Appendix B shows the raw plots across fifteen countries. There are Ushapes in a dozen countries in the raw data; the exceptions are Italy, Portugal and Finland. In Table $2 \mathrm{~b}$ using the ESS I also did not find a U-shape in the raw data for these three countries, but there was evidence for a U-shape with them with controls in Tables 1a, 1c, 2a and 3.

Chart 3e plots the MO data when I simply included sweep and country dummies along with single year of age dummies and added the coefficients to the constant. There is no obvious M-shape in either series. It emerges when the authors include education controls they constructed by country, 
although they didn't explain this in their paper that the $\mathrm{M}$ had nothing to do with cohort dummies. Chart 3b and Chart 3d also using EB data, showed there is no M-shape when controls for education, marital status and labor market status are added.

Table 2a, with controls and Table 2b without them, uses eight sweeps of the European Social Surveys but this time the dependent variable is 11-step happiness. There are over a third of a million observations. The question asked in the ESS is "Taking all things together, how happy would you say you are?" and the responses are coded from 0 to 10 with zero 'extremely unhappy" and 10 "extremely happy". The data file contains data on four developing countries - Israel, Russia, Turkey and Ukraine - plus twenty-eight European countries.

The pooled samples in Table 2a have U-shapes although the minima are high without controls for all three groupings, but very consistent with the results from the Eurobarometers at age 57 for advanced countries and overall and 62 for developing with controls. There is a minimum again in every country equation that again includes controls for those under seventy that are also in the forties and fifties.

Table 2 b without controls has a significant U-shape for 24/32 countries. All of the flour developing countries have a U-shape and there are eight advanced countries with no U-shape (Denmark, Estonia, Finland, Iceland, Italy and Lithuania, Poland and Slovenia). All six of these countries had significant U-shapes with larger samples with the EB data.

Table 3 makes use of 10-step life satisfaction data from four sweeps (2003, 2007, 2011 and 2016) of the European Quality of Life Survey (EQLS). Results are very similar to those from the EB and the ESS. There are significant U-shapes everywhere, with and without controls. Minima with controls are in the fifties for western and Eastern Europe and for the four developing countries. Minima are a little higher without controls.

Table 4 now moves to using 7-step life satisfaction data from the 2012 ISSP which is not limited to Europe. The question asked is "If you were to consider your life in general, how happy or unhappy would you say you are, on the whole? Completely happy =7; Very happy=6; Fairly happy=5; Neither happy nor unhappy=4; Fairly unhappy=3; Very unhappy=2; completely unhappy=1?" Numbers are my coding to ensure a a larger coefficient means more happiness.

Again, the pooled samples give happiness curves for Advanced, Eastern European and developing countries that are higher without controls than with. The overall minimum is 55 and 51 for developing. All 31 countries have significant U-shapes, mostly in the forties and fifties again.

Table 5 does the same but with the 2017 ISSP with a slightly different 7-step life satisfaction question. All things considered, how satisfied are you with your life as a whole nowadays? Completely satisfied=7; Very satisfied=6; Fairly satisfied=5; Neither satisfied nor dissatisfied=4; Fairly dissatisfied=3; Very dissatisfied=2; Completely dissatisfied=1?" Numbers are my coding again. The overall minimum is a little lower than in earlier tables at 48. The age minimum for advanced countries is 54 and for developing 46. There are U-shapes everywhere with and without controls. 
Table 6 looks in turn at sweeps 2-6 of the World Values Survey. In the five sweeps there is always a minimum between forty and fifty overall with controls, and only in Wave 2 is there no U-shape without controls. In every one of the 137 reported country estimates, for advanced and developing countries, remarkably, given the small sample sizes, there are significant happiness curves.

Table 7 now turns to look at 5-step happiness data in five sweeps of the Asia Barometers of 2003$2007 .{ }^{18}$ The question asked is "All things considered would you say that you are happy these days? - Very happy=5; pretty happy=4' neither happy nor unhappy=3; not too happy=2 and very unhappy=1?" Once again, the numbers refer to my codes. In each case, there is a well-defined U-shape with controls and only without controls in two of the five sweeps. Significant U-shapes are found in fourteen Asian developing countries - China; India; Laos; Maldives; Mongolia; Myanmar; Philippines; Singapore; South Korea; Sri Lanka; Taiwan; Tajikistan; Thailand; Uzbekistan.

Table 8 makes use of 4-step life satisfaction data from the Latino Barometers for 2017 and 2018. The question asked was "Generally speaking, would you say you are satisfied with your life? Would you say you are...? Very satisfied $=4$; Quite satisfied $=3$ Not very satisfied $=2$ and Not at all satisfied=1?" Blanchflower and Oswald (2008a) examined data from this survey series for the years 1997, 2000, 2001 and 2003-2005 and found a U-shape at age 50 for men and age 43 for women with a full set of controls, so this updates that analysis. For both 2017 and 2018 there is a well-defined U-shape that minimizes in the sixties without controls and in the fifties with them. There are U-shapes for those under the age of seventy in twelve, for Bolivia; Brazil; Columbia; Costa Rica; Ecuador; Honduras; Mexico; Panama; Paraguay; Peru, Uruguay, and Venezuela.

Chart 4 also shows a U-shape when single year of age dummies are included with controls using the EQLS. Chart 5a does a similar exercise using the data for advanced countries from the ESS sweeps 1-8. There is a flattening around age seventy after a minimum in the late fifties and a pickup at age eighty. Chart $5 b$ repeats but for the sample of four developing countries - Israel, Russia, Turkey and Ukraine with controls. It has a U-shape with a later turning point in the early sixties and a later pick-up. Chart 6a does the same for the ISSP 2012 while Chart 6b has it for developing countries with controls. Charts 7a and 7b do the same for the ISSP 2017. All have U-shapes with minima around age fifty.

I now turn to plotting well-being data only for developing countries from Wave 5 (2005-2009) and Wave 6 (2010-2014) of the WVS. Chart 8a plots a U-shape in life satisfaction using Wave 5 and Chart $8 b$ in life satisfaction using sweep five of the WVS. Charts 9a and 9b do the same using data from Wave 6 of the WVS. All have well-defined U-shapes minimizing in the mid-fifties.

Chart 10a and 10b report on 4-step life satisfaction equations from the Latino Barometers for 2017 and 2018 respectively with controls and once again show a clear well-defined U-shape. ${ }^{19}$ Chart 10 does the same from the 2005 Asia Barometer, with controls chosen as it has a larger sample size than the other sweeps. That also has a significant U-shape in age.

\footnotetext{
${ }^{18}$ Blanchflower and Oswald (2008a) used data from the 2003-2005 Asia Barometers.

${ }^{19}$ Easterlin et al (2010) also used the (1994-2006) LatinoBarometers.
} 
There are obvious U-shapes in age in life satisfaction and happiness across the developed and developing world from these year of age plots that do not rely on a specific functional form such as a quadratic.

To conclude, these tables and charts suggest the following

1) There are well-being U-shapes in advanced and developing countries

2) thee answers seem to be similar using happiness or life satisfaction data.

3) It doesn't seem to matter how many steps there are in the dependent variable, essentially the same answer is found with a 4-step, 7-step, 10 or an 11-step measure.

4) The answers are broadly the same whichever data file is used.

5) Adding cohort dummies does not remove the U-shape.

6) There is a minimum around age fifty with controls of the happiness curve in both advanced and developing countries, and a little higher than that without controls.

\section{Alternative Measures of Well-being}

I now turn to other ways of measuring satisfaction, which it turns out also show U-shapes. Easterlin (2006) found evidence of a U-shape in age in the US General Social Survey for the years 1972-1993 in answers to the question - We are interested in how people are getting along financially these days. So far as you and your family are concerned, would you say that you are pretty well satisfied with your present financial situation, more or less satisfied, or not satisfied at all? He finds that satisfaction with one's financial situation, "declines very slightly through age 36, but thereafter rises considerably, with the biggest increase late in life." This contrasts with his findings on happiness overall as well as happiness with the family that he found followed an inverted U-shape. ${ }^{20}$

I took the data Easterlin (2006) used and re-estimated, with and without controls, for a longer time period, from 1972-2018. T-statistics are in parentheses and I restricted the sample to those under age 70 for simplicity. Without controls year dummies are included, with controls adds controls for gender, marital status, years of education, race and labor force status. Sample size is with controls.

\begin{tabular}{lll|llc}
\multicolumn{4}{c|}{ Without Controls } & \multicolumn{2}{c}{ With controls } \\
Age & \multicolumn{1}{c}{ Age $^{2}$} & \multicolumn{1}{c}{ Age } & \multicolumn{1}{c}{ Age $^{2}$} & $\mathrm{~N}$ \\
Happiness & $+.0028(2.16)$ & $-.00003(8.58)$ & $-.0132(8.91)$ & $.00016(9.45)$ & 52,433 \\
Family situation & $+.0316(7.35)$ & $-.00037(7.45)$ & $-.0252(5.32)$ & $.00023(4.15)$ & 22,231 \\
Financial situation & $-.0158(10.34)$ & $+.00025(14.40)$ & $-.0246(14.21)$ & $.00036(18.37)$ & 59,836
\end{tabular}

I confirm Easterlin's findings; both happiness and family situation without controls generate inverted U-shapes in age, whereas financial situation has a U-shape in age even without controls. All three though have U-shapes once controls for education, marital status and work status are

\footnotetext{
${ }^{20}$ Data for satisfaction with family life are only available for the years 1972-1993 hence the sample restriction but in what follows I used data for both happiness and financial situation for the years 1972-2018. The family situation question was SATFAM: "For each area of life I am going to name, tell me the number that shows how much satisfaction you get from that area. Your family life (my codes) - 7. A very great deal; 6. A great deal; 5. Quite a bit; 4. A fair amount; 3. Some; 2. A little; 1. None."
} 
included. The minima are 41 for happiness, 55 for family situation and 32 for financial situation with controls.

It is apparent that a U-shape seems more robust using the financial situation data than the other two measures of well-being. I explored the characteristics of this rather intriguing financial circumstance variable as data is available in WVS sweeps 5 and 6 for developing and developed countries.

In Table 10 I model responses in turn from waves 5 and 6 of the WVS that contains a 10-step question on how satisfied the respondent is with the financial situation of the household. Responses are from 1 - very dissatisfied to 10 very satisfied. As with the data for the US discussed above, I find statistically significant U-shapes with and without controls in developed and developing countries in both wave 5 and wave 6 . The minimum is in the low to mid-forties with controls in developed and developing countries in both years. With controls in the country equations with the sample restricted to those under 70 years of age, there are U-shapes in thirtyfour developing countries from around the world. ${ }^{21}$

A great deal of use is made in economics of survey responses from individuals on the general state of the economy, including in Consumer Confidence measures such as the Michigan and Conference Board measures in the United States and conducted by the European Commission monthly for every EU member state. For example, respondents in the EU Commission survey are asked for their views on the "general situation of the economy over the last twelve months." and their "financial situation over the last twelve months"22 These variables are then collapsed into a score. In Chart 11 I plot the two series for the EU28 as a whole: separate scores are available for every EU member country monthly. Their decline in 2007 onwards gave early warnings as did other similar attitudinal variables that few spotted of the oncoming global recession in 2007 (Blanchflower, 2008 and 2009b). Responses to the financial situation variable as noted above has a U-shape in age, but the general economic situation type question appears to also have that shape as I illustrate below. A concern is that the general economic situation series turned down at the end of 2018.

Part a) of Table 11 uses similar data from a recent Eurobarometer Survey 90.3 from November 2018 also conducted in the EU28 countries by the European Commission. I estimate six separate regressions starting with the life satisfaction question used in Table 1 with the same controls gender, marital and labor force status and education. A well-defined U-shape in life satisfaction, as expected is apparent with a minimum at age 55 compared with 52 with controls in Table 1 for the years 2009-2018. I re-estimated the same equation five more times using different attitudinal questions on the individual's situation and that of the country as follows.

\footnotetext{
${ }^{21}$ Algeria; Belarus; Brazil; Chile; China; Colombia; Ecuador; Egypt; Georgia; Ghana; Indonesia; Iran; Iraq; Jordan; Kyrgyzstan; Libya; Mali; Malaysia; Mexico; Morocco; Peru; Philippines; Russia; Singapore; South Africa; South Korea; Taiwan; Thailand; Trinidad; Turkey; Uruguay; Yemen; Zambia and Zimbabwe.

${ }^{22}$ See the EU consumer surveys available for download here for every EU country https://ec.europa.eu/info/business-economy-euro/indicators-statistics/economic-databases/business-and-consumersurveys/download-business-and-consumer-survey-data/time-series_en
} 
How would you judge the situation in each of the following? Very good=4; Rather good=3;

Rather bad $=2$ and Very bad $=1$

Q2. The situation in our country?

Q3. The situation of the national economy?

Q4. The financial situation of your household?

Q5. The employment situation in the country?

Q6. The presence of public services in our country?

In every case the age term is significant and negative, and the square term is positive in Table 10. Each of the variables have well-defined and statistically significant U-shapes in age and the tstatistics on age and its square are everywhere above five. The age minima vary from ages 47-54.

Part b) of Table 11 uses the most recently released \#9 sweep of the ESS for 2018. I estimate both happiness and life satisfaction equations (Q10 and Q11) with controls and have well-defined Ushapes again and a minimum of 60 and 56 respectively. I then estimate for four more attitudinal questions about the economy, government, the state of education and the state of health services. Again, age is significant and negative and its square significant and positive, and all have U-shapes with minima from 50-56.

Q9. On the whole how satisfied are you with the present state of the economy in [country] Q10. Now thinking about the [country] government, how satisfied are you with the way it is doing its job?

Q11. Please say what you think overall about the state of education in [country] nowadays?

Q12. Please say what you think overall about the state of health services in [country] nowadays?

Part c of Table 11 uses data from various sweeps of the EQLS 2003-2016. It contains a question o the respondents' views of their financial situation in the next twelve months, which also has a Ushape in age. It has seven 10-step satisfaction questions relating to their education, if they were working, to their job, their family life, the local area, the way democracy works, the state of the economy and their living standards. All have U-shapes.

Very little analysis has been done on how well-being moves by age in Africa. ${ }^{23}$ The Afro Barometers are a natural place to turn, but unfortunately, they don't contain any questions on happiness or life satisfaction. Both the 2016 and 2019 surveys do though contain a question on living standards. Participants are asked the following: "In general, how would you describe your own present living conditions?" Possible responses include: 1 = Very bad, $2=$ Fairly bad, $3=$ Neither good nor bad, 4 = Fairly good, 5 = Very good." This is broadly similar to the question I examined in Table 11 using the EQLS, which showed a U-shape with a minimum of forty-five.

This, living standard, measure of well-being, has been widely used in the development literature for measuring well-being in Africa. It was used by Sulemana, Doabil and Anarfo (2019) for a

\footnotetext{
${ }^{23}$ Or indeed of happiness in Africa, for an exception see Helliwell, Huang and Wang (2019) who found evidence over the years 2006-2018 that happiness in the Middle East and North Africa had dropped steadily while Sub-Saharan Africa had no overall trend. The authors identify how much happiness has changed over the last decade and how low it is in Africa. They note big declines in happiness in Rwanda, Malawi; Tanzania; Central African Republic; and Botswana (their Figure 2.8)
} 
study of well-being in Sub-Saharan Africa. They justified its use arguing that "the question taps into the individual's evaluations of their life we used this construct as a suitable measure of subjective wellbeing." The authors argued that "many other studies have constructed well-being measures in the same way," which turns out to be correct. Deutsch et al (2016) used this variable from the 2008 Afro arometer as did Pokimica et al (2012) and Sulemana (2015b) in their studies of well-being in Ghana. Sulemana (2015a) in a study of the impact of crime on well-being in Africa used data from the $4^{\text {th }}$ sweep of the Afro Barometer for 2008. Sulemana et al (2017) used this measure with the Afro Barometer data in their study of the relationship between corruption and well-being in Africa.

Others have been creative in their use of measures of well-being for Africa. Bookwalter et al. (2011) in a study of South Africa use a household level life satisfaction variable. Life satisfaction in both surveys was reported at the household level. The head of the household was asked, "Taking everything into account, how satisfied is this household with the way it lives these days?" Responses were given on a five-point scale that we have ordered: very dissatisfied (1), dissatisfied (2), neutral (3), satisfied (4), and very satisfied (5).

Table 12 reports the results from estimating an OLS equation with this as a dependent variable with and without controls. Here controls are gender, race, education, marital and labor force status. There is a U-shape minimizing at age 67 in 2016 and 59 in 2019 without controls and with them 53 and 55 respectively. Limiting age to less than seventy there are 22 countries with significant U-shapes in 2016 and seventeen in 2019. Charts 12a and 12b plot the single year of age plots for the two years with controls and there are obvious U-shapes again, with minima mostly in the midfifties. There are U-shapes for thirty African countries using the Afro Barometer data for those under age seventy. ${ }^{24}$

The U-shape appears to have broad applicability to a range of attitudinal questions on the economy and an individual's personal economic situation as well as to their happiness and life satisfaction.

\section{Conclusions}

No ifs, no buts, well-being is U-shaped in age. In this paper I undertook what Deaton (2018) called a "daunting task" of drawing systematic comparisons across data files and countries of the relationship between well-being, variously defined, and age. I found evidence of that in one hundred and thirty-two countries, including ninety-five developing and thirty-seven developed. I found it in Europe, Asia, North and South America, in Australasia and Africa. I identified it in every member country of the European Union, as well as a further thirteen European countries. ${ }^{25}$

\footnotetext{
${ }^{24}$ Algeria; Benin; Botswana; Burkina Faso; Burundi; Cameroon; Cape Verde; Cote d'Ivoire; eSwatini; Gabon; Ghana; Kenya; Lesotho; Liberia; Madagascar; Malawi; Mauritius; Mozambique; Namibia; Niger; Nigeria; São Tomé; Senegal; South Africa; Swaziland; Tanzania; Togo; Tunisia; Uganda and Zimbabwe.

${ }^{25}$ There are fifty one European countries https://www.countries-ofthe-world.com/countries-of-europe.html. The only ones I didn't find it for were small and only Kazakhstan I had data for, while the remaining five I had zero data Andorra, Liechtenstein, Monaco, San Marino and Vatican City. The thirteen non-EU European countries are Albania; Armenia; Belarus; Georgia; Iceland, Norway, Macedonia; Montenegro, Russia; Serbia; Switzerland, Turkey and Ukraine.
} 
I have a well-being U-shape for every one of the thirty-five member countries of the OECD. ${ }^{26}$ There were very few countries I did not find it for, and that happened mostly where there were small samples or I had no data.

I found the well-being U-shape in English-speaking countries and non-English speaking countries. A U-shape is revealed in countries ranked highly in the CIA World Factbook for countries with both high and low life expectancy at birth. ${ }^{27}$ I found it in twelve countries ranked in the top twenty for life expectancy of 82 or more. ${ }^{28}$ I also found a U-shape in ten countries in the bottom twenty for life expectancy of 223 countries in the world according to the CIA. ${ }^{29}$ The U-shape is found with or without cohort controls.

The curve's trajectory holds true in countries where the median wage is high and where it is not and where people tend to live longer and where they don't.

I found additional evidence from an array of attitudinal questions that were worded slightly differently. Evidence of a U-shape was found in a variety of questions across European countries relating to an individual's finances as well as to the state of the economy and democracy and how public services work. In Africa I used a question that development scholars had used relating to living standards and found a U-shape for Africa as well as for thirty African countries. This suggests the U-curve in age may have much broader applicability than just in well-being data.

It seems to make relatively little difference in finding a U-shape if controls are included or not although in the former case the minima have a tendency to be higher. It does seem more appropriate to include them rather than not, given I am able to do so in a consistent way across countries, time and a variety of data sets. Education, marital status and unemployment are the major influences in a well-being equation. Unemployment, for example has seen major swings since 1973 and needs to be controlled for and has impacted various groups differently. Unemployment enters negatively in happiness equations and is a major source of hurt. Low education groups have been impacted especially hard by the Great Recession. Being married conveys markedly more happiness than being single, and especially more than, say being separated. These are all standard controls in happiness equations.

Averaging across the 257 individual country estimates from developing countries gives an age minimum of 48.2 for well-being and doing the same across the 187 country estimates for advanced countries gives a similar minimum of 47.2.

\footnotetext{
${ }^{26}$ Australia; Austria; Belgium; Canada; Chile; Czech Republic; Denmark; Estonia; Finland; France; Germany; Greece; Hungary; Iceland; Ireland; Israel; Italy; Japan; Latvia; Lithuania; Luxembourg; Mexico; Netherlands; New Zealand; Norway; Poland; Portugal; Slovenia; South Korea; Spain; Sweden; Switzerland; Turkey; United Kingdom and the United States.

${ }^{27}$ https://www.cia.gov/library/publications/resources/the-world-factbook/fields/355rank.html

${ }^{28}$ (Japan (2), Iceland (7), Israel (10), Malta (11), Switzerland (12), South Korea (13), Australia (14), Italy (15); Luxembourg (16); Sweden (17); Canada; (18) and France (19).

${ }^{29}$ Lesotho (221); Mozambique (218); Uganda (217), Niger (216); Eswatini (215); Nigeria (211); Cameroon (210) Cote d'Ivoire (209); Mali (206) at 6.8 and Zimbabwe (205). Those countries ranked below $209^{\text {th }}$ with life expectancies of less than sixty years at birth.
} 
The happiness curve is found in 132 countries. No myth. 


\title{
Compliance with Ethical Standards:
}

The author declares that I have no conflicts of interest.

\begin{abstract}
References
Argyle, M. (1999). Causes and correlates of happiness. In D. Kahneman, E. Diener, \& N. Schwarz (Eds.), Wellbeing: The foundations of hedonic psychology (pp. 353-373). New York: Russell Sage.
\end{abstract}

Argyle, M. (2001). The psychology of happiness (2nd ed.). New York: Routledge.

Baird, B., R.E. Lucas and M.B. Donovan, M.B. (2010). 'Life satisfaction across the life span: findings from two nationally representative panel studies', Social Indicators Research, 99(2), pp. 183-203.

Beja, E.L. Jr. (2018), 'The U-shaped relationship between happiness and age: evidence using World Values Survey data,' Quality and Quantity, 52, pp.1817-1829.

Bell, D.N.F. and D.G. Blanchflower (2019), 'The well-being of the overemployed and the underemployed and the rise in depression in the UK', Journal of Economic Behavior and Organization, 161, May, pp. 180-196.

Blanchflower D.G. (2009a), 'International evidence on well-being' in Measuring the Subjective Well-Being of Nations: National Accounts of Time Use and Well-Being edited by Alan B. Krueger, editor (p. 155 - 226), NBER and University of Chicago Press.

Blanchflower D.G. (2009b), 'Where next for the UK economy?', Scottish Journal of Political Economy, 56(1), 2009, February, pp. 1-23.

Blanchflower D.G. (2008), 'Inflation expectations and monetary policy', Bank of England Quarterly Bulletin, 2008Q2, pp. 229-237 plus appendix https://www.bankofengland.co.uk//media/boe/files/speech/2008/inflation-expectations-and-monetary-policy

Blanchflower, D.G. and, A. Clark (2019), 'Children, unhappiness and family finances: evidence from one million Europeans', NBER Working Paper \#25597, February.

Blanchflower, D.G. and, A.J. Oswald (2019), 'Do modern humans suffer a psychological low in midlife? Two approaches (with and without controls) in seven data sets', in The Economics of Happiness. How the Easterlin Paradox Transformed Our Understanding of Well-Being and Progress, edited by Mariano Rojas, 2019, Springer.

Blanchflower, D.G. and, A.J. Oswald (2016), 'Anti-depressants and age: a new form of evidence for U-shaped well-being through life', Journal of Economic Behavior and Organization, 127, pp. 46-58.

Blanchflower, D.G. and, A.J. Oswald (2011), 'International happiness: a new view on the measure of performance', Academy of Management Perspectives, February 2011, 25(1), pp. 6-22. 
Blanchflower, D.G. and, A.J. Oswald (2009), 'The U-shape without controls: A response to Glenn', Social Science and Medicine, 69, pp. 486-488.

Blanchflower, D.G. and, A.J. Oswald (2008a), 'Is well-being U-shaped over the life cycle?' $\underline{\text { Social }}$ Science and Medicine, 66, pp. 1733-1749.

Blanchflower, D.G. and, A.J. Oswald (2008b), 'Hypertension and happiness across nations', Journal of Health Economics, 27(2), pp. 218-233.

Blanchflower, D.G. and, A.J. Oswald (2004), 'Well-being over time in Britain and the USA,' Journal of Public Economics, 88, Issues 7-8, July, pp. 1359-1386.

Blanchflower, D.G., A.J. Oswald and S. Stewart-Brown (2012), 'Is psychological well-being linked to the consumption of fruit and vegetables?' Social Indicators Research: An International and Interdisciplinary Journal for Quality-of-Life Measurement, 114(3), pp. 785-801, December.

Bookwalter, J., B. Fitch-Fleischmann and D. Dalenberg (2011), 'Understanding life-satisfaction changes in post-apartheid South Africa,' MPRA Paper No. 34579.

Cantril, H., (1965), The Pattern of Human Concerns, Rutgers University Press, New Brunswick, NJ.

Carstensen, L.L., B. Turan, S. Scheibe, R. Ram, H. Ersnser-Hershfield, G.R. Samanez-Larkin, K.P. Brooksand J.R. Nesselroade (2011), 'Emotional experience improves with age: Evidence based on over 10 years of experience sampling,' Psychology and Aging, 26, pp. 21-33.

Charles, S.T., C.A. Reynolds and M. Gatz (2001), 'Age-related differences and change in positive and negative affect over 23 years,' Journal of Personality and Social Psychology, 80, PP. 136-151.

Cheng, T.C., N. Powdthavee and A.J. Oswald, (2017) 'Longitudinal evidence for a midlife nadir: Result from four data sets', Economic Journal, 127, February, pp.126-142.

Clark, A.E. (2019), 'Born to be mild? cohort effects don't (fully) explain why well-being is Ushaped in Age,' in The Economics of Happiness. How the Easterlin Paradox Transformed Our Understanding of Well-Being and Progress, 2019, edited by Mariano Rojas, Springer, pp 387-408.

Clark, A.E. and A.J. Oswald (1994), 'Unhappiness and unemployment,' The Economic Journal, 104 (May), pp. 648-659.

'Deaton, A. (2018) 'What do self-reports of wellbeing say about life-cycle theory and policy?', Journal of Public Economics, 162, June, pp. 18-25.

Deutsch, J., H. Musahara, H., and J. Silber, (2016), 'On the measurement of multidimensional wellbeing in some countries in eastern and southern Africa, in Poverty and Well-being in East Africa (pp. 191-214). Cham: Springer. 
Diener, E., E.M. Suh, R.E. Lucas, R. E., and H.L. Smith (1999), 'Subjective well-being: three decades of progress,' Psychological Bulletin, 125, pp. 302-376.

Easterlin, R.A. (2003), 'Explaining happiness.', Proceedings of the National Academy of Sciences, 100(19), pp. 11176-11183.

Easterlin, R.A. (2006), 'Life cycle happiness and its sources: Intersections of psychology, economics and demography,' Journal of Economic Psychology, 27(4), pp. 463-482.

Easterlin, R.A., L.A. McVey, S. Malgorzata, O. Sawangfa, and J.S. Zweig (2010), The happinessincome paradox revisited,' Proceedings National Academy of Sciences of the United States, 2010 Dec 28; 107(52), pp. 22463-22468.

Fortin, N. J.F. Helliwell and S. Wang (2015), 'How does subjective well-being vary around the world by gender and age?' in World Happiness Report, 2015, edited by John Helliwell, Richard Layard and Jeffrey Sachs

Frijters, P., and T. Beaton (2012), 'The mystery of the U-shaped relationship between happiness and age,' Journal of Economic Behavior and Organization, 82, 525-542.

Glenn, N. (2009), 'Is the apparent U-shape of well-being over the life course a result of inappropriate use of control variables? A commentary on Blanchflower and Oswald (66:8, 2008, 1733-1749),' Social Science and Medicine, 69(4), 481-485.

Graham, C. and J. R. Pozuelo (2017), 'Happiness, stress, and age: how the U curve varies across people and places', Journal of Population Economics, 30, pp.225-264.

Grover, S. and J.F. Helliwell (2019), 'How's life at home? New evidence on marriage and the set point for happiness,' Journal of Happiness Studies, February, 20(2), pp 373-390| .

Giuntella, O., S. McManus, R. Mujcic, A. J. Oswald, N. Powdthavee, A. Tohamy (2019), 'Why is there so much midlife distress in affluent nations?', Working Paper April.

Hellevik, O. (2017), 'The U-shaped age-happiness relationship: real or methodological artifact?' Quality and Quantity, 51, pp. 177-197.

Helliwell, J.F., (2019), 'Measuring and using happiness to support public policies,' NBER Working Paper \#26529.

Helliwell, J.F., H. Huang and S. Wang (2019). 'Changing world happiness', in The World Happiness Report, 2019, edited by J.F. Helliwell, R. Layard and J.D. Sachs.

Helliwell, J.F., M.B. Norton, H. Huang and S. Wang (2019), 'Happiness at different ages: the social context matters,' in The Economics of Happiness. How the Easterlin Paradox Transformed Our Understanding of Well-Being and Progress, edited by Mariano Rojas, 2019, Springer. 
Hudson, N.W., R.E. Lucas and M.B Donellan (2016), Getting older, feeling less? A cross-sectional and longitudinal investigation of developmental patterns in experiential well-being,' Psychology and Aging, 31, pp. 847-861.

Kassenboehmer, S.C. and J.P. Haisken-DeNew, J.P. (2012). 'Heresy or enlightenment? The wellbeing age U-shape effect is flat’, Economic Letters, 117(1), pp. 235-8.

Laaksonen, S. (2018), 'A research note: happiness by age is more complex than U-shaped,' Journal of Happiness Studies, 19, pp. 471-482.

Lachman, M.E. (2015), 'Mind the gap in the middle: A call to study midlife,' Development, 12, pp. 327-334.

Leland, J. (2018), Happiness Is a Choice You Make: Lessons from a Year Among the Oldest Old, Sarah Crichton Books.

Marcelli, E.A. and Richard A. Easterlin (2005), 'Beyond gender differences in U.S. life cycle happiness.' working paper.

Morgan, R, and K.J. O’Connor (2017), 'Experienced life cycle satisfaction in Europe', Review of Behavioral Economics, 4, pp. 371-396

Mroczek, D.K., and C.M. Kolanz, C.M. (1998), 'The effect of age on positive and negative affect: A developmental perspective on happiness,' Journal of Personality and Social Psychology, 75, pp. 1333-1349.

Mroczek, D.K., and A. Spiro (2005), 'Change in life satisfaction during adulthood: Findings from the Veterans Affairs Normative Aging study,' Journal of Personality and Social Psychology, 88, pp. 189-202.

Myers, D. G. (2000), 'The funds, friends, and faith of happy people,' American Psychologist, 55(1), pp. 56-67.

Palmore, E., Luikart, C., (1972), 'Health and social factors related to life satisfaction,' Journal of Health and Social Behavior 13 (1), pp. 68-78.

Pokimica, J., I. Addai, I., B.K. Takyi (2012) 'Religion and subjective well-being in Ghana,' $\underline{\text { Social }}$ Indicators Research, 106, pp. 61-79.

Price, A. (2015), 'Sliding down the U-shape? A dynamic panel investigation of the age-wellbeing relationship, focusing on young adults,' Social Science and Medicine,143, pp. 54-61

Ranjbar, S. and S. Sperlich (2019), 'A Note on empirical studies of life-satisfaction: unhappy with semiparametrics?', Journal of Happiness Studies, First Online16 September 2019

Rauch, J. (2018), The U-shape of Happiness. New York: St. Martin’s Press. 
Schwandt, H. (2016), 'Unmet aspirations as an explanation for the age U-shape in well-being. Journal of Economic Behavior and Organization,' 122, pp. 75-87.

Shields, M.A. and S. W. Price (2005), 'Exploring the economic and social determinants of psychological well-being and perceived social support in England, Journal of the Royal Statistical Society (Series A), 168, pp. 513-537.

Steptoe, A., A. Deaton and A.A. Stone (2015), 'Subjective wellbeing, health, and ageing,' The Lancet, 385, pp. 640-648.

Stone, A.A., J.E. Schwartz, J.E., Broderick and A. Deaton (2010), 'A snapshot of the age distribution of psychological well-being in the United States,' Proceedings of the National Academy of Sciences, 107, pp. 9985-999.

Sulemana, I. (2015a), 'The effect of fear of crime and crime victimization on subjective well-being in Africa,' Social Indicators Research, 121(3), pp. 849-872.

Sulemana, I. (2015b), 'An empirical investigation of the relationship between social capital and subjective well-being in Ghana,' Journal of Happiness Studies, 16(5), pp. 1299-1321.

Sulemana, I., L. Doabil and E.B. Anarfo (2019), 'International remittances and subjective wellbeing in Sub-Saharan Africa: a micro-level study', Journal of Family and Economic Issues, 40(3), pp. 524-539, September.

Sulemana, I., A.M. Iddrisu and J.E. Kyoore (2017), 'A micro-level study of the relationship between experienced corruption and subjective wellbeing in Africa,' The Journal of Development Studies, 53(1), pp. 138-155.

Ulloa, B.F.L., Moller, V. and A. Sousa-Poza (2013), 'How does subjective well-being evolve with age? A literature review,' Journal of Population Ageing, 6, pp. 227-246.

Weiss, A., J.E. King, M. Inoue-Murayama M, T. Matsuzawa and A.J. Oswald AJ (2012), 'Evidence for a midlife crisis in great apes consistent with the U-shape in human well-being', Proceedings of the National Academy of Sciences, December 4, 109 (49), pp. 19949-19952.

Whitbourne. S.K. (2018), 'That midlife happiness curve? It's more like a line,' $\underline{\text { sychology Today, }}$ September $18^{\text {th }}$. https://www.psychologytoday.com/us/blog/fulfillment-any-age/201809/midlifehappiness-curve-its-more-line

Wunder, C., A. Wiencierz, J., Schwarze and H. Küchenhoff (2013), 'Well-being over the life span: Semi-parametric evidence from British and German longitudinal data', Review of Economics and Statistics, 95, pp. 154-167. 
Table 1a. Life satisfaction equations 2009-2019 Eurobarometers. Country estimates age $<70$ with controls

\begin{tabular}{|c|c|c|c|c|c|c|}
\hline & Age & $\mathrm{T}$ & $\mathrm{Age}^{2}$ & $\mathrm{~T}$ & $\mathrm{~N}$ & Age minimum \\
\hline Without controls & -.01771 & 97.22 & .00014 & 79.93 & $1,221,863$ & 63 \\
\hline With controls & -.01940 & 87.74 & .00018 & 85.88 & $1,219,888$ & 54 \\
\hline +9 cohort dummies & -.01188 & 22.46 & .00011 & 22.59 & $1,219,898$ & 54 \\
\hline \multicolumn{7}{|l|}{ Western Europe } \\
\hline Without controls & -.01380 & 61.55 & .00012 & 52.78 & 743,565 & 58 \\
\hline With controls & -.01658 & 60.74 & .00016 & 62.09 & 742,392 & 52 \\
\hline 1. Austria & -.01362 & 6.92 & .00014 & 6.04 & 34704 & 49 \\
\hline 2. Belgium & -.03140 & 17.60 & .00038 & 17.45 & 34717 & 41 \\
\hline 3. Cyprus & -.03481 & 10.45 & .00037 & 9.84 & 19,407 & 47 \\
\hline 4. Denmark & -.02931 & 18.58 & .00034 & 19.67 & 31,369 & 43 \\
\hline 5. Finland & -.03194 & 17.90 & .00033 & 16.89 & 31,009 & 48 \\
\hline 6. France & -.03595 & 17.83 & .00036 & 15.65 & 33864 & 50 \\
\hline 7. Greece & -.03572 & 13.40 & .00029 & 9.76 & 33219 & 62 \\
\hline 8. Iceland (non-EU) & -.03378 & 8.12 & .00035 & 6.80 & 6,293 & 50 \\
\hline 9. Ireland & -.02291 & 12.63 & .00026 & 12.71 & 35,756 & 48 \\
\hline 10. Italy & -.01211 & 5.42 & .00010 & 4.20 & 36,190 & 61 \\
\hline 11. Luxembourg & -.01042 & 5.73 & .00018 & 6.43 & 19087 & 29 \\
\hline 12. Malta & -.03002 & 11.01 & .00031 & 10.35 & 17646 & 48 \\
\hline 13. Netherlands & -.04123 & 20.72 & .00047 & 21.69 & 35,011 & 44 \\
\hline 14. Norway (non-EU) & -.02444 & 5.14 & .00027 & 5.03 & 3451 & 45 \\
\hline 15. Portugal & -.01992 & 10.29 & .00019 & 8.70 & 35,008 & 52 \\
\hline 16. Spain & -.03868 & 8.46 & .00041 & 17.57 & 34432 & 47 \\
\hline 17. Sweden & -.03424 & 16.86 & .00038 & 16.86 & 27,961 & 45 \\
\hline 18. UK (GB+NI) & -.03611 & 20.19 & .00042 & 20.57 & 32,181 & 43 \\
\hline 19. West Germany & -.03062 & 15.66 & .00035 & 15.60 & 31,394 & 44 \\
\hline \multicolumn{7}{|c|}{ EU28 Eastern Europe } \\
\hline Without controls & -.02419 & 74.73 & .00018 & 58.06 & 396,928 & 55 \\
\hline With controls & -.02233 & 56.99 & .00020 & 52.96 & 396,289 & 53 \\
\hline 20. Bulgaria & -.01587 & 6.78 & .00011 & 4.02 & 35,829 & 72 \\
\hline 21. Croatia & -.02960 & 12.90 & .00027 & 9.83 & 33,818 & 55 \\
\hline 22. Czech Republic & -.02841 & 14.57 & .00028 & 12.90 & 37,772 & 51 \\
\hline 23. East Germany & -.01637 & 6.57 & .00019 & 6.60 & 18,477 & 43 \\
\hline 24. Estonia & -.03630 & 18.09 & .00035 & 15.58 & 31225 & 52 \\
\hline 25. Hungary & -.03927 & 17.60 & .00041 & 15.93 & 35,863 & 48 \\
\hline 26. Latvia & -.04094 & 21.87 & .00039 & 18.37 & 36,568 & 52 \\
\hline 27. Lithuania & -.04869 & 20.79 & .00047 & 17.79 & 30,346 & 52 \\
\hline 28. Poland & -.02474 & 13.19 & .00023 & 10.59 & 35,405 & 54 \\
\hline 29. Romania & -.01904 & 8.52 & .00015 & 5.68 & 37,442 & 63 \\
\hline 30. Slovakia & -.02524 & 12.04 & .00026 & 10.80 & 36,206 & 72 \\
\hline 31. Slovenia & -.02231 & 11.05 & .00019 & 8.47 & 34052 & 49 \\
\hline \multicolumn{7}{|c|}{ Developing countries } \\
\hline Without controls & -.02256 & 22.67 & .00019 & 17.77 & 81,370 & 59 \\
\hline With controls & -.02188 & 17.43 & .00020 & 14.52 & 81,217 & 55 \\
\hline 32. Albania & -.02035 & 3.49 & .00014 & 2.14 & 7,125 & 73 \\
\hline 33. Macedonia & -.03428 & 8.19 & .00036 & 7.49 & 14,871 & 48 \\
\hline 34. Montenegro & -.02081 & 3.80 & .00013 & 1.88 & 9,434 & 80 \\
\hline 35. Serbia & -.02852 & 6.29 & .00022 & 4.19 & 12,213 & 65 \\
\hline 36. Turkey & -.01241 & 3.63 & .00011 & 2.60 & 19,150 & 56 \\
\hline 37. Turkish Cyprus & -.01172 & 3.02 & .00011 & 2.49 & 13,655 & 53 \\
\hline
\end{tabular}


Table 1b. Life satisfaction equations from 2009-2018 Eurobarometers with no controls just year dummies. Country estimates age $<70$ (ALL 49 1b and 1c no control ESTIMATES AVERAGE 56.6)

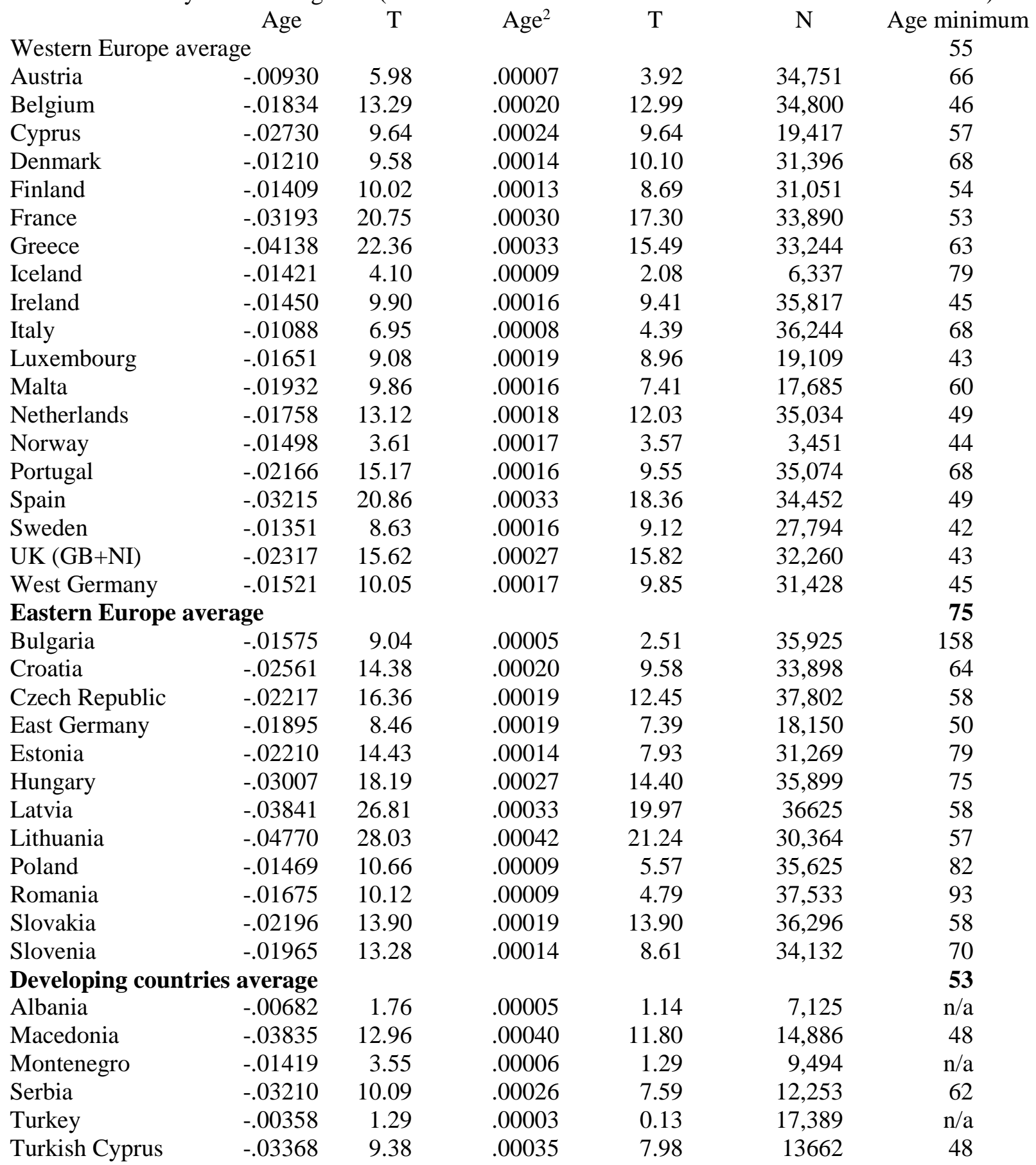


Table 1c. Life satisfaction equations Mannheim Trends File, 1973-2002, Eurobarometers. Country estimates age $<70$ with controls

\begin{tabular}{|c|c|c|c|c|c|c|}
\hline 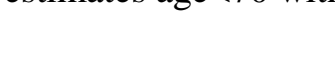 & Age & $\mathrm{T}$ & Age $^{2}$ & $\mathrm{~T}$ & $\mathrm{~N}$ & Age minimum \\
\hline \multicolumn{7}{|l|}{ All ages } \\
\hline Without controls & -.00985 & 39.42 & .00009 & 35.37 & 648,083 & 55 \\
\hline With controls & -.01944 & 44.16 & .00016 & 85.88 & 603,656 & 61 \\
\hline + 7 cohort dummies & -.01250 & 24.26 & .00014 & 31.27 & 603,656 & 45 \\
\hline \multicolumn{7}{|c|}{ Age $<70$ with controls } \\
\hline Average & & & & & & 45 \\
\hline 38. Belgium & -.02100 & 11.86 & .00022 & 10.85 & 45,628 & 48 \\
\hline 39. Denmark & -.01660 & 13.04 & .00019 & 13.04 & 44,411 & 44 \\
\hline 40. Finland & -.03699 & 11.23 & .00040 & 10.20 & 8,954 & 46 \\
\hline 41. France & -.02484 & 13.58 & .00029 & 13.36 & 47,005 & 43 \\
\hline 42. Greece & -.02240 & 9.11 & .00021 & 7.55 & 36,510 & 53 \\
\hline 43. Ireland & -.01535 & 8.92 & .00021 & 10.67 & 45,926 & 37 \\
\hline 44. Italy & -.02381 & 13.21 & .00023 & 11.23 & 48,159 & 52 \\
\hline 45. Luxembourg & -.01157 & 4.65 & .00014 & 4.97 & 18,297 & 41 \\
\hline 46. Netherlands & -.02033 & 14.94 & .00023 & 14.34 & 46,280 & 44 \\
\hline 47. Norway & -.02487 & 5.49 & .00028 & 5.40 & 6,395 & 44 \\
\hline 48. Portugal & -.02537 & 10.29 & .00025 & 10.60 & 28,515 & 51 \\
\hline 49. Spain & -.02963 & 13.19 & .00031 & 12.01 & 28,636 & 48 \\
\hline 50. Sweden & -.03336 & 10.16 & .00037 & 9.51 & 8,723 & 45 \\
\hline 51. UK (GB+NI) & -.01670 & 12.99 & .00023 & 14.82 & 60,011 & 36 \\
\hline 52. Germany & -.01452 & 11.05 & .00018 & 11.45 & 65,534 & 40 \\
\hline
\end{tabular}


Table 2a. Happiness using European Social Surveys Sweeps 1-8, 2002-2016, country estimates age $<70$ Controls include gender, marital and labor force dummies, education, country and sweep dummies. Without controls includes sweep and country dummies only.

\begin{tabular}{|c|c|c|c|c|c|c|}
\hline & Age & $\mathrm{T}$ & Age $^{2}$ & $\mathrm{~T}$ & $\mathrm{~N}$ & Age minimum \\
\hline \multicolumn{7}{|l|}{ All ages } \\
\hline Without controls & -.0300 & 34.41 & .00019 & 21.49 & 370,542 & 80 \\
\hline With controls & -.0670 & 56.74 & .00059 & 49.78 & 361,072 & 57 \\
\hline \multicolumn{7}{|c|}{ Developing countries } \\
\hline Without controls & -.0347 & 11.24 & .00014 & 4.58 & 40,594 & 124 \\
\hline With controls & -.0703 & 17.18 & .00057 & 13.92 & 39,790 & 62 \\
\hline 53. Israel & -.0892 & 9.74 & .00086 & 8.29 & 12,251 & 52 \\
\hline 54. Russia & -.0912 & 7.31 & .00077 & 5.29 & 10,934 & 59 \\
\hline 55. Turkey & -.1105 & 4.83 & .00128 & 4.80 & 3,870 & 43 \\
\hline 56. Ukraine & -.1065 & 7.37 & .00090 & 5.44 & 7,896 & 59 \\
\hline \multicolumn{7}{|c|}{ Advanced Countries } \\
\hline Without controls & -.0289 & 31.93 & .00019 & 2.72 & 329,948 & 77 \\
\hline With controls & -.0658 & 53.47 & .00058 & 47.52 & 321,130 & 57 \\
\hline 57. Austria & -.0619 & 5.63 & .00056 & 4.32 & 9,197 & 55 \\
\hline 58. Belgium & -.0621 & 7.92 & .00066 & 7.37 & 12,256 & 47 \\
\hline 59. Bulgaria & -.1931 & 1.51 & .00161 & 8.01 & 6,594 & 60 \\
\hline 60. Croatia & -.1445 & 6.29 & .00129 & 5.01 & 2,413 & 56 \\
\hline 61. Cyprus & -.0580 & 3.18 & .00061 & 2.93 & 3,702 & 48 \\
\hline 62. Czech Republic & -.0772 & 6.94 & .00070 & 5.68 & 12,766 & 55 \\
\hline 63. Denmark & -.0591 & 7.40 & .00066 & 7.44 & 9,153 & 45 \\
\hline 64. Estonia & -.0813 & 7.40 & .00061 & 4.92 & 9,612 & 67 \\
\hline 65. Finland & -.0633 & 9.01 & .00061 & 7.47 & 12,145 & 52 \\
\hline 66. France & -.1013 & 1.65 & .00093 & 8.39 & 12,512 & 54 \\
\hline 67. Germany & -.1160 & 15.26 & .00119 & 14.00 & 19,681 & 49 \\
\hline 68. Great Britain & -.0950 & 11.06 & .00109 & 11.14 & 14,204 & 44 \\
\hline 69. Greece & -.1188 & 9.14 & .00109 & 7.47 & 8,025 & 54 \\
\hline 70. Hungary & -.1205 & 9.60 & .00104 & 7.31 & 10,877 & 58 \\
\hline 71. Iceland & -.0566 & 3.35 & .00064 & 3.39 & 1,798 & 44 \\
\hline 72. Ireland & -.0880 & 1.68 & .00103 & 11.10 & 15,169 & 43 \\
\hline 73. Italy & -.0752 & 4.39 & .00071 & 3.63 & 3,874 & 53 \\
\hline 74. Lithuania & -.0942 & 5.80 & .00072 & 3.92 & 6,443 & 65 \\
\hline 75. Luxembourg & -.0810 & 3.97 & .00104 & 4.46 & 2,703 & 39 \\
\hline 76. Netherlands & -.0651 & 9.18 & .00069 & 8.77 & 12,700 & 47 \\
\hline 77. Norway & -.0647 & 8.42 & .00066 & 7.59 & 11,665 & 49 \\
\hline 78. Poland & -.1034 & 1.01 & .00091 & 7.61 & 12,220 & 57 \\
\hline 79. Portugal & -.0856 & 8.74 & .00072 & 6.54 & 11,185 & 59 \\
\hline 80. Slovakia & -.0964 & 7.14 & .00090 & 5.82 & 7,231 & 54 \\
\hline 81. Slovenia & -.0962 & 8.43 & .00075 & 5.72 & 8,876 & 64 \\
\hline 82. Spain & -.0980 & 11.53 & .00089 & 9.25 & 12,877 & 55 \\
\hline 83. Sweden & -.0630 & 8.18 & .00064 & 7.23 & 12,089 & 49 \\
\hline 84. Switzerland & -.0598 & 7.70 & .00064 & 7.20 & 11,697 & 47 \\
\hline
\end{tabular}


Table 2b. Happiness using European Social Surveys Sweeps 1-8, 2002-2016, country estimates age $<70$ Without controls includes sweep dummies only.

\begin{tabular}{lrrrrrr} 
& Age & \multicolumn{1}{c}{$\mathrm{T}$} & Age $^{2}$ & \multicolumn{1}{c}{$\mathrm{T}$} & $\mathrm{N}$ & Age minimum \\
Israel & -.02761 & 4.15 & .00018 & 2.23 & 12,609 & 77 \\
Russia & -.06047 & 7.08 & .00038 & 3.88 & 10,545 & 80 \\
Turkey & -.08041 & 4.73 & .00095 & 4.54 & 3,893 & 42 \\
Ukraine & -.05717 & 5.49 & .00024 & 2.04 & 8,054 & 119 \\
Austria & -.02304 & 2.86 & .00020 & 2.00 & 9,329 & 58 \\
Belgium & -.02346 & 4.75 & .00025 & 4.07 & 12,400 & 47 \\
Bulgaria & -.11103 & 8.21 & .00072 & 4.79 & 6,625 & 77 \\
Croatia & -.05479 & 3.23 & .00030 & 1.53 & 2,512 & 91 \\
Cyprus & -.03245 & 2.72 & .00025 & 1.77 & 3,780 & 65 \\
Czech Republic & -.05518 & 8.11 & .00040 & 5.18 & 13,198 & 69 \\
Denmark & -.00740 & 1.30 & .00014 & 2.05 & 9,340 & $\mathrm{n} / \mathrm{a}$ \\
Estonia & -.01312 & 1.86 & -.00018 & 2.18 & 11,024 & $\mathrm{n} / \mathrm{a}$ \\
Finland & -.00403 & 0.88 & -.00018 & 0.34 & 13,760 & $\mathrm{n} / \mathrm{a}$ \\
France & -.05389 & 8.08 & .00043 & 5.68 & 12,548 & 63 \\
Germany & -.04673 & 9.16 & .00048 & 8.19 & 19,860 & 49 \\
Great Britain & -.07341 & 11.13 & .00089 & 11.81 & 14,310 & 41 \\
Greece & -.05968 & 6.04 & .00040 & 3.73 & 8,074 & 75 \\
Hungary & -.06819 & 7.87 & .00042 & 4.21 & 11,071 & 81 \\
Iceland & -.01544 & 1.20 & .00025 & 1.66 & 1,923 & $\mathrm{n} / \mathrm{a}$ \\
Ireland & -.04960 & 7.89 & .00061 & 8.49 & 15,488 & 41 \\
Italy & -.02180 & 1.87 & .00001 & 0.70 & 4,035 & $\mathrm{n} / \mathrm{a}$ \\
Lithuania & -.04611 & 4.88 & .00010 & 0.87 & 6,542 & $\mathrm{n} / \mathrm{a}$ \\
Luxembourg & -.05249 & 3.94 & .00067 & 4.22 & 2,839 & 39 \\
Netherlands & -.02791 & 5.31 & .00028 & 4.70 & 12,811 & 50 \\
Norway & -.02957 & 5.36 & .00035 & 5.31 & 11,742 & 42 \\
Poland & -.03566 & 5.09 & .00011 & 1.31 & 12,333 & $\mathrm{n} / \mathrm{a}$ \\
Portugal & -.04785 & 6.84 & .00025 & 3.16 & 11,643 & 96 \\
Slovakia & -.05393 & 5.81 & .00035 & 3.37 & 7,510 & 77 \\
Slovenia & -.02880 & 3.82 & -.00000 & 0.04 & 9,304 & $\mathrm{n} / \mathrm{a}$ \\
Spain & -.04653 & 7.84 & .00040 & 5.43 & 13,073 & 58 \\
Sweden & -.02261 & 4.15 & .00028 & 4.47 & 12,156 & 40 \\
Switzerland & -.01886 & 3.42 & .00021 & 3.28 & 11,846 & 45 \\
& & & & & &
\end{tabular}


Table 3. European Quality of Life Surveys, 2003-2016, Life satisfaction

\begin{tabular}{|c|c|c|c|c|c|c|}
\hline & Age & $\mathrm{T}$ & Age $^{2}$ & $\mathrm{~T}$ & $\mathrm{~N}$ & Age minimum \\
\hline \multicolumn{7}{|l|}{ All ages } \\
\hline Without controls & -.04367 & 25.49 & .00037 & 21.90 & 141,780 & 59 \\
\hline With controls & -.05529 & 26.85 & .00054 & 26.08 & 139,721 & 51 \\
\hline \multicolumn{7}{|l|}{ Western Europe } \\
\hline Without controls & -.02403 & 11.60 & .00024 & 11.88 & 84640 & 50 \\
\hline With controls & -.03593 & 14.59 & .00039 & 15.92 & 83182 & 46 \\
\hline 85. Austria & -.06627 & 3.29 & .00079 & 3.37 & 3835 & 42 \\
\hline 86. Belgium & -.05045 & 2.86 & .00059 & 2.92 & 3344 & 43 \\
\hline 87. Denmark & -.08580 & 5.39 & .00110 & 6.27 & 3193 & 39 \\
\hline 88. Germany & -.07925 & 5.08 & .00091 & 5.16 & 6236 & 44 \\
\hline 89. Greece & -.07616 & 3.45 & .00060 & 2.42 & 3270 & 63 \\
\hline 90. Finland & -.09116 & 6.52 & .00111 & 7.02 & 3218 & 41 \\
\hline 91. France & -.05428 & 3.44 & .00062 & 3.34 & 4,040 & 44 \\
\hline 92. Iceland & -.09464 & 3.26 & .00104 & 3.22 & 864 & 46 \\
\hline 93. Ireland & -.07595 & 4.45 & .00095 & 4.89 & 3,515 & 40 \\
\hline 94. Italy & -.10606 & 6.95 & .00113 & 6.62 & 5,823 & 47 \\
\hline 95. Malta & -.04918 & 2.42 & .00055 & 2.39 & 3,036 & 45 \\
\hline 96. Netherlands & -.05084 & 3.75 & .00065 & 4.23 & 3,468 & 39 \\
\hline 97. Portugal & -.07764 & 4.14 & .00078 & 3.68 & 3,205 & 50 \\
\hline 98. Spain & -.06332 & 3.80 & .00064 & 3.36 & 3,692 & 49 \\
\hline 99. Sweden & -.04340 & 2.70 & .00058 & 3.22 & 3,325 & 37 \\
\hline 100. United Kingdom & -.10431 & 6.41 & -.00120 & 6.43 & 4,738 & 43 \\
\hline \multicolumn{7}{|c|}{ Eastern Europe } \\
\hline Without controls & -.07389 & 21.91 & .00054 & 16.37 & 41,016 & 68 \\
\hline With controls & -.08249 & 20.21 & .00070 & 17.27 & 40,571 & 59 \\
\hline 101. Bulgaria & -.10310 & 4.45 & .00089 & 3.35 & 3,208 & 58 \\
\hline 102. Croatia & -.13786 & 5.30 & .00125 & 4.26 & 2,503 & 55 \\
\hline 103. Czech Republic & -.05031 & 2.31 & .00048 & 1.92 & 3,718 & 52 \\
\hline 104. Estonia & -.11716 & 5.31 & .00113 & 4.52 & 2,742 & 52 \\
\hline 105. Hungary & -.10976 & 4.86 & .00104 & 4.02 & 3,302 & 53 \\
\hline 106. Latvia & -.11664 & 5.41 & .00104 & 4.14 & 3,093 & 56 \\
\hline 107. Lithuania & -.17038 & 7.36 & .00163 & 6.13 & 3,170 & 52 \\
\hline 108. Poland & -.08943 & 4.97 & .00067 & 3.20 & 4,922 & 67 \\
\hline 109. Romania & -.11735 & 5.36 & .00121 & 4.83 & 3,789 & 48 \\
\hline 110. Slovenia & -.07331 & 3.13 & .00069 & 2.60 & 3,030 & 53 \\
\hline 111. Slovakia & -.06724 & 2.91 & .00058 & 2.16 & 3600 & 58 \\
\hline \multicolumn{7}{|c|}{ Developing countries } \\
\hline Without controls & -.05603 & 9.00 & .00049 & 7.47 & 16,124 & 57 \\
\hline With controls & -.05817 & 7.54 & .00054 & 6.65 & 15,968 & 54 \\
\hline 112. Albania & -.17222 & 2.90 & .00199 & 3.04 & 883 & 43 \\
\hline 113. Kosovo & -.09041 & 2.17 & .00105 & 2.13 & 1,021 & 43 \\
\hline 114. Macedonia & -.12428 & 4.50 & .00125 & 3.95 & 2,661 & 50 \\
\hline 115. Montenegro & -.12197 & 3.87 & .00121 & 3.21 & 1,840 & 50 \\
\hline 116. Serbia & -.17651 & 5.17 & .00169 & 4.33 & 1,822 & 52 \\
\hline 117. Turkey & -.09548 & 5.77 & .00115 & 5.89 & 6,582 & 42 \\
\hline
\end{tabular}


Table 4. ISSP 2012 coefficients in a happiness equation. Uses gender, education, marital and labor force status as controls and single country results age $<70$

\begin{tabular}{|c|c|c|c|c|c|c|}
\hline & Age & $\mathrm{T}$ & Age $^{2}$ & $\mathrm{~T}$ & $\mathrm{~N}$ & Age minimum \\
\hline \multicolumn{7}{|l|}{ All ages } \\
\hline Without controls & -.0162 & 12.03 & .00012 & 8.60 & 60,664 & 68 \\
\hline With controls & -.0355 & 21.88 & .00032 & 19.81 & 60,664 & 55 \\
\hline \multicolumn{7}{|l|}{ Advanced } \\
\hline Without controls & -.0142 & 7.64 & .00012 & 6.72 & 26534 & 59 \\
\hline With controls & -.0375 & 16.36 & .00033 & 14.68 & 26534 & 57 \\
\hline 118. Australia & -.0240 & 1.51 & .0002 & 1.50 & 1,297 & 60 \\
\hline 119. Belgium & -.0490 & 3.20 & .0005 & 3.02 & 1,794 & 49 \\
\hline 120. Canada & -.0537 & 2.33 & .0004 & 1.94 & 735 & 67 \\
\hline 121. Finland & -.0402 & 2.24 & .0003 & 1.91 & 1,054 & 67 \\
\hline 122. France & -.0432 & 2.85 & .0003 & 1.85 & 1,926 & 72 \\
\hline 123. Germany & -.0430 & 3.31 & .0003 & 2.61 & 1,450 & 72 \\
\hline 124. Iceland & -.0298 & 2.04 & .0003 & 1.78 & 1,040 & 50 \\
\hline 125. Japan & -.0584 & 2.59 & .0004 & 1.91 & 982 & 73 \\
\hline 126. Netherlands & -.0626 & 3.43 & .0005 & 2.87 & 1,021 & 63 \\
\hline 127. Norway & -.0495 & 3.22 & .0004 & 2.79 & 1,292 & 62 \\
\hline 128. Spain & -.0839 & 6.58 & .0008 & 5.66 & 2,161 & 52 \\
\hline 129. Sweden & -.0372 & 1.83 & .0003 & 1.52 & 873 & 62 \\
\hline 130. UK & -.0369 & 1.69 & .0003 & 1.56 & 748 & 62 \\
\hline 131. USA & -.0411 & 2.58 & .0004 & 2.49 & 1,109 & 51 \\
\hline \multicolumn{7}{|l|}{ Eastern Europe } \\
\hline Without controls & -.0321 & 1.21 & .0002 & 5.73 & 10,177 & 89 \\
\hline With controls & -.0588 & 14.49 & .0008 & 11.65 & 10,177 & 35 \\
\hline 132. Bulgaria & -.0737 & 3.20 & .0005 & 2.03 & 794 & 74 \\
\hline 133. Croatia & -.0774 & 3.93 & .0006 & 2.92 & 915 & 65 \\
\hline 134. Czech Republic & -.0635 & 3.5 & .0005 & 2.69 & 1,596 & 64 \\
\hline 135. Hungary & -.0794 & 3.84 & .0007 & 3.30 & 890 & 57 \\
\hline 136. Latvia & -.0800 & 4.29 & .0007 & 3.07 & 953 & 57 \\
\hline 137. Lithuania & -.1161 & 6.39 & .0011 & 5.76 & 1,004 & 53 \\
\hline 138. Poland & -.0733 & 3.95 & .0007 & 3.54 & 964 & 52 \\
\hline 139. Slovakia & -.0868 & 3.89 & .0008 & 3.27 & 968 & 54 \\
\hline 140. Slovenia & -.0819 & 3.52 & .0007 & 2.87 & 832 & 59 \\
\hline \multicolumn{7}{|l|}{ Developing } \\
\hline Without controls & -.0096 & 3.99 & .00006 & 2.32 & 23,953 & 85 \\
\hline With controls & -.0238 & 8.53 & .00023 & 8.23 & 23,953 & 51 \\
\hline 141. Chile & -.0399 & 2.87 & .0004 & 2.85 & 1,335 & 45 \\
\hline 142. China & -.0760 & 8.64 & .0008 & 8.59 & 5,287 & 46 \\
\hline 143. Israel & -.0678 & 3.69 & .0006 & 3.00 & 1,049 & 54 \\
\hline 144. Mexico & -.0225 & 1.56 & .0002 & 1.33 & 1,379 & 49 \\
\hline 145. Russia & -.0485 & 2.93 & .0005 & 2.43 & 1,249 & 50 \\
\hline 146. South Africa & -.0584 & 3.46 & .0006 & 3.31 & 2,316 & 44 \\
\hline 147. South Korea & -.0659 & 2.92 & .0005 & 2.51 & 1,135 & 55 \\
\hline 148. Taiwan & -.0468 & 3.00 & .0005 & 3.03 & 1,838 & 43 \\
\hline
\end{tabular}


Table 5. ISSP 2017 coefficients in a life satisfaction equation. Uses gender, education, marital and labor force status as controls. Country equations are all for age $<70$

\begin{tabular}{|c|c|c|c|c|c|c|}
\hline & Age & $\mathrm{T}$ & $\operatorname{Age}^{2}$ & $\mathrm{~T}$ & $\mathrm{~N}$ & Age minimum \\
\hline \multicolumn{7}{|l|}{ All countries } \\
\hline Without controls & -.01294 & 7.46 & .00012 & 6.87 & 43,606 & 54 \\
\hline With controls & -.03016 & 14.56 & .000316 & 6.32 & 43,565 & 48 \\
\hline \multicolumn{7}{|l|}{ Advanced countries } \\
\hline Without controls & -.01226 & 5.78 & .00011 & 5.16 & 25,397 & 56 \\
\hline With controls & -.03021 & 11.43 & .00028 & 10.87 & 25,371 & 54 \\
\hline 149. Australia & -.04215 & 2.18 & .00048 & 2.30 & 965 & 44 \\
\hline 150. Austria & -.05726 & 3.00 & .00057 & 2.63 & 982 & 50 \\
\hline 151. Czech Republic & -.06298 & 2.84 & .00061 & 2.45 & 1197 & 52 \\
\hline 152. Croatia & -.05966 & 3.00 & .00053 & 2.26 & 950 & 56 \\
\hline 153. Denmark & -.04000 & 1.85 & .00045 & 1.85 & 855 & 44 \\
\hline 154. France & -.05346 & 2.09 & .00058 & 2.00 & 1,133 & 46 \\
\hline 155. Germany & -.02691 & 1.62 & .00028 & 1.54 & 1,405 & 48 \\
\hline 156. Japan & -.05663 & 2.55 & .00054 & 2.29 & 1,232 & 52 \\
\hline 157. Lithuania & -.07204 & 3.02 & .00055 & 2.06 & 883 & 65 \\
\hline 158. New Zealand & -.02872 & 1.64 & .00036 & 1.85 & 1,130 & 40 \\
\hline 159. Spain & -.04027 & 2.37 & .00032 & 1.59 & 1,440 & 63 \\
\hline 160. Sweden & -.04947 & 2.55 & .00055 & 2.57 & 897 & 45 \\
\hline 161. Switzerland & -.06241 & 3.61 & .00069 & 3.55 & 914 & 45 \\
\hline 162. UK & -.04805 & 2.71 & .00054 & 2.70 & 1,246 & 44 \\
\hline 163. USA & -.04234 & 2.21 & .00047 & 2.21 & 1,001 & 45 \\
\hline \multicolumn{7}{|l|}{ Developing countries } \\
\hline Without controls & -.01486 & 5.01 & .00015 & 4.83 & 18,209 & 50 \\
\hline With controls & -.03099 & 9.10 & .00034 & 9.76 & 18,194 & 46 \\
\hline 164. China & -.04507 & 4.20 & .00054 & 4.72 & 3,602 & 42 \\
\hline 165. Taiwan & -.03097 & 1.98 & .00041 & 2.38 & 1,721 & 38 \\
\hline 166. India & -.04818 & 2.41 & .00047 & 2.00 & 1,395 & 51 \\
\hline 167. Israel & -.04486 & 2.13 & .00041 & 1.78 & 1,015 & 55 \\
\hline 168. Russia & -.04625 & 2.39 & .00041 & 1.85 & 1,392 & 56 \\
\hline 169. South Africa & -.08626 & 7.48 & .00103 & 7.59 & 2,853 & 42 \\
\hline 170. Surinam & -.05566 & 2.36 & .00065 & 2.44 & 1,094 & 43 \\
\hline
\end{tabular}


Table 6. Life satisfaction using WVS 2-6. Controls are gender, education marital and labor force status

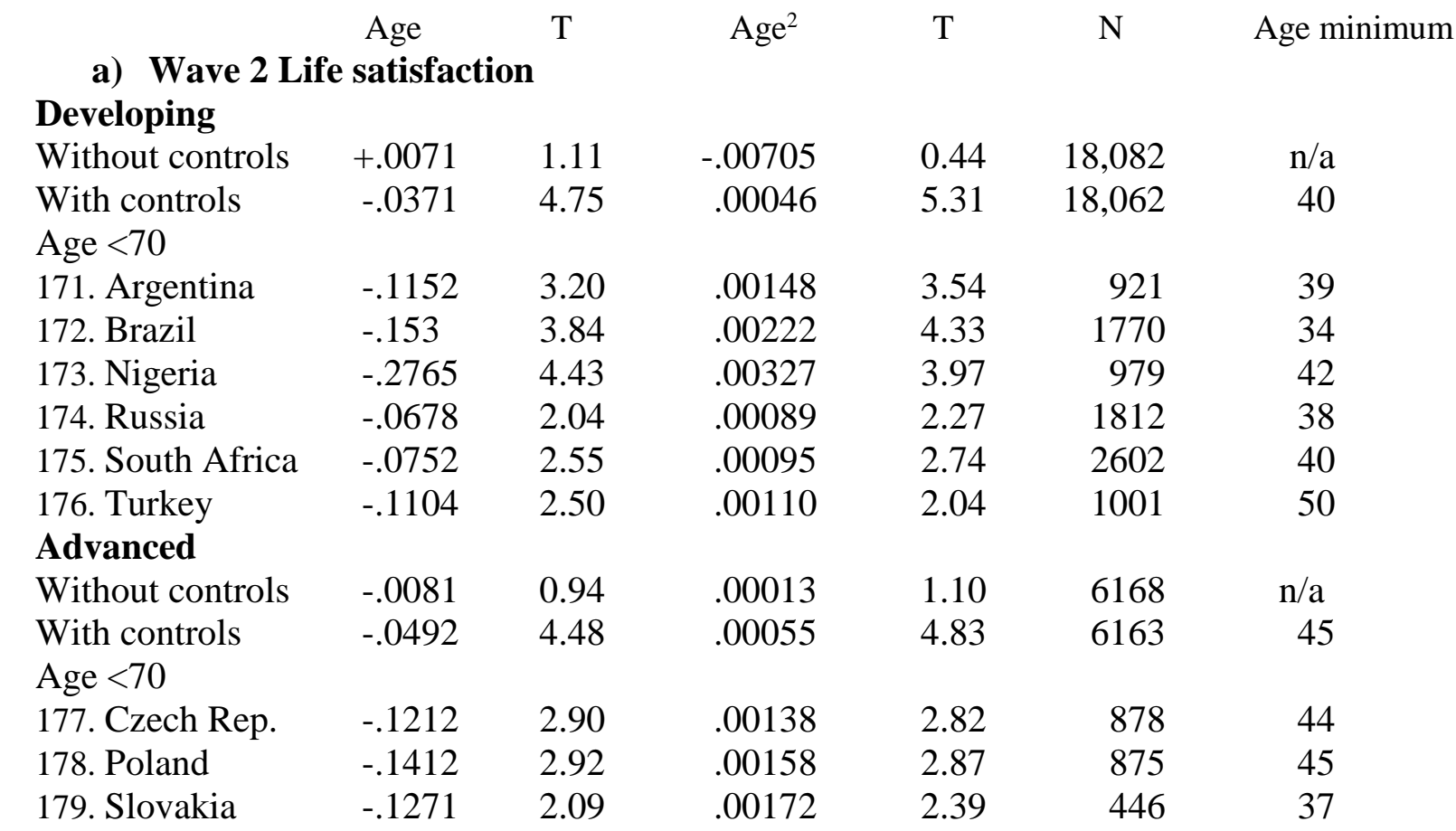

\section{b) Wave 3 Life satisfaction}

\section{Developing}

Without controls $\quad-.0236$

With controls $\quad-.0570$

6.14

.00016

3.68

48,849

74

Age $<70$

180. Albania

$-.1169$

12.06

.00058

10.94

48,813

49

181. Azerbaijan

3.18

.00134

3.19

964

44

182. Argentine

$-.1040$

.00114

2.79

1,928

990

46

183. Armenia

$-.1039$

2.70

.00113

2.54

1,920

.00084

2.28

1,902

46

184. Belarus

$-.0908$

3.07

2.39

.00111

1.94

767

186. China

$-.0734$

1.84

.00082

1.73

1,454

405

1.76

1,183

1.61

1,887

955

1,442

904

228

1,943

2.87

1,168

1,812

6.24

11,617

1.91

2,916

4.77

1,848 


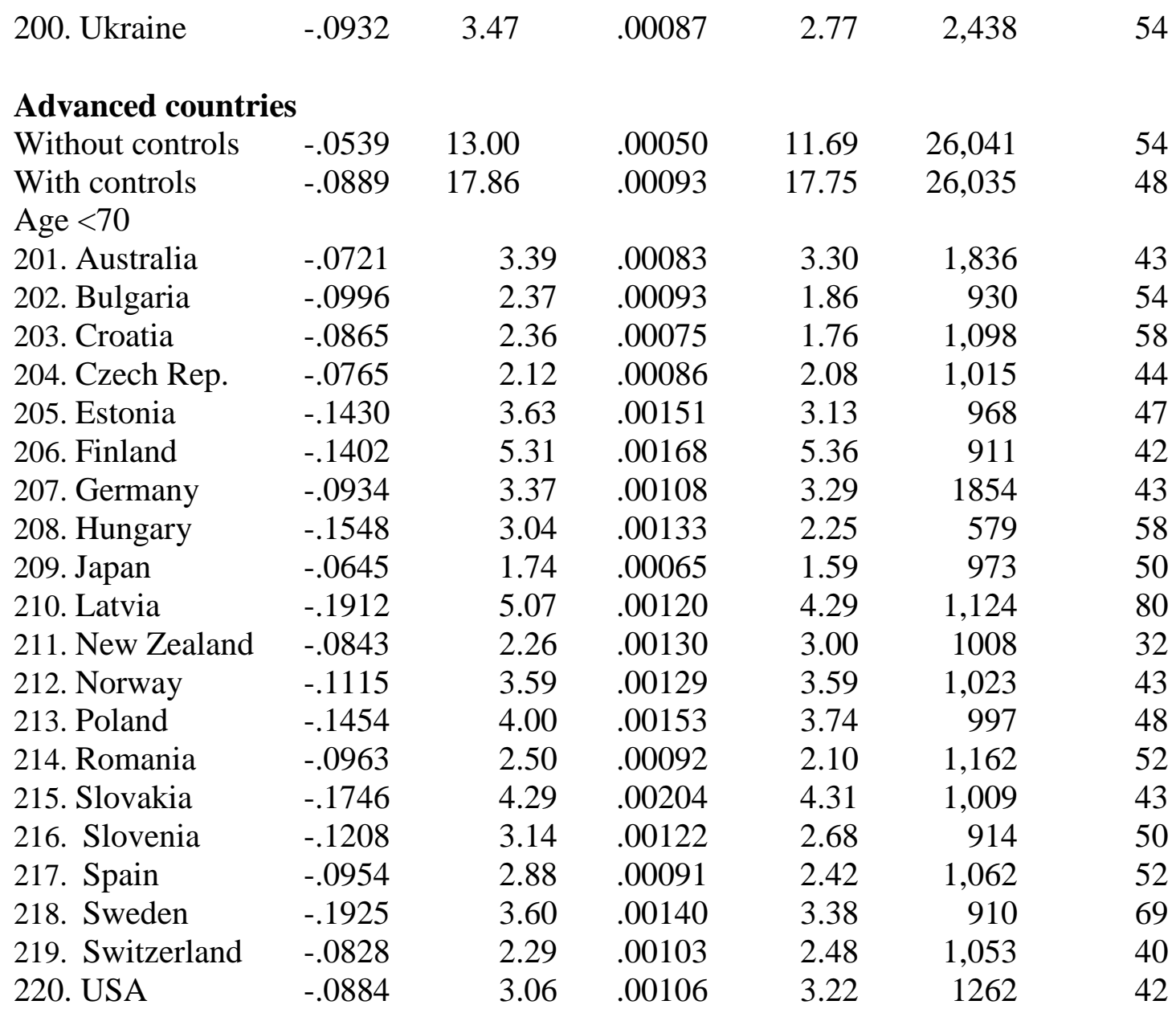

c) Wave 4 Life satisfaction Developing

$\begin{array}{lrrrrrr}\text { Without controls } & -.0271 & 6.87 & .00027 & 5.93 & 49,166 & 50 \\ \text { With controls } & -.0534 & 10.76 & .00061 & 11.13 & 48,004 & 44 \\ \text { Age }<70 & & & & & & \\ \text { 221. Argentina } & -.1078 & 3.20 & .00110 & 2.82 & 1,169 & 49 \\ \text { 222. Bangladesh } & -.1448 & 3.54 & .00193 & 3.75 & 1,375 & 38 \\ \text { 223. China } & -.1214 & 2.14 & .00147 & 2.20 & 934 & 41 \\ \text { 224. Iraq } & -.0612 & 2.09 & .00069 & 1.93 & 2,199 & 44 \\ \text { 225. Israel } & -.0973 & 2.59 & .00077 & 1.74 & 1,046 & 63 \\ \text { 226. Jordan } & -.0770 & 1.85 & .00102 & 2.06 & 1,173 & 38 \\ \text { 227. Mexico } & -.0683 & 2.05 & .00079 & 1.96 & 1,423 & 43 \\ \text { 228. Peru } & -.0673 & 1.81 & .00081 & 2.78 & 1,483 & 42 \\ \text { 229. Philippines } & -.0971 & 2.38 & .00119 & 2.46 & 1,146 & 41 \\ \text { 230. Puerto Rico } & -.0777 & 1.81 & .00103 & 2.09 & 620 & 38 \\ \text { 231. Singapore } & -.0513 & 1.78 & .00072 & 2.02 & 1,479 & 36 \\ \text { 232. South Africa } & -.1691 & 6.36 & .00206 & 6.41 & 2,837 & 41 \\ \text { 233. South Korea } & -.0956 & 1.93 & .00125 & 2.18 & 1,159 & 38 \\ \text { 234. Tanzania } & -.1319 & 2.42 & .00162 & 2.48 & 1,067 & 41\end{array}$




\begin{tabular}{|c|c|c|c|c|c|c|}
\hline 235. Turkey & -.1286 & 4.64 & .00139 & 4.17 & 3,005 & 46 \\
\hline 236. Zimbabwe & -.1581 & 3.31 & .00182 & 3.15 & 959 & 43 \\
\hline \multicolumn{7}{|c|}{ Advanced countries } \\
\hline Without controls & -.0376 & 5.41 & .00039 & 5.40 & 10,103 & 48 \\
\hline With controls & -.0808 & 9.45 & .00085 & 9.49 & 9,900 & 48 \\
\hline \multicolumn{7}{|l|}{ Age $<70$} \\
\hline 237. Canada & -.1388 & 5.64 & .00158. & 5.39 & 1,682 & 44 \\
\hline 238. Japan & -.1163 & 3.22 & .00134 & 3.39 & 1,084 & 43 \\
\hline 239. Macedonia & -.1519 & 3.17 & .00177 & 3.18 & 980 & 43 \\
\hline 240. Serbia & -.1388 & 3.05 & .00129 & 2.52 & 1070 & 54 \\
\hline 241. Sweden & -.0734 & 2.12 & .00083 & 2.08 & 927 & 44 \\
\hline 242. USA & -.1522 & 5.49 & .00193 & 5.83 & 1,109 & 39 \\
\hline \multicolumn{7}{|c|}{ c) Wave 5 Life satisfaction } \\
\hline \multicolumn{7}{|c|}{ Developing countries } \\
\hline Without controls & -.0175 & 5.53 & .00011 & 3.04 & 57,707 & 82 \\
\hline With controls & -.0395 & 1.01 & .00040 & 9.17 & 55,014 & 50 \\
\hline \multicolumn{7}{|l|}{ Age $<70$} \\
\hline 243. Chile & -.1238 & 3.44 & .00123 & 2.95 & 907 & 50 \\
\hline 244. China & -.1538 & 4.43 & .00188 & 4.95 & 1,727 & 41 \\
\hline 245. Georgia & -.1501 & 4.46 & .00145 & 3.66 & 1,297 & 52 \\
\hline 246. Ghana & -.0777 & 1.86 & .00083 & 1.66 & 1,498 & 47 \\
\hline 247. Indonesia & -.0512 & 1.51 & .00069 & 1.71 & 1,880 & 37 \\
\hline 248. Iran & -.1074 & 3.65 & .00124 & 3.26 & 2,587 & 43 \\
\hline 249. Malaysia & -.0938 & 2.53 & .00122 & 2.49 & 1,196 & 38 \\
\hline 250. Mali & -.0949 & 2.38 & .00098 & 2.03 & 1,169 & 48 \\
\hline 251. Russia & -.1250 & 4.06 & .00109 & 2.98 & 1,863 & 57 \\
\hline 252. Serbia & -.1185 & 3.02 & .00097 & 2.07 & 1,053 & 61 \\
\hline 253. Vietnam & -.0624 & 2.28 & .00072 & 2.31 & 1,377 & 43 \\
\hline 254. South Africa & -.0766 & 3.10 & .00092 & 3.08 & 2,804 & 42 \\
\hline 255. Taiwan & -.0580 & 1.51 & .00066 & 1.53 & 1,138 & 44 \\
\hline 256. Trinidad & -.1118 & 3.05 & .00126 & 2.86 & 916 & 44 \\
\hline 257. Turkey & -.1040 & 2.95 & .00111 & 2.60 & 1,310 & 47 \\
\hline 258. Uruguay & -.0795 & 2.45 & .00087 & 2.31 & 847 & 46 \\
\hline \multicolumn{7}{|c|}{ Advanced countries } \\
\hline Without controls & -.0827 & 6.50 & .00051 & 3.97 & 25,092 & 81 \\
\hline With controls & -.0651 & 14.26 & .00062 & 13.40 & 24,602 & 53 \\
\hline 259. Australia & -.0904 & 3.13 & .00112 & 3.42 & 1,180 & 41 \\
\hline 260. Bulgaria & -.1137 & 2.50 & .00104 & 2.03 & 871 & 55 \\
\hline 261. Canada & -.1037 & 5.01 & .00122 & 4.92 & 1,812 & 43 \\
\hline 262. Finland & -.0592 & 1.94 & .00067 & 1.90 & 876 & 44 \\
\hline 263. France & -.1289 & 3.18 & .00134 & 2.76 & 854 & 48 \\
\hline 264. Germany & -.1445 & 5.20 & .00143 & 4.54 & 1,701 & 51 \\
\hline 265. Hungary & -.1526 & 3.80 & .00152 & 3.28 & 912 & 50 \\
\hline 266. Italy & -.1233 & 3.52 & .00121 & 3.13 & 914 & 51 \\
\hline 267. Japan & -.1628 & 4.21 & .00174 & 4.15 & 924 & 47 \\
\hline
\end{tabular}




$\begin{array}{lllllrl}\text { 268. New Zealand } & -.0978 & 2.50 & .00125 & 2.85 & 744 & 39 \\ \text { 269. Romania } & -.1304 & 3.78 & .00127 & 3.18 & 1,384 & 51 \\ \text { 270. Slovenia } & -.1184 & 3.12 & .00106 & 2.41 & 897 & 56 \\ \text { 271. Switzerland } & -.1142 & 3.48 & .00122 & 3.45 & 1,018 & 47 \\ \text { 272. UK } & -.0663 & 2.29 & .00077 & 2.07 & 885 & 43 \\ \text { 273. USA } & -.1258 & 4.45 & .00138 & 4.22 & 1,084 & 46\end{array}$

d) Wave 6 life satisfaction Developing countries

$\begin{array}{lrrrrrr}\text { Without controls } & -.0080 & 8.72 & .00004 & 4.50 & 69,468 & 100 \\ \text { With controls } & -.0378 & 11.03 & .00038 & 1.03 & 69,541 & 50 \\ \text { 274. Algeria } & -.2262 & 5.23 & .00275 & 5.22 & 1,119 & 41 \\ \text { 275. Armenia } & -.1442 & 3.08 & .00127 & 2.29 & 935 & 57 \\ \text { 276. Belarus } & -.1377 & 4.18 & .00133 & 3.44 & 1,394 & 52 \\ \text { 277. Brazil } & -.0514 & 1.76 & .00065 & 1.89 & 1,382 & 40 \\ \text { 278. China } & -.0513 & 2.03 & .00059 & 2.09 & 2,142 & 43 \\ \text { 279. Egypt } & -.1150 & 2.68 & .00145 & 2.85 & 1,452 & 40 \\ \text { 280. Georgia } & -.1746 & 4.77 & .00144 & 3.34 & 1,070 & 61 \\ \text { 281. Iraq } & -.0791 & 2.12 & .00098 & 2.18 & 1,176 & 40 \\ \text { 282. Kuwait } & -.0859 & 1.93 & .00108 & 1.98 & 1,196 & 40 \\ \text { 283. Lebanon } & -.0715 & 1.99 & .00067 & 1.58 & 1,117 & 53 \\ \text { 284. Libya } & -.0734 & 2.16 & .00095 & 2.33 & 2,065 & 39 \\ \text { 285. Mexico } & -.0592 & 2.67 & .00069 & 2.55 & 1,908 & 43 \\ \text { 286. Philippines } & -.1024 & 2.31 & .00108 & 2.00 & 1,134 & 47 \\ \text { 287. Russia } & -.1170 & 4.41 & .00137 & 3.62 & 2,152 & 43 \\ \text { 288. South Africa } & -.0616 & 2.59 & .00068 & 2.28 & 3,428 & 45 \\ \text { 289. Tunisia } & -.1188 & 2.71 & .00133 & 2.67 & 1,145 & 45 \\ \text { 290. Ukraine } & -.0919 & 2.33 & .00080 & 1.75 & 1,267 & 57 \\ \text { 291. Uzbekistan } & -.1500 & 4.78 & .00159 & 4.07 & 1,411 & 47 \\ \text { 292. Zimbabwe } & -.0851 & 2.56 & .00104 & 2.41 & 1,467 & 43 \\ \text { Advanced countries } & & & & & & \\ \text { Without controls } & -.0355 & 7.92 & .00032 & 7.29 & 19,197 & 55 \\ \text { With controls } & -.0777 & 14.48 & .00078 & 14.42 & 19,058 & 50 \\ \text { 293. Australia } & -.0990 & 3.16 & .00185 & 3.47 & 1,198 & 27 \\ \text { 294. Estonia } & -.1566 & 5.18 & .00148 & 4.31 & 1,272 & 53 \\ \text { 295. Germany } & -.0737 & 2.94 & .00066 & 2.33 & 1,709 & 56 \\ \text { 296. Japan } & -.1523 & 5.91 & .00161 & 5.82 & 2,021 & 47 \\ \text { 297. Netherlands } & -.0861 & 3.75 & .00103 & 4.06 & 1,535 & 42 \\ \text { 298. New Zealand } & -.0929 & 2.23 & .00115 & 2.46 & 660 & 40 \\ \text { 299. Poland } & -.2224 & 5.67 & .00224 & 4.91 & 832 & 51 \\ \text { 300. Romania } & -.1395 & 3.66 & .00135 & 3.11 & 1,294 & 52 \\ \text { 301. Slovenia } & -.0851 & 1.91 & .00078 & 1.54 & 890 & 55 \\ \text { 302. Spain } & -.1252 & 3.83 & .00128 & 3.40 & 1,002 & 49 \\ \text { 303. Sweden } & -.1311 & 4.85 & .00161 & 5.17 & 997 & 41 \\ \text { 304. USA } & -.0740 & 3.36 & .00076 & 3.06 & 1,965 & 49\end{array}$


Table 7. Asiabarometers, 2005-2007

\begin{tabular}{|c|c|c|c|c|c|c|}
\hline 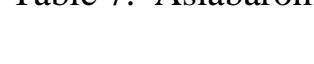 & Age & $\mathrm{T}$ & Age $^{2}$ & $\mathrm{~T}$ & $\mathrm{~N}$ & Age minimum \\
\hline \multicolumn{7}{|c|}{ a) 2003 5-step Happiness } \\
\hline Without controls & -.00385 & 0.57 & .00000 & 0.01 & 8,068 & $\mathrm{n} / \mathrm{a}$ \\
\hline With controls & -.02886 & 3.56 & .00029 & 2.82 & 7,989 & 50 \\
\hline 305. South Korea & -.10070 & 3.42 & .00112 & 3.11 & 795 & 45 \\
\hline 306. Uzbekistan & -.07822 & 2.33 & .00080 & 2.82 & 792 & 49 \\
\hline \multicolumn{7}{|c|}{ b) 2004 5-step Happiness } \\
\hline Without controls & -.00465 & 0.82 & .00005 & 0.74 & 9,644 & 47 \\
\hline With controls & -.02063 & 3.13 & .00024 & 2.94 & 9,640 & 43 \\
\hline 307. Laos & -.05175 & 2.47 & .00069 & 2.54 & 798 & 38 \\
\hline 308. Myanmar & -.06889 & 2.72 & .00089 & 2.72 & 800 & 39 \\
\hline 309. Singapore & -.04518 & 1.77 & .00049 & 1.57 & 793 & 46 \\
\hline \multicolumn{7}{|c|}{ c) 2005 5-step happiness } \\
\hline Without controls & -.01325 & 3.06 & .00010 & 1.99 & 12,097 & 64 \\
\hline With controls & -.02041 & 3.85 & .00021 & 3.38 & 11,953 & 49 \\
\hline 310. India & -.03704 & 2.28 & .0004 & 2.15 & 1,221 & 46 \\
\hline 311. Maldives & -.0277 & 1.63 & .00038 & 1.89 & 773 & 36 \\
\hline 312. Mongolia & -.03163 & 1.93 & .00046 & 2.35 & 796 & 34 \\
\hline 313. Sri Lanka & -.05025 & 3.00 & .00051 & 2.69 & 799 & 49 \\
\hline 314. Tajikistan & -.06382 & 2.50 & .00074 & 2.39 & 794 & 43 \\
\hline \multicolumn{7}{|c|}{ d) 2006 5-step happiness } \\
\hline Without controls & -.00934 & 1.97 & .00008 & 1.39 & 8,060 & 58 \\
\hline With controls & -.03064 & 5.12 & .0003 & 4.3 & 8,044 & 51 \\
\hline 315. China & -.03414 & 2.67 & .00037 & 2.55 & 1,998 & 46 \\
\hline 316. Japan & -.07872 & 4.99 & .0008 & 4.66 & 992 & 49 \\
\hline 317. South Korea & -.07771 & 3.87 & .00067 & 3.1 & 1,019 & 58 \\
\hline 318. Taiwan & -.06723 & 3.10 & .00078 & 3.31 & 1,003 & 43 \\
\hline \multicolumn{7}{|c|}{ e) 2007 5-step happiness } \\
\hline Without controls & -.00955 & 2.03 & .00007 & 1.23 & 7,008 & $\mathrm{n} / \mathrm{a}$ \\
\hline With controls & -.01284 & 2.34 & .00014 & 2.13 & 6,999 & 64 \\
\hline 319. Philippines & -.02286 & 1.63 & .00031 & 1.92 & 996 & 37 \\
\hline 320. Thailand & -.03389 & 2.49 & .00035 & 2.21 & 1,000 & 48 \\
\hline
\end{tabular}


Table 8. Life satisfaction using 2017-2018 Latino Barometers
Age $\quad \mathrm{T}$
Age $^{2} \quad \mathrm{~T}$
$\mathrm{N}$
Age minimum

a) $\mathbf{2 0 1 7}$

Without controls -.01597

With controls $\quad-.01809$

$\begin{array}{lllll}8.46 & .00013 & 6.32 & 20,053 & 61 \\ 8.53 & .00017 & 7.33 & 20,010 & 53\end{array}$

Age $<70$

321. Bolivi

$1.97 \quad .00022$

$1.53 \quad 1,140$

56

322. Brazil

$-.02478$

2.15

.00024

2.01

1,116

44

323. Columbia $\quad-.01970$

1.70

.00021

1.53

1,143

46

324. Costa Rica - -02899

2.35

.00041

931

35

325. Mexico

3.34

326. Panama $\quad-.03176$

2.40

.00040

2.82

1,097

49

327. Paraguay $\quad-.03891$

.00034

924

47

3.26

.00044

2.28

1,161

44

328. Peru $\quad-.03623$

2.61

3.17

1,102

53

329. Uruguay $\quad-.02791$

2.44

.00034

2.12

1,059

52

\section{b) $\mathbf{2 0 1 8}$}

Without controls -.01715

With controls $\quad-.01876$

9.11

.00013

6.42

20,052

65

8.78

.000168

7.16

19,991

56

Age $<70$

330. Bolivi

331. Brazil

1.82

.00022

1.51

1,133

50

332. Columbia - -03239

3.47

.00031

2.59

1,097

56

2.96

.00035

2.67

1,126

46

333. Costa Rica - -.03634

2.83

.00039

2.57

923

47

334. Ecuador $\quad-.02633$

2.14

.00027

1.84

1,136

49

335. Honduras $\quad-.03077$

2.37

.00026

945

59

336. Uruguay $\quad-.03675$

3.23

.00041

1.69

1,058

45

337. Venezuela - -.02649

1.69

.00028

1.51

1,145

47 
Table 9. Satisfaction with financial conditions in the household, WVS Wave 6

1) Wave 6

\begin{tabular}{|c|c|c|c|c|c|c|}
\hline 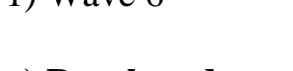 & Age & $\mathrm{T}$ & Age $^{2}$ & $\mathrm{~T}$ & $\mathrm{~N}$ & Age minimum \\
\hline \multicolumn{7}{|l|}{ a) Developed } \\
\hline Without controls & -.0487 & 9.11 & .00056 & 10.61 & 19,100 & 43 \\
\hline With controls & -.0947 & 14.91 & .00108 & 16.99 & 18,976 & 44 \\
\hline \multicolumn{7}{|c|}{ Age $<70$ with controls } \\
\hline 338. Australia & -.1755 & 4.71 & .00211 & 5.20 & 1,196 & 42 \\
\hline 339. Cyprus & -.1524 & 3.20 & .00172 & 3.13 & 913 & 44 \\
\hline 340. Estonia & -.1319 & 3.92 & .00132 & 3.43 & 1,276 & 50 \\
\hline 341. Germany* & -.0473 & 2.42 & .00062 & 3.11 & 1,702 & 38 \\
\hline 342. Japan & -.1498 & 4.85 & .00171 & 5.17 & 1,964 & 44 \\
\hline 343. Netherlands & -.1025 & 3.48 & .00134 & 4.12 & 1,534 & 38 \\
\hline 344. New Zealand & -.1408 & 2.92 & .00169 & 3.12 & 656 & 42 \\
\hline 345. Poland & -.2514 & 5.40 & .00261 & 4.92 & 831 & 48 \\
\hline 346. Romania & -.2027 & 4.79 & .00199 & 4.11 & 1,297 & 51 \\
\hline 347. Slovenia & -.1825 & 3.47 & .00204 & 3.41 & 892 & 45 \\
\hline 348. Spain & -.0854 & 2.33 & .00113 & 2.66 & 1,012 & 38 \\
\hline 349. Sweden & -.1335 & 3.59 & .00183 & 4.30 & 993 & 36 \\
\hline 350. USA & -.1078 & 3.88 & .00127 & 4.06 & 1,966 & 42 \\
\hline \multicolumn{7}{|l|}{$*$ all ages } \\
\hline \multicolumn{7}{|l|}{ b) Developing } \\
\hline Without controls & -.0342 & 11.31 & .00030 & 9.00 & 69,644 & 57 \\
\hline With controls & -.0428 & 11.78 & .00047 & 11.69 & 69,546 & 46 \\
\hline \multicolumn{7}{|c|}{ Age $<70$ with controls } \\
\hline 351. Algeria & -.1350 & 3.08 & .00153 & 2.89 & 1,131 & 44 \\
\hline 352. Belarus & -.0947 & 2.82 & .00088 & 2.22 & 1,395 & 54 \\
\hline 353. Brazil & -.1106 & 3.07 & .00129 & 3.03 & 1,384 & 43 \\
\hline 354. Colombia & -.0541 & 1.68 & .00064 & 1.65 & 1,441 & 42 \\
\hline 355. Ecuador & -.1008 & 3.46 & .00109 & 3.18 & 1,146 & 46 \\
\hline 356. Egypt & -.1269 & 3.10 & .00165 & 3.39 & 1,452 & 38 \\
\hline 357. Georgia & -.1766 & 5.13 & .00168 & 4.15 & 1,070 & 53 \\
\hline 358. Ghana & -.0864 & 2.40 & .00096 & 2.16 & 1,533 & 45 \\
\hline 359. Jordan & -.0964 & 2.54 & .00101 & 2.30 & 1,144 & 48 \\
\hline 360. Kyrgyzstan & -.0624 & 1.64 & .00073 & 1.56 & 1,445 & 43 \\
\hline 361. Libya & -.0948 & 2.61 & .00122 & 2.81 & 2,074 & 39 \\
\hline 362. Mexico & -.1026 & 3.39 & .00118 & 3.18 & 1,908 & 43 \\
\hline 363. Morocco & -.0980 & 2.28 & .00138 & 2.82 & 1,181 & 36 \\
\hline 364. Peru & -.0808 & 2.29 & .00079 & 1.89 & 1,146 & 51 \\
\hline 365. Philippines & -.1376 & 2.91 & .00140 & 2.58 & 1,134 & 49 \\
\hline 366. Russia & -.1119 & 3.78 & .00131 & 3.72 & 2,161 & 43 \\
\hline 367. Singapore & -.0551 & 2.21 & .00077 & 2.69 & 1,809 & 36 \\
\hline 368. South Africa & -.0448 & 1.80 & .00051 & 1.63 & 3,416 & 44 \\
\hline 369. South Korea & -.0896 & 2.22 & .00094 & 2.13 & 1,129 & 48 \\
\hline 370. Trinidad & -.0924 & 2.08 & .00112 & 2.12 & 890 & 41 \\
\hline 371. Uruguay & -.0779 & 1.97 & .00077 & 1.64 & 876 & 51 \\
\hline 372. Yemen & -.0859 & 1.68 & .00114 & 1.79 & 969 & 38 \\
\hline 373. Zimbabwe & -.0850 & 2.48 & .00116 & 2.75 & 1,467 & 37 \\
\hline
\end{tabular}

2) WVS Wave 5 


\begin{tabular}{|c|c|c|c|c|c|c|}
\hline & Age & $\mathrm{T}$ & Age $^{2}$ & $\mathrm{~T}$ & $\mathrm{~N}$ & Age minimum \\
\hline \multicolumn{7}{|l|}{ a) Developed } \\
\hline Without controls & -.0328 & 7.33 & .00040 & 8.81 & 25,026 & 41 \\
\hline With controls & -.0752 & 13.90 & .00092 & 16.65 & 24,591 & 41 \\
\hline \multicolumn{7}{|c|}{ Age $<70$ with controls } \\
\hline 374. Australia & -.0583 & 1.53 & .00097 & 2.28 & 1,170 & 30 \\
\hline 375. Bulgaria & -.1360 & 3.14 & .00131 & 2.70 & 894 & 52 \\
\hline 376. Canada & -.2150 & 7.96 & .00260 & 8.17 & 1,807 & 41 \\
\hline 377. Finland & -.1729 & 4.50 & .00228 & 5.14 & 876 & 38 \\
\hline 378. Germany & -.1003 & 3.15 & .00112 & 3.09 & 1,694 & 45 \\
\hline 379. Hungary & -.1076 & 2.48 & .00116 & 2.32 & 905 & 46 \\
\hline 380. Italy & -.1186 & 3.08 & .00133 & 3.13 & 912 & 45 \\
\hline 381. Japan & -.1720 & 3.66 & .00208 & 4.07 & 861 & 41 \\
\hline 382. New Zealand & -.1084 & 2.28 & .00164 & 3.07 & 748 & 33 \\
\hline 383. Poland & -.1687 & 3.86 & .00183 & 3.60 & 877 & 46 \\
\hline 384. Romania & -.1391 & 4.00 & .00146 & 3.66 & 1,468 & 48 \\
\hline 385. Slovenia & -.1565 & 3.65 & .00162 & 3.24 & 897 & 48 \\
\hline 386. Sweden & -.20321 & 4.65 & .00274 & 5.58 & 873 & 37 \\
\hline 387. Switzerland & -.0771 & 1.86 & .00104 & 2.32 & 1,024 & 37 \\
\hline 388. UK & -.1758 & 4.26 & .00241 & 4.94 & 879 & 36 \\
\hline 389. USA & -.1186 & 3.21 & .00135 & 3.24 & 1,077 & 44 \\
\hline \multicolumn{7}{|l|}{ b) Developing } \\
\hline Without controls & -.0303 & 8.83 & .00023 & 5.92 & 54,611 & 66 \\
\hline With controls & -.0461 & 10.75 & .00049 & 10.48 & 51,915 & 47 \\
\hline \multicolumn{7}{|c|}{ Age $<70$ with controls } \\
\hline 390. Brazil & -.0773 & 2.19 & .00079 & 1.88 & 1,393 & 49 \\
\hline 391. Chile & -.1374 & 3.53 & .00151 & 3.34 & 907 & 45 \\
\hline 392. China & -.1378 & 3.66 & .00172 & 4.18 & 1,732 & 40 \\
\hline 393. Egypt & -.0540 & 1.94 & .00062 & 1.90 & 2,905 & 44 \\
\hline 394. Georgia & -.1264 & 4.01 & .00110 & 2.99 & 1,307 & 57 \\
\hline 395. Indonesia & -.1030 & 3.03 & .00144 & 3.51 & 1,867 & 36 \\
\hline 396. Iran & -.1584 & 5.36 & .00175 & 4.61 & 2,555 & 45 \\
\hline 397. Iraq & -.0511 & 1.94 & .00070 & 2.17 & 2,538 & 36 \\
\hline 398. Mali & -.0674 & 1.66 & .00081 & 1.64 & 1,184 & 42 \\
\hline 399. Malaysia & -.0556 & 1.55 & .00097 & 2.06 & 1,195 & 29 \\
\hline 400. Taiwan & -.0646 & 1.55 & .00092 & 1.95 & 1,137 & 35 \\
\hline 401. Thailand & -.0551 & 1.71 & .00059 & 1.63 & 1,352 & 47 \\
\hline 402. Trinidad & -.1504 & 3.45 & .00176 & 3.38 & 916 & 43 \\
\hline 403. Turkey & -.1007 & 3.12 & .00122 & 3.09 & 1,306 & 41 \\
\hline 404. Uruguay & -.0815 & 2.07 & .00078 & 1.70 & 849 & 52 \\
\hline 405. Zambia & -.0798 & 1.94 & .00093 & 1.73 & 1,421 & 43 \\
\hline
\end{tabular}


Table 11. Various Broad Satisfaction Equations

a) Eurobarometer 90.3, November 2018

$\begin{array}{llrrrrr} & \text { Age } & \mathrm{t} & \text { Age }^{2} & \mathrm{t} & \mathrm{N} & \text { Age minimum } \\ \text { 1. Life satisfaction } & -.0324 & 13.74 & .00029 & 11.1 & 27,122 & 55 \\ \text { 2. Situation in the country } & -.0222 & 8.77 & .00021 & 7.6 & 26,282 & 52 \\ \text { 3. Situation with the national economy } & -.0191 & 7.51 & .00020 & 7.1 & 26,063 & 47 \\ \text { 4. Own financial situation } & -.0322 & 13.44 & .00033 & 12.4 & 26,187 & 48 \\ \text { 5. Employment situation } & -.0183 & 7.05 & .00019 & 6.4 & 25,953 & 49 \\ \text { 6. Public services } & -.0172 & 6.41 & .00011 & 5.3 & 25,644\end{array}$

Q1. On the whole, are you very satisfied, fairly satisfied, not very satisfied or not at all satisfied with the life you lead? Very satisfied=4; Fairly satisfied=3; Not very satisfied=2; Not at all satisfied $=1$

How would you judge the situation in each of the following? Very good=4; Rather good=3; Rather bad=2 and Very bad=1

Q2. The situation in our country?

Q3. The situation of the national economy?

Q4. The financial situation of your household?

Q5. The employment situation in the country?

Q6. The presence of public services in our country?

\section{b) ESS Sweep 9 - 2018}

\begin{tabular}{|c|c|c|c|c|c|c|}
\hline & Age & $\mathrm{T}$ & $\mathrm{Age}^{2}$ & $\mathrm{~T}$ & $\mathrm{~N}$ & Age minimum \\
\hline 7. Happiness & -.0524 & 14.15 & .000433 & 11.99 & 35,300 & 60 \\
\hline 8. Life & -.0649 & 15.79 & .000577 & 14.39 & 35,255 & 56 \\
\hline 9. Present state of the economy & -.0436 & 9.99 & .000428 & 1.03 & 34,534 & 51 \\
\hline 10. National government & -.0621 & 12.29 & .000618 & 12.54 & 34,187 & 50 \\
\hline 11. Way democracy works in country & -.0463 & 9.42 & .000458 & 9.52 & 34,144 & 51 \\
\hline 12. State of education & -.0401 & 8.79 & .000361 & 8.09 & 34,112 & 56 \\
\hline 13. State of health services & -.0603 & 12.89 & .000584 & 12.80 & 35,188 & 52 \\
\hline \multicolumn{7}{|c|}{ Q7. Taking all things together, how happy would you say you are? Extremely unhappy=1 to extremely happy=10 } \\
\hline \multicolumn{7}{|c|}{$\begin{array}{l}\text { Q8. All things considered, how satisfied are you with your life as a whole nowadays? Please answer using this card, where } 0 \text { means extremely11 } \\
\text { dissatisfied and } 10 \text { means extremely satisfied. }\end{array}$} \\
\hline \multicolumn{7}{|c|}{ Q9. On the whole how satisfied are you with the present state of the economy in [country] } \\
\hline \multicolumn{7}{|c|}{ Q10. Now thinking about the [country] government, how satisfied are you with the way it is doing its job? } \\
\hline \multicolumn{7}{|c|}{ Q11. Now thinking about the way democracy is working in our country. } \\
\hline
\end{tabular}


Q13. Please say what you think overall about the state of health services in [country] nowadays?

\section{c) EQLS 2003-2016}

14. Financial situation next 12 mths (3-4)-.02046

10-step Satisfaction with:

15. Education (1-4)

16. Job (1-4)

17. Family life (1-4)

18. Local area (4)

19. Way democracy works (4)

20. State of the economy (4)

21. Living standards (1-4)

$\begin{array}{rr}-.00953 & 4.22 \\ -.02961 & 6.08 \\ -.04679 & 22.50 \\ -.00919 & 2.22 \\ -.03987 & 8.37 \\ -.04291 & 9.88 \\ -.05273 & 24.64\end{array}$

\section{$\mathrm{T}$}

25.50

4.22

2.22

9.88

24.64

\section{Age $^{2}$ \\ $\mathrm{T}$}

.00016

.00016

.00043

.00044

.00015

.00037

.00041

.00058
20.26

7.22

7.65

21.03

3.57

7.93

9.60

26.96

\section{N}

79,116

138,202

65,540

138,493

36,542

35,535

35,780

139,551
Minimum

64

30
34
53
31
54
52
45

Q14. Financial situation since 12 months ago - worse $=1 ;$ same $=2 ;$ better $=3$.

Q15. Satisfaction with education. $1=$ very dissatisfied...10=very satisfied

Q16. Satisfaction with job. $1=$ very dissatisfied...10=very satisfied

Q17. Satisfaction with your family life. $1=$ very dissatisfied...10=very satisfied

Q18. Satisfaction with your local area. $1=$ very dissatisfied...10=very satisfied

Q19. Satisfaction with the way democracy works. $1=$ very dissatisfied...10=very satisfied

Q20. Satisfaction with the state of the economy. $1=$ very dissatisfied...10=very satisfied

Q21. Satisfaction with your standard of living 1=very dissatisfied...10=very satisfied 
Table 12. Satisfaction with living conditions, Afrobarometers controls education; labor force status and race. Without controls includes country dummies.
Age
$\mathrm{T}$
Age $^{2}$
$\mathrm{T}$
$\mathrm{N}$
Age minimum

\section{a) $\mathbf{2 0 1 9}$}

Without controls

With controls

406. Botswana

407. Burkina Faso

408. Cameroon

409. Cote d'Ivoire

$$
-.0247
$$

$-.0207$

$13.11 \quad .00021$

$\begin{array}{rrr}-.0740 & 5.13 & .00019 \\ .0486 & 2.64 & -.00089\end{array}$

$\begin{array}{lll}.0486 & 2.64 & -.00062\end{array}$

$\begin{array}{lll}-.0409 & 3.09 & .00040\end{array}$

$-.0506$

2.7

410. eSwatini

$-.0567$

.00057

411. Kenya

412. Lesotho

$-.0654$

3.39

4.28

$-.0368$

2.02

413. Liberia

$-.0669$

2.99

414. Malawi

$-.0343$

2.02

415. Mozambique

.0271

2.01

416. Namibia

$-.0502$

2.62

417. Niger

$-.0473$

2.88

418. Swaziland

$-.0497$

3.86

419. South Africa

$-.0538$

3.14

$-.0192$

2.26

$-.0594$

3.36

421. Togo

$-.0679$

3.94

.00057

.00064

.00033

.00070

.00033

$-.00030$

.00058

.00050

.00055

.00059

.00021

.00056

.00065

1.17

45,642

8.53

45,579

5.19

2.74

1,115

1,155

2.72

2.42

2.86

3.48

1.55

2.50

1,198

1,177

1,135

1527

1,065

1,174

1,146

2,285

1,167

1,140

1,163

1,766

2,308

1,162

1,144

$\mathrm{n} / \mathrm{a}$

55

42

39

51

44

50

51

56

48

52

45

43

47

3.47

2.90

1.67

2.55

3.30

.00019

1.38

53,306

53,306

1,191

1,198

1,197

1,198

1,183

1,199

1,198

2,334

2,393

1,192

1,200

2,373

1,200

1,199

2,370

1,171

1,191

2,380

1,194

1,191

$\begin{array}{ll}2.19 & 2,375 \\ 2.72 & 2,387\end{array}$

$\begin{array}{ll}2.19 & 2,375 \\ 2.72 & 2,387\end{array}$

.00020

2.72

2.04

.00025

.00050

443. Uganda

444. Zimbabwe

$-.0245 \quad 3.28$ 


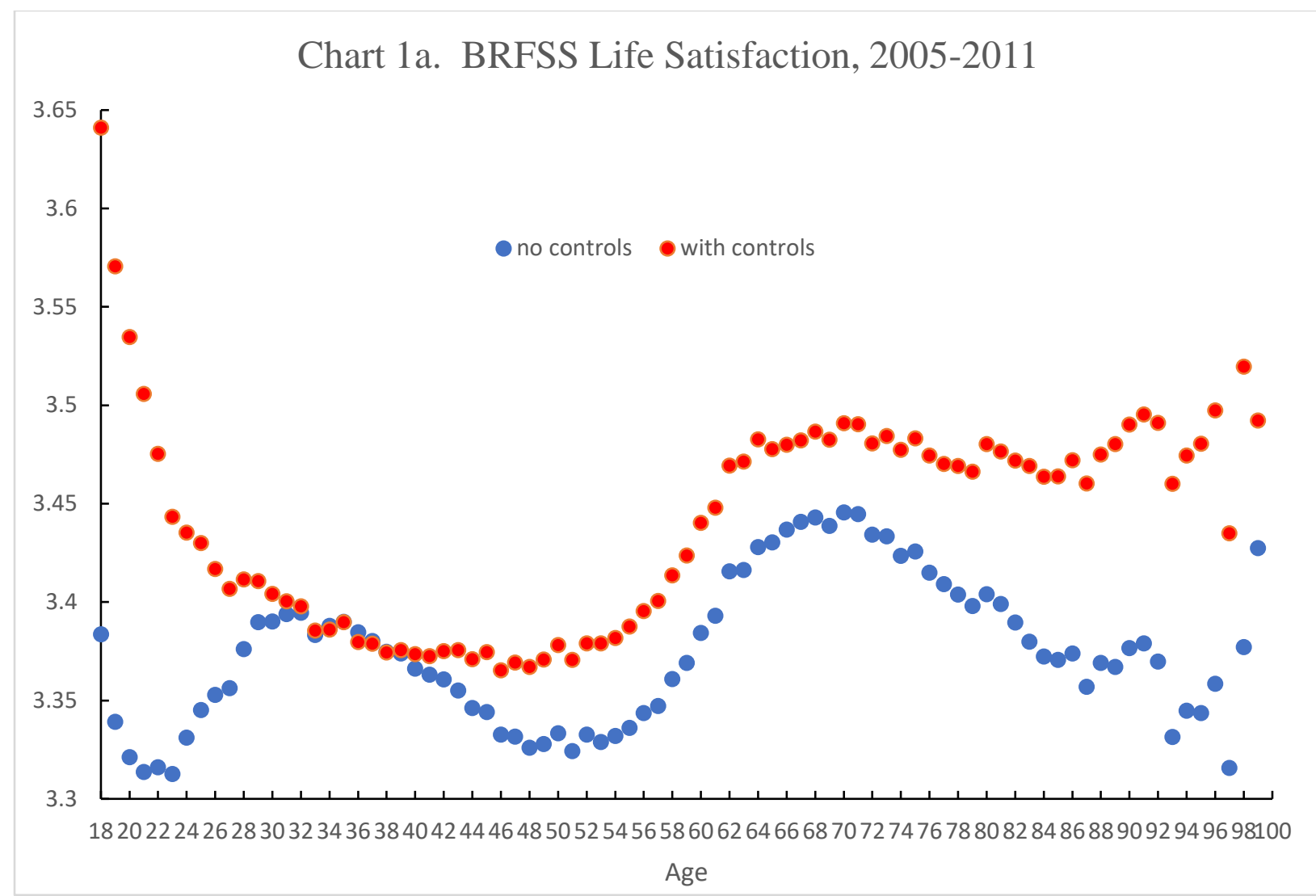

Chart 1b. GSS Happiness, 1972-2018

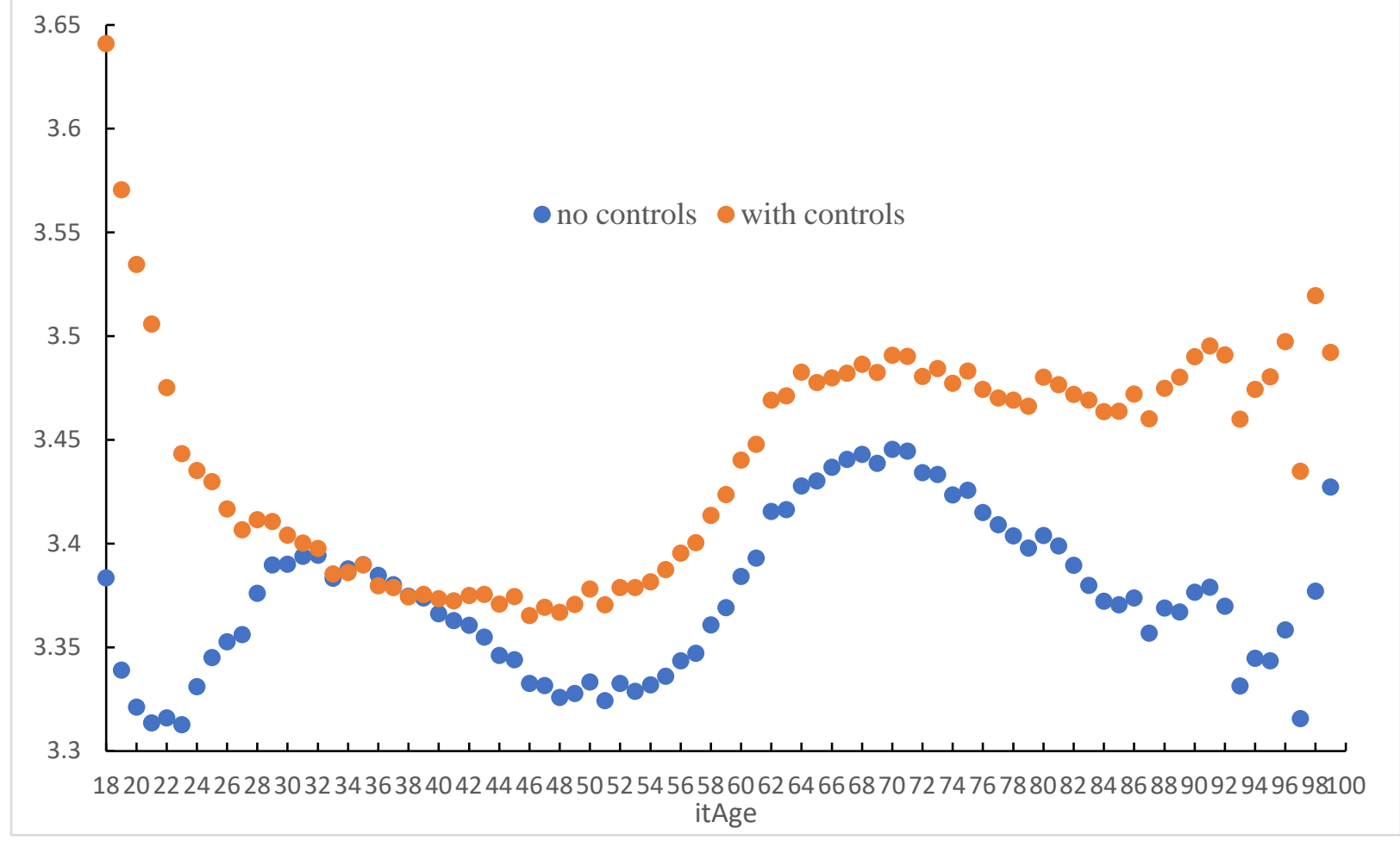




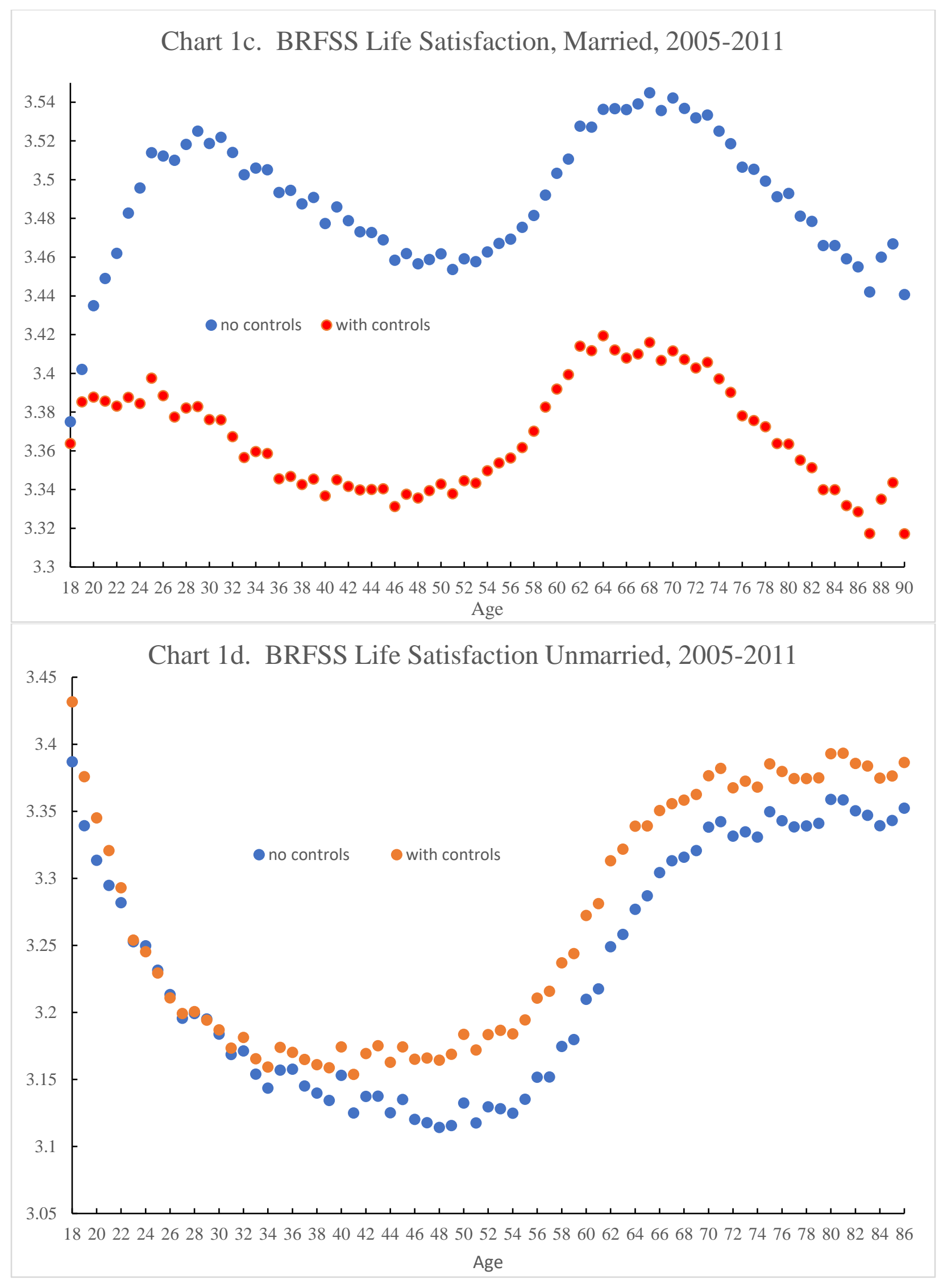



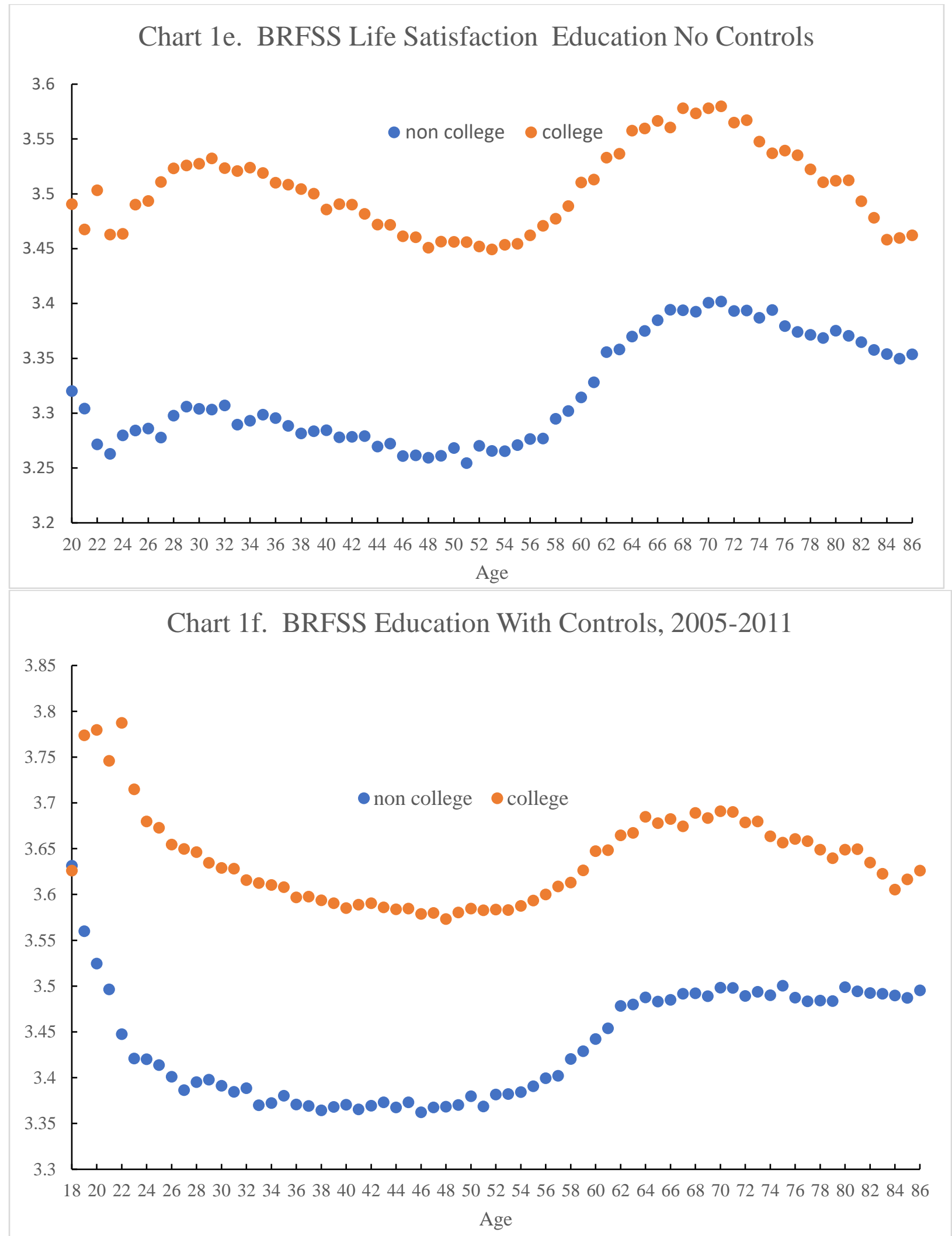


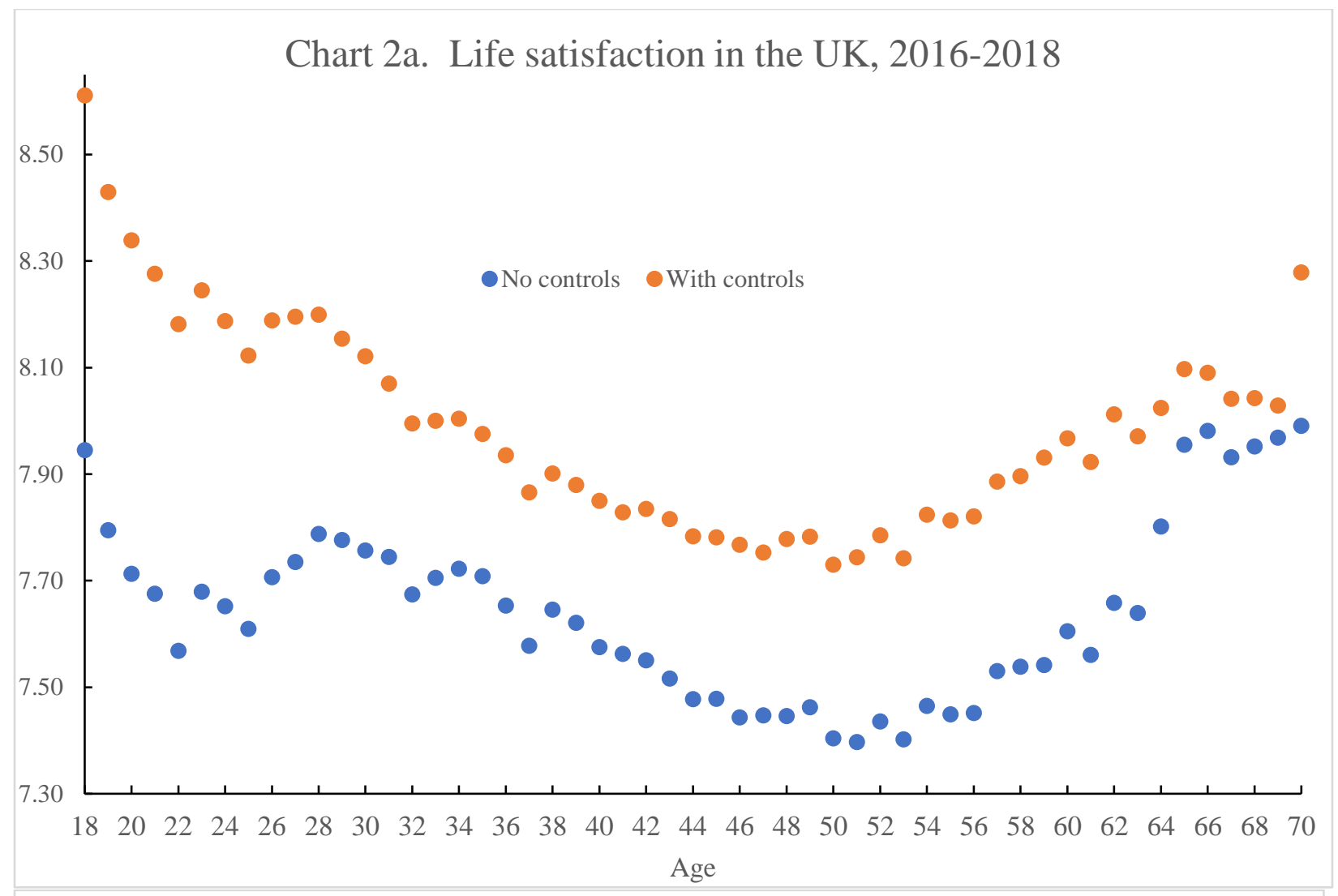

Chart 2b. Life satisfaction in the UK by marital status with and

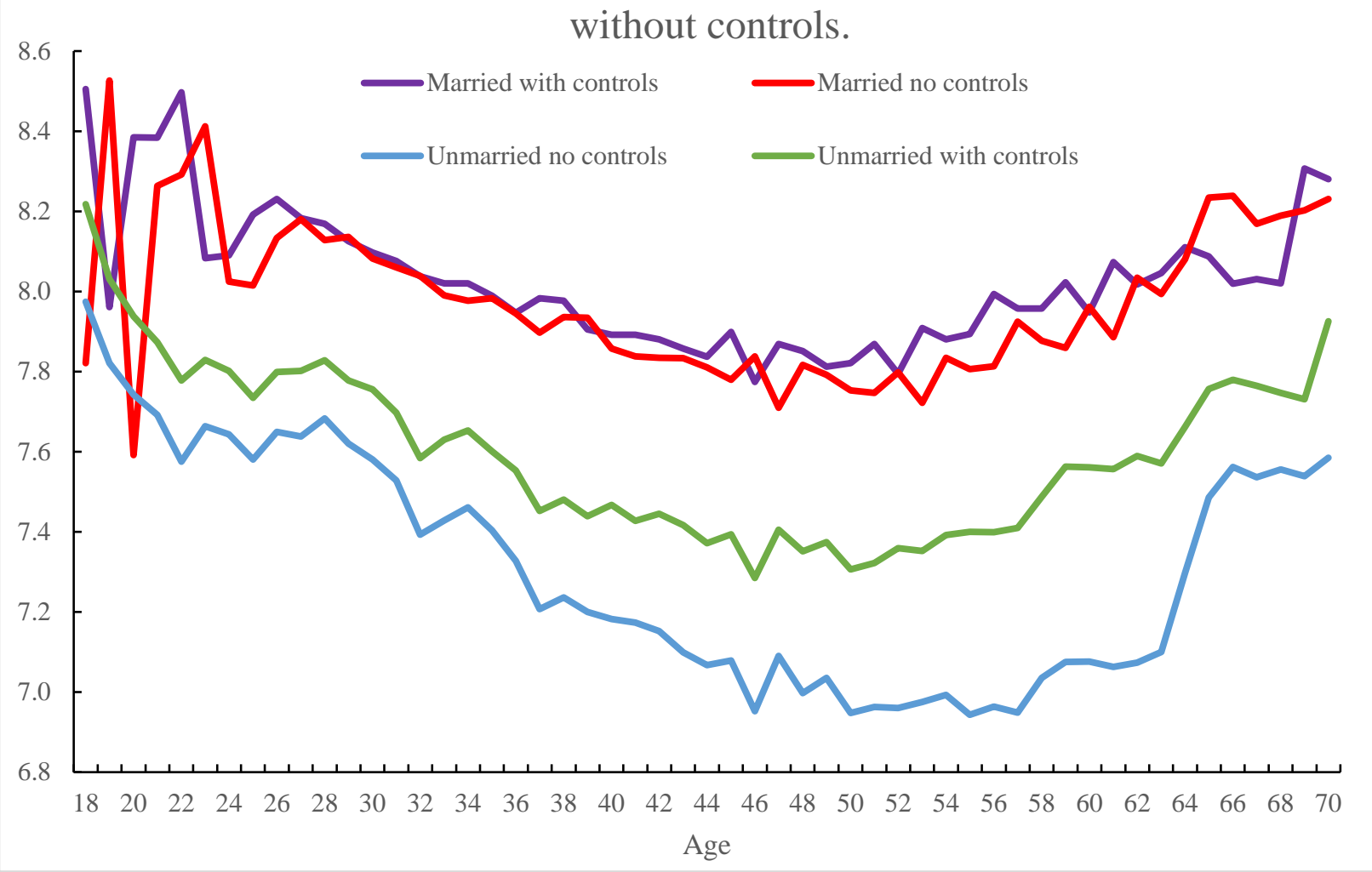



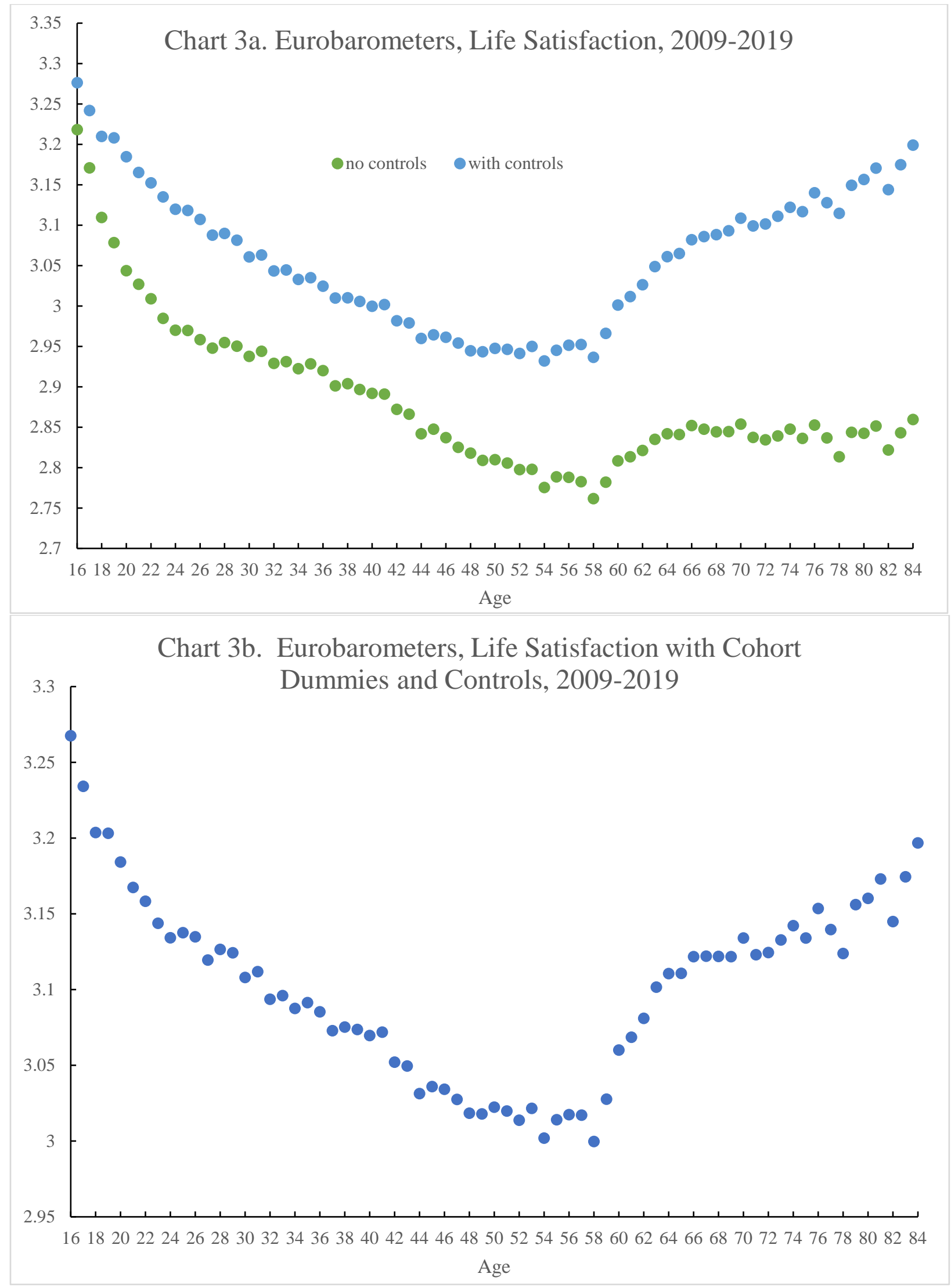

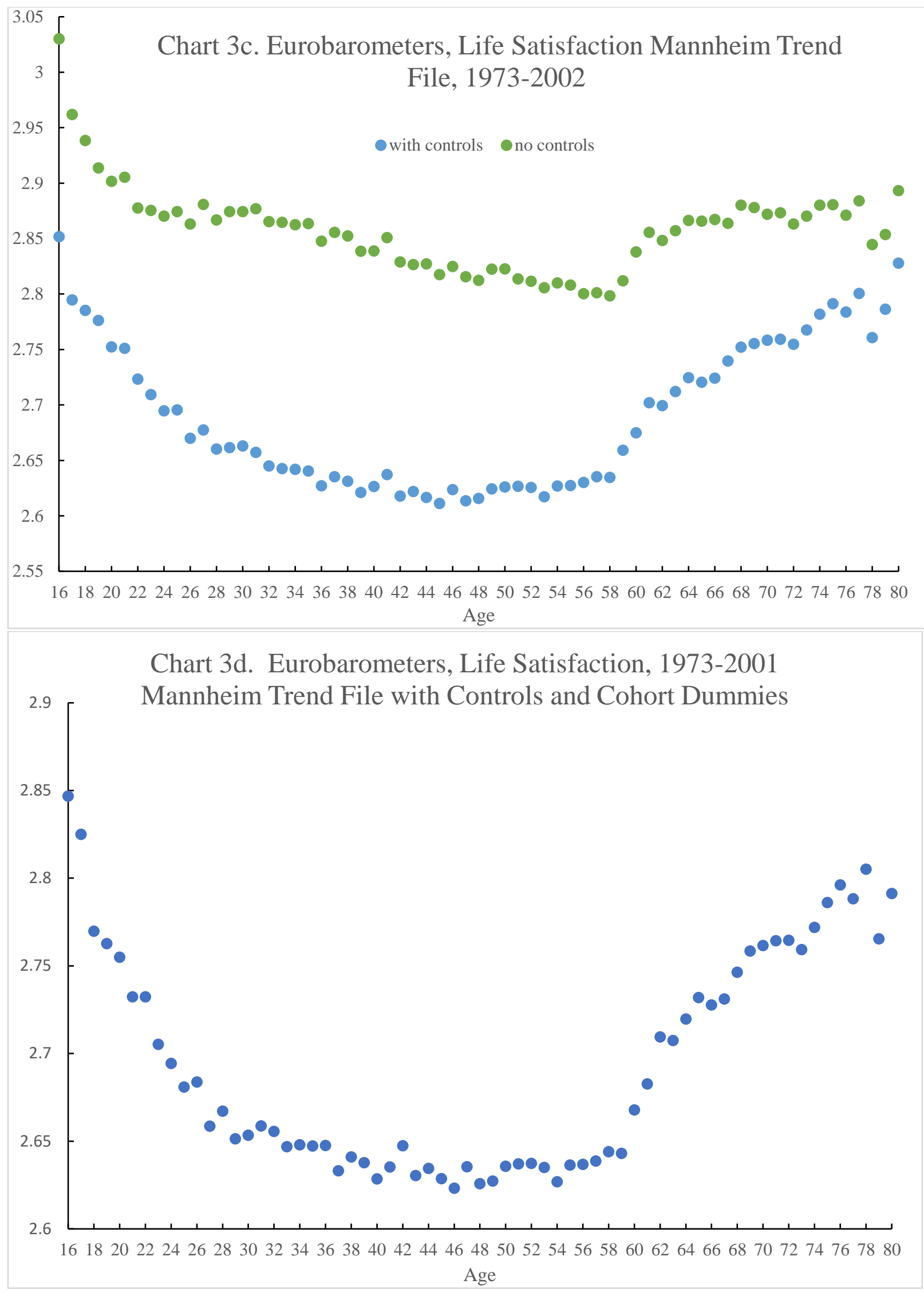


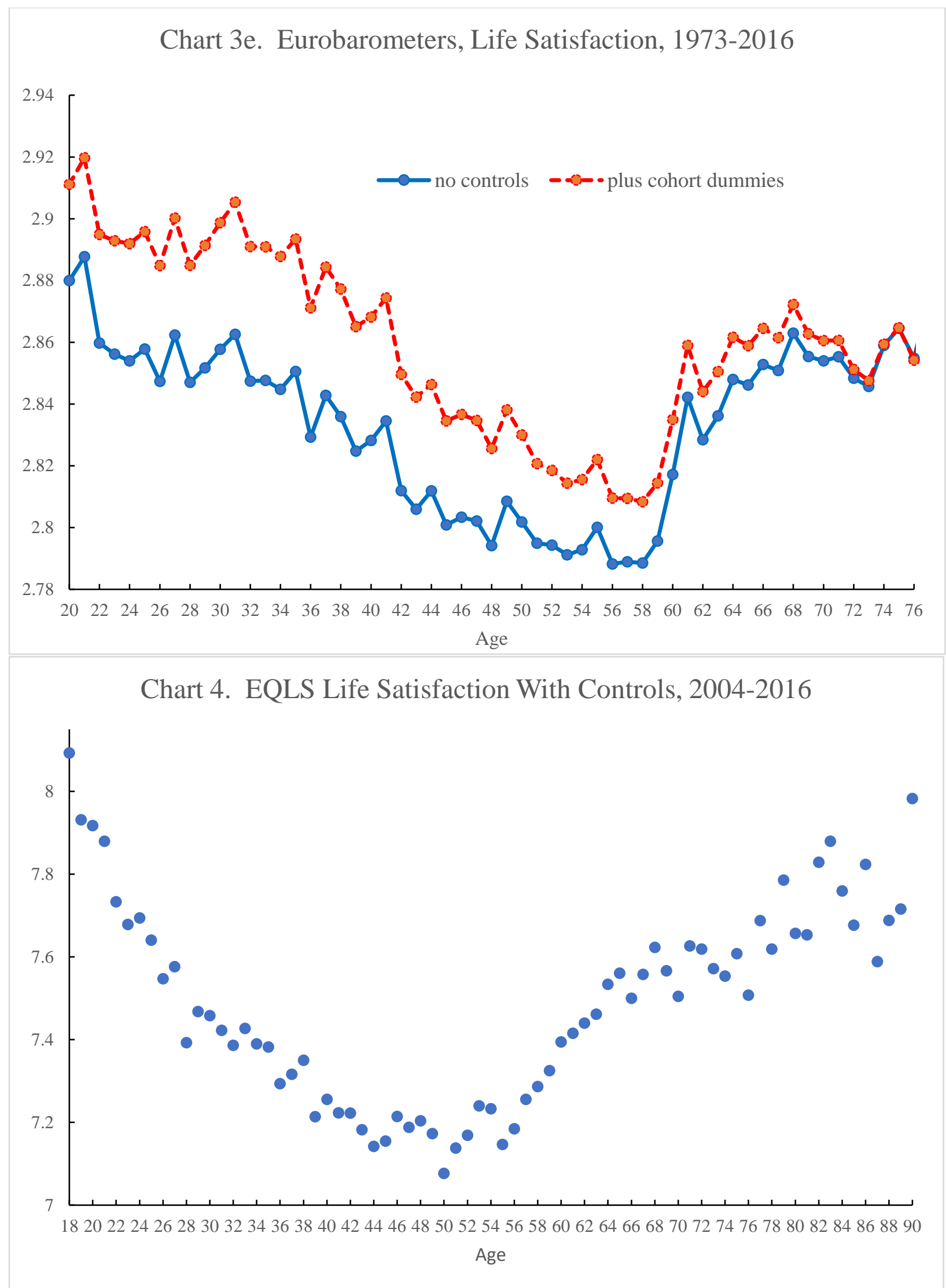



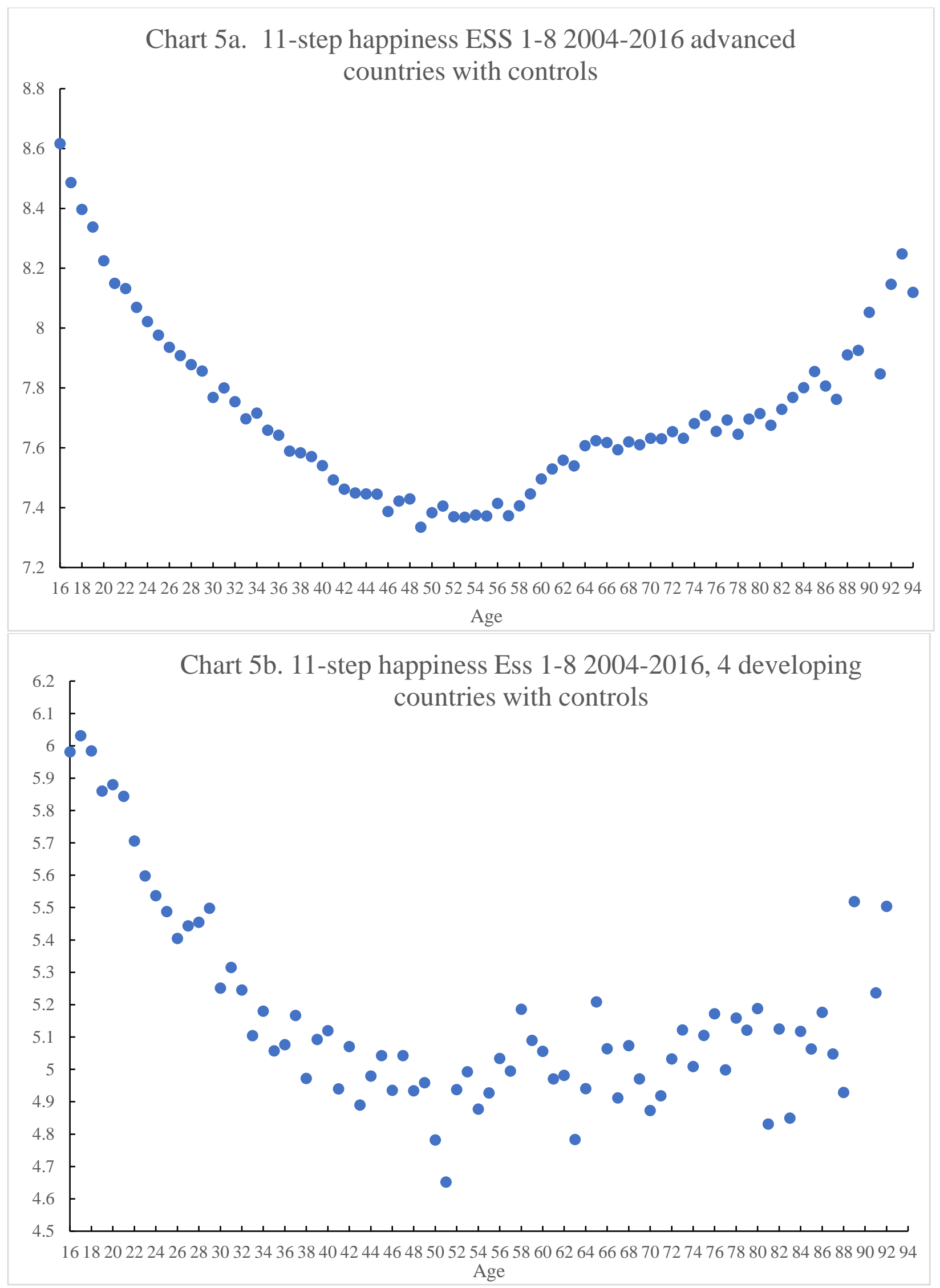


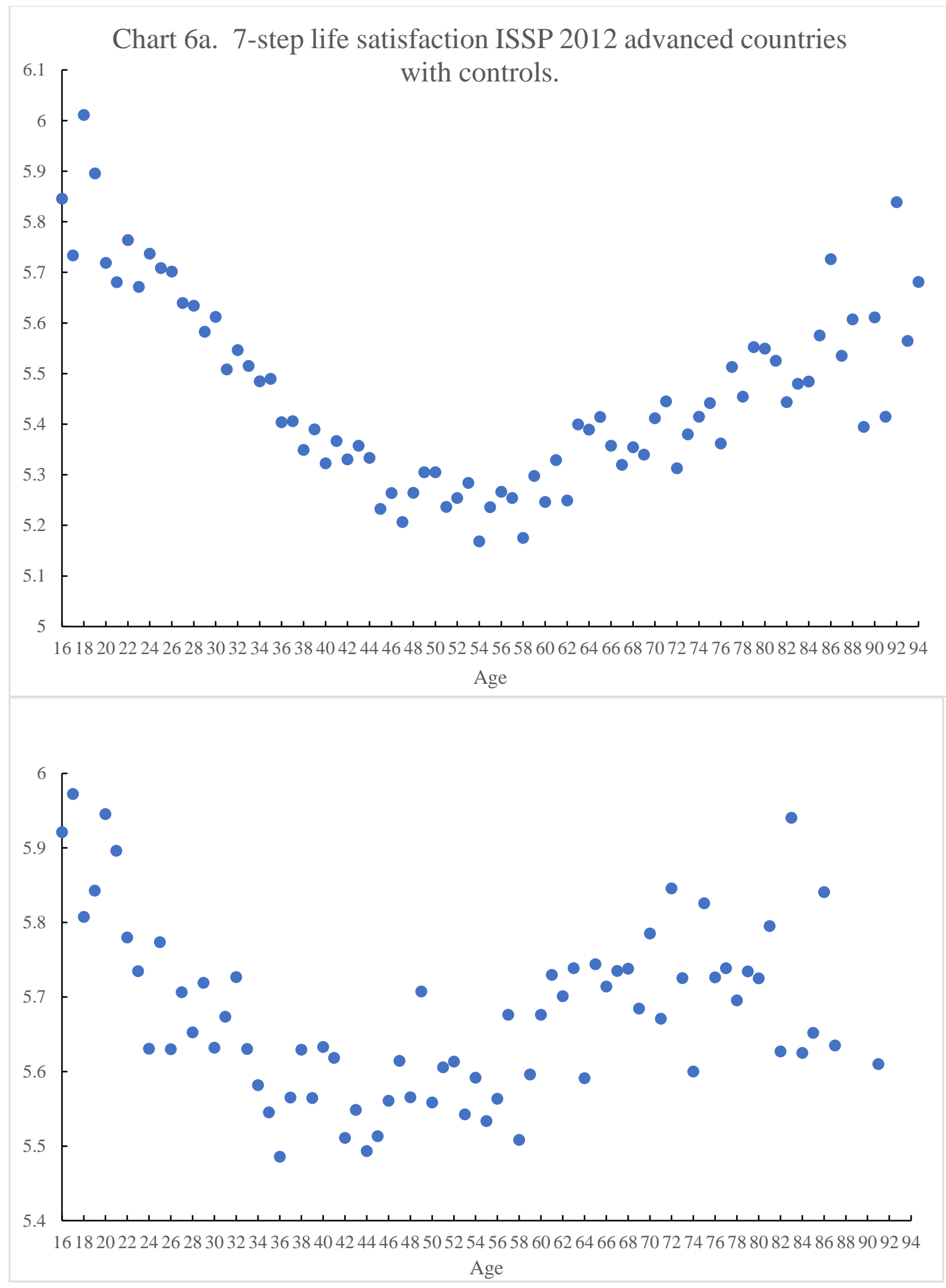




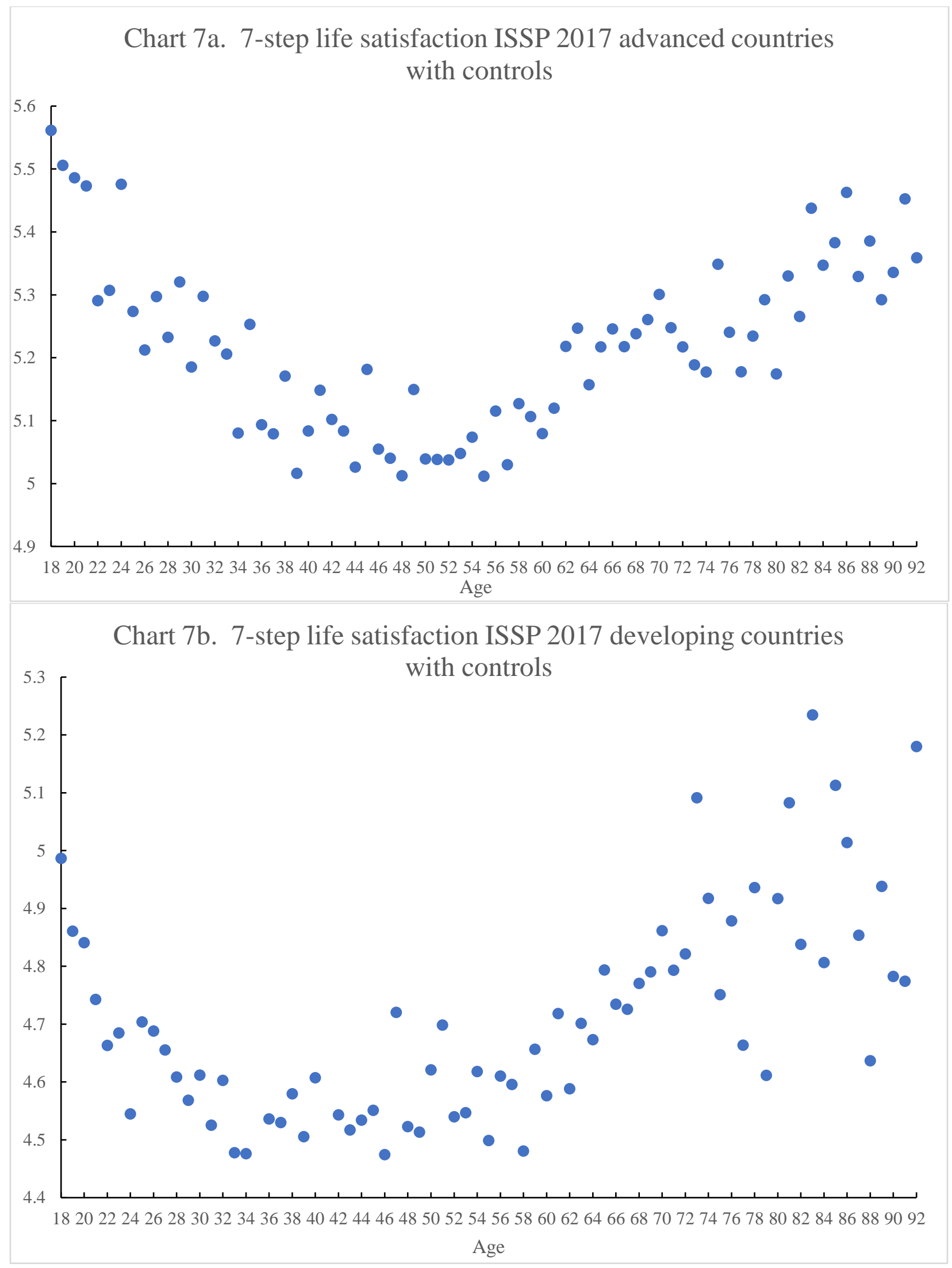




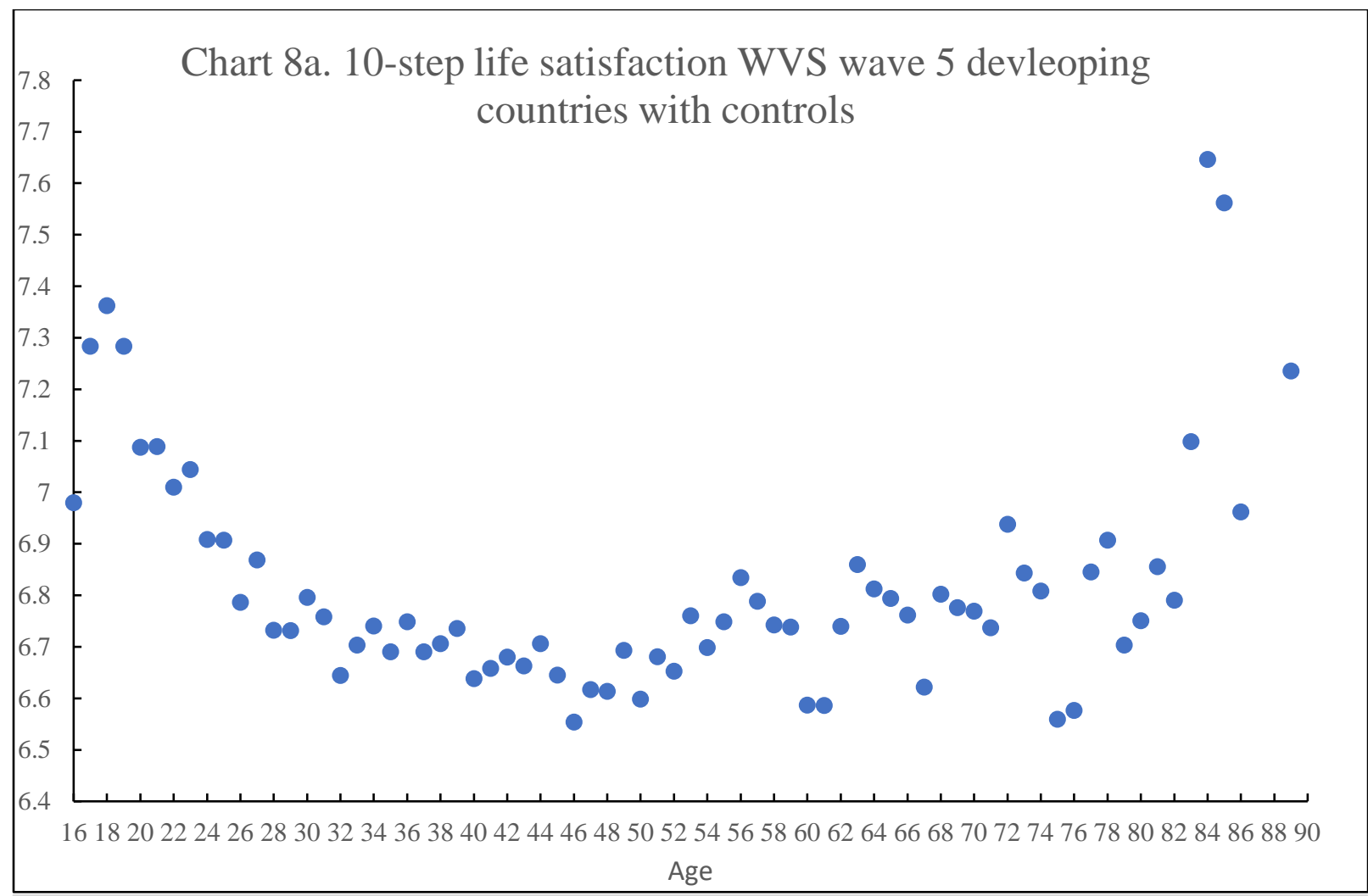

Chart 8b. 4-step happiness WVS wave 5 developing countries with controls

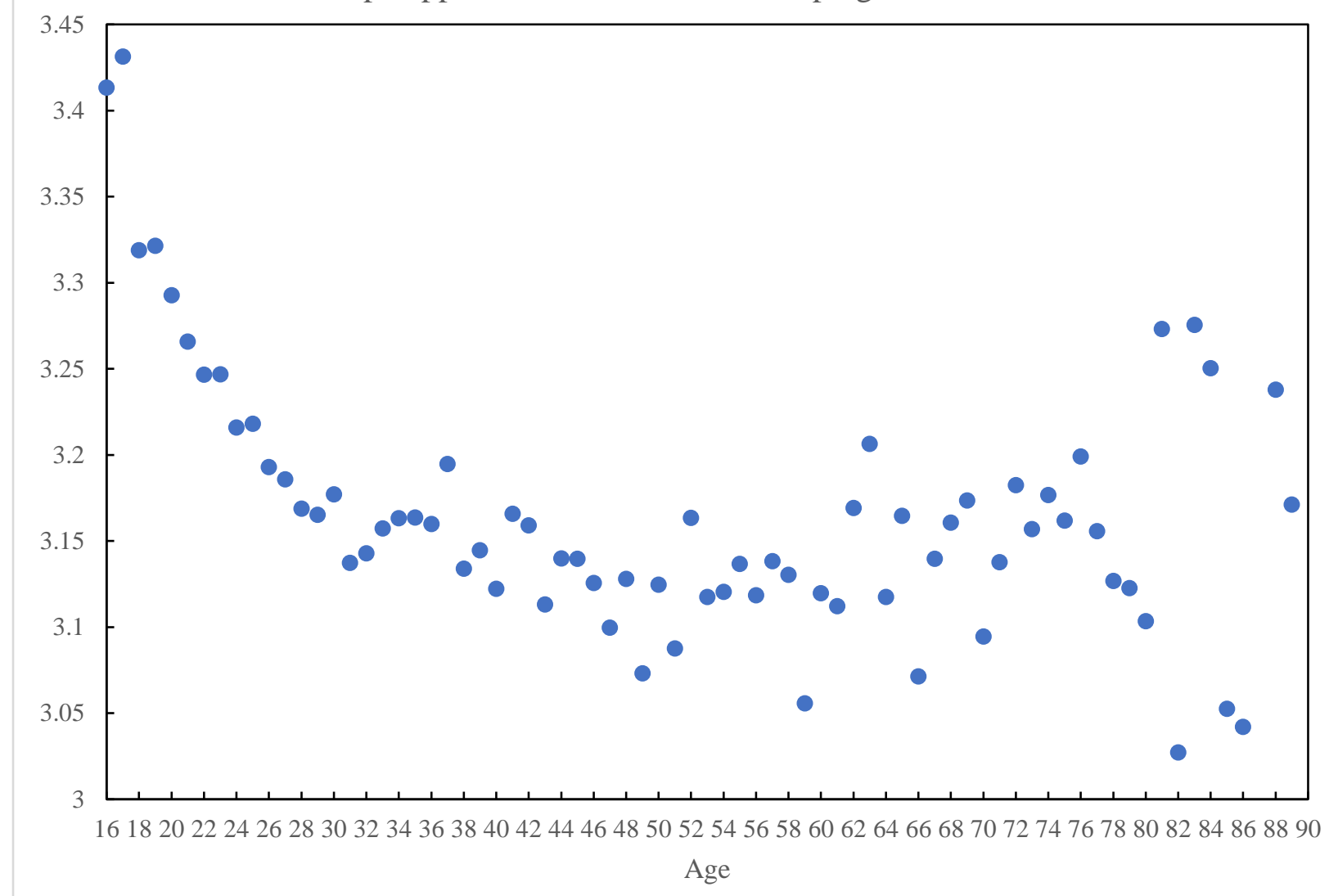




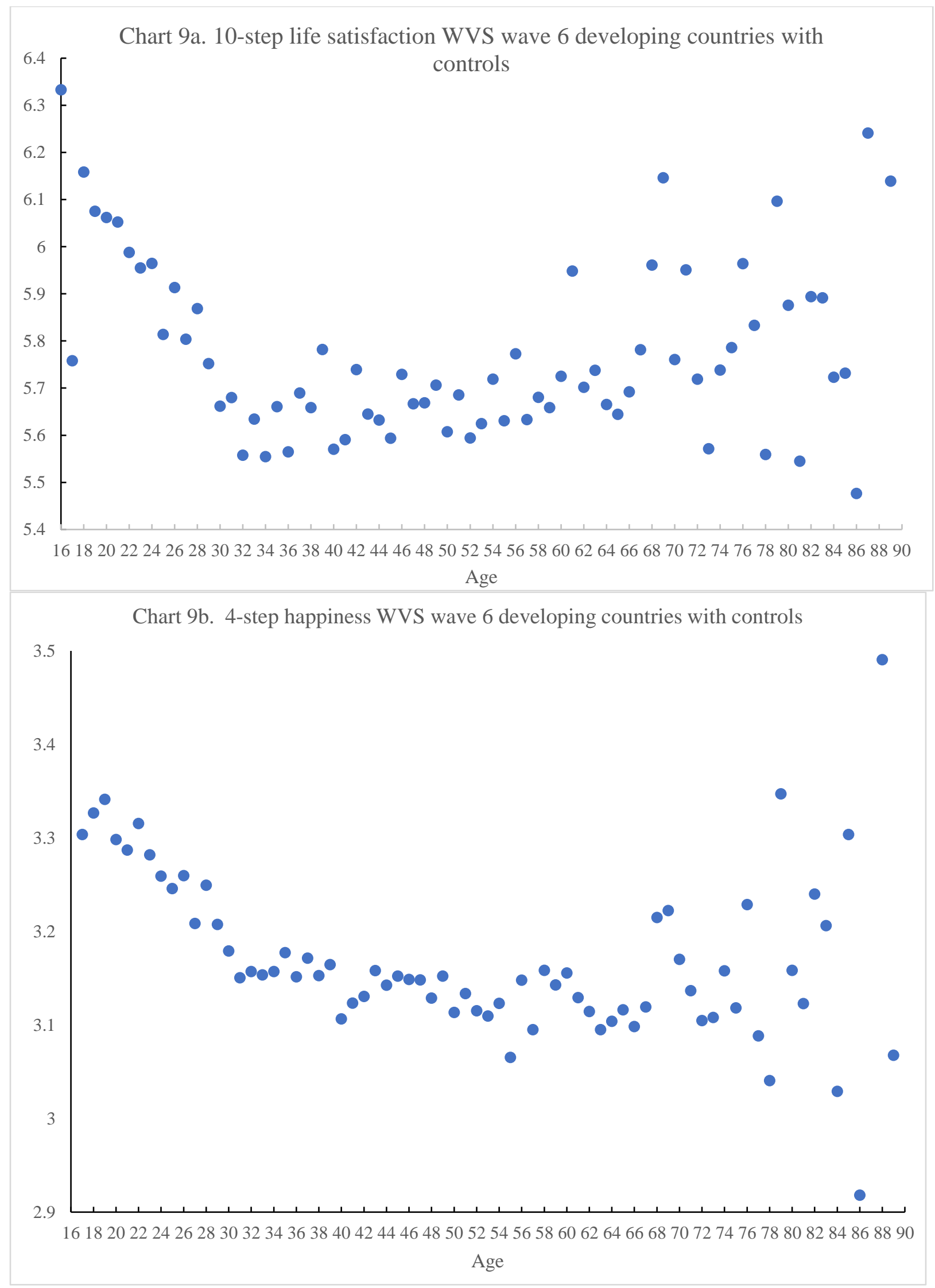



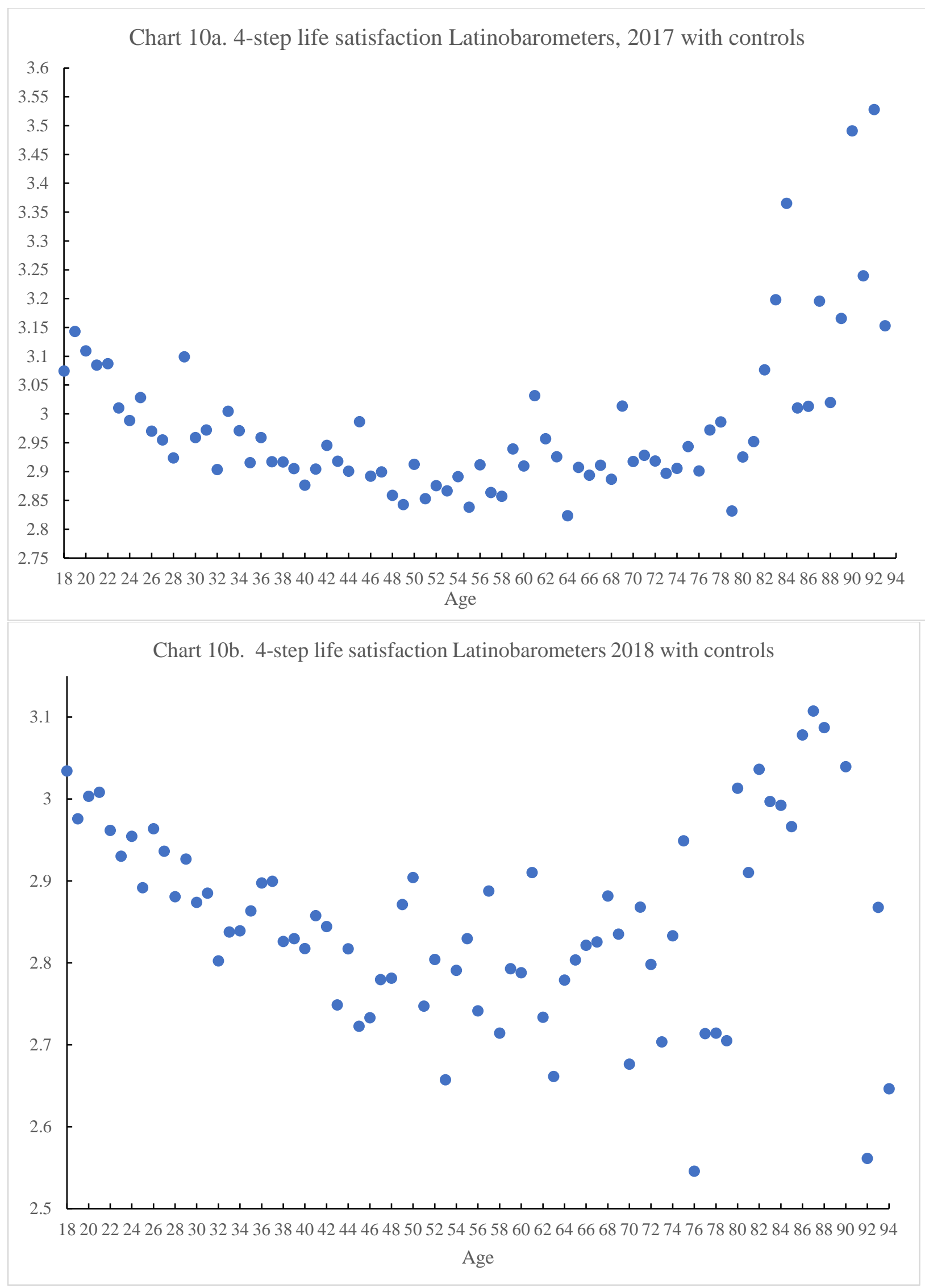


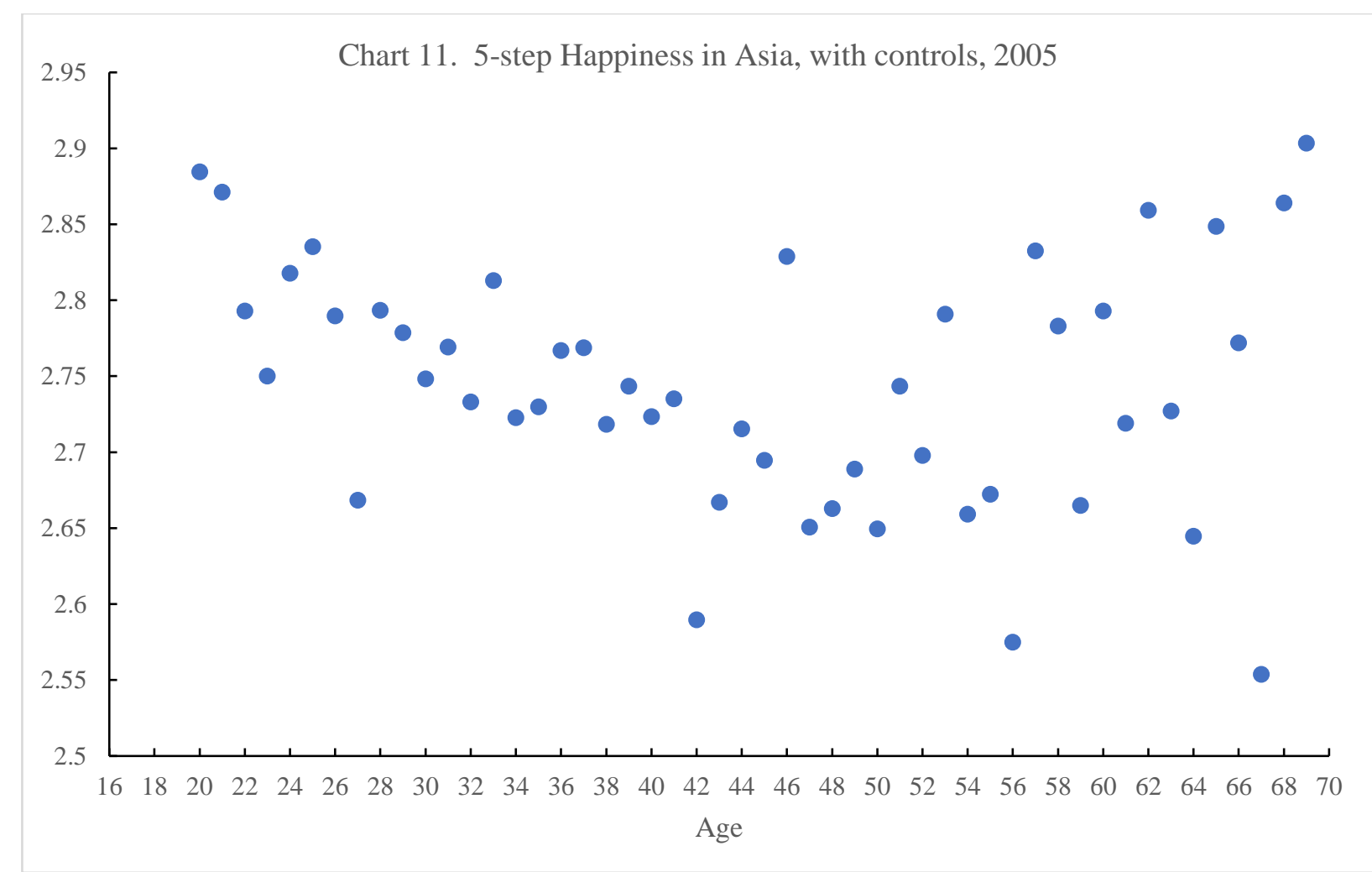

Chart 12. Consumer Attitudes in European Union 28 - over the last twelve months from the EU Commission

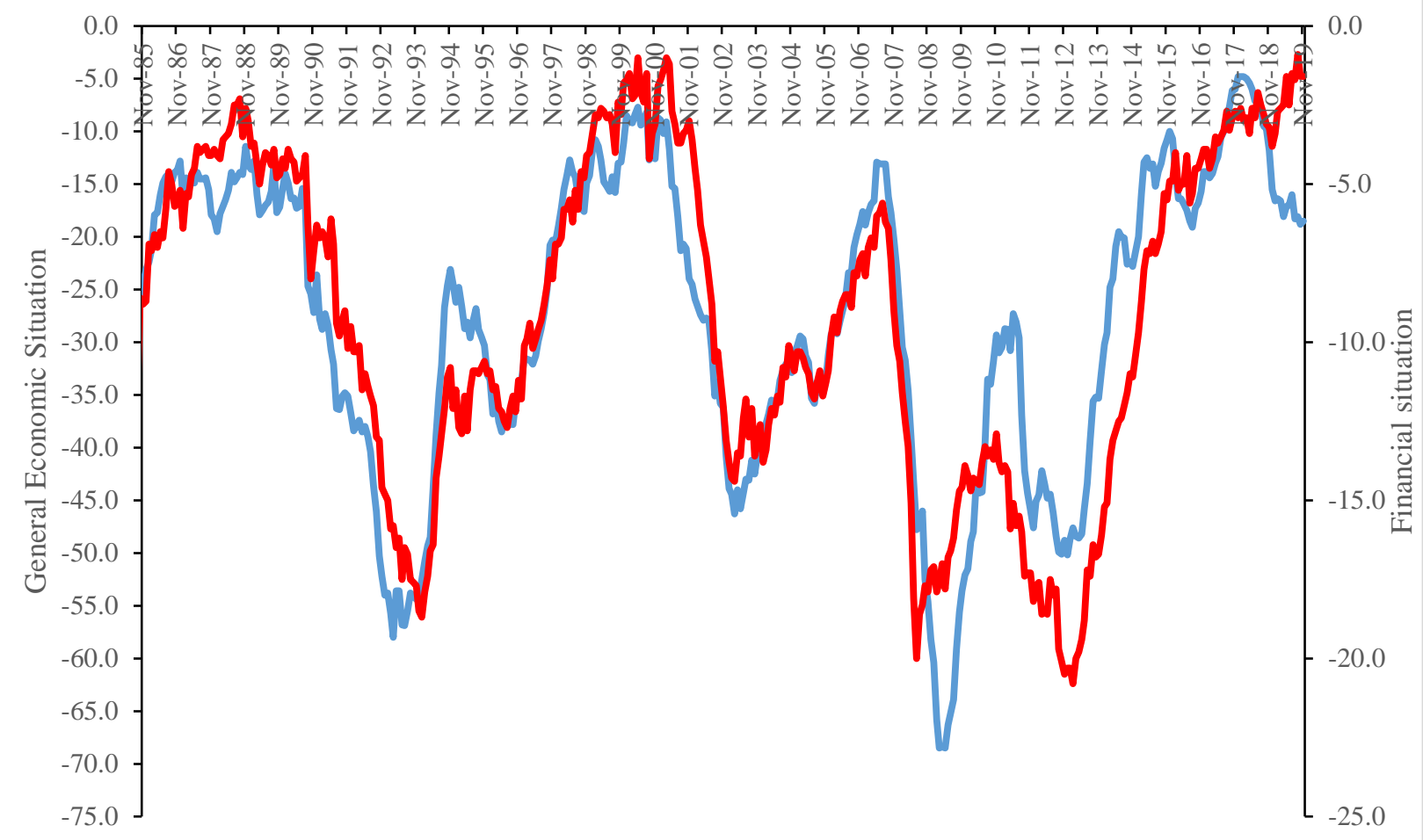

General Economic situation over last 12 months (LHS) — Financial situation last 12 months (RHS) 


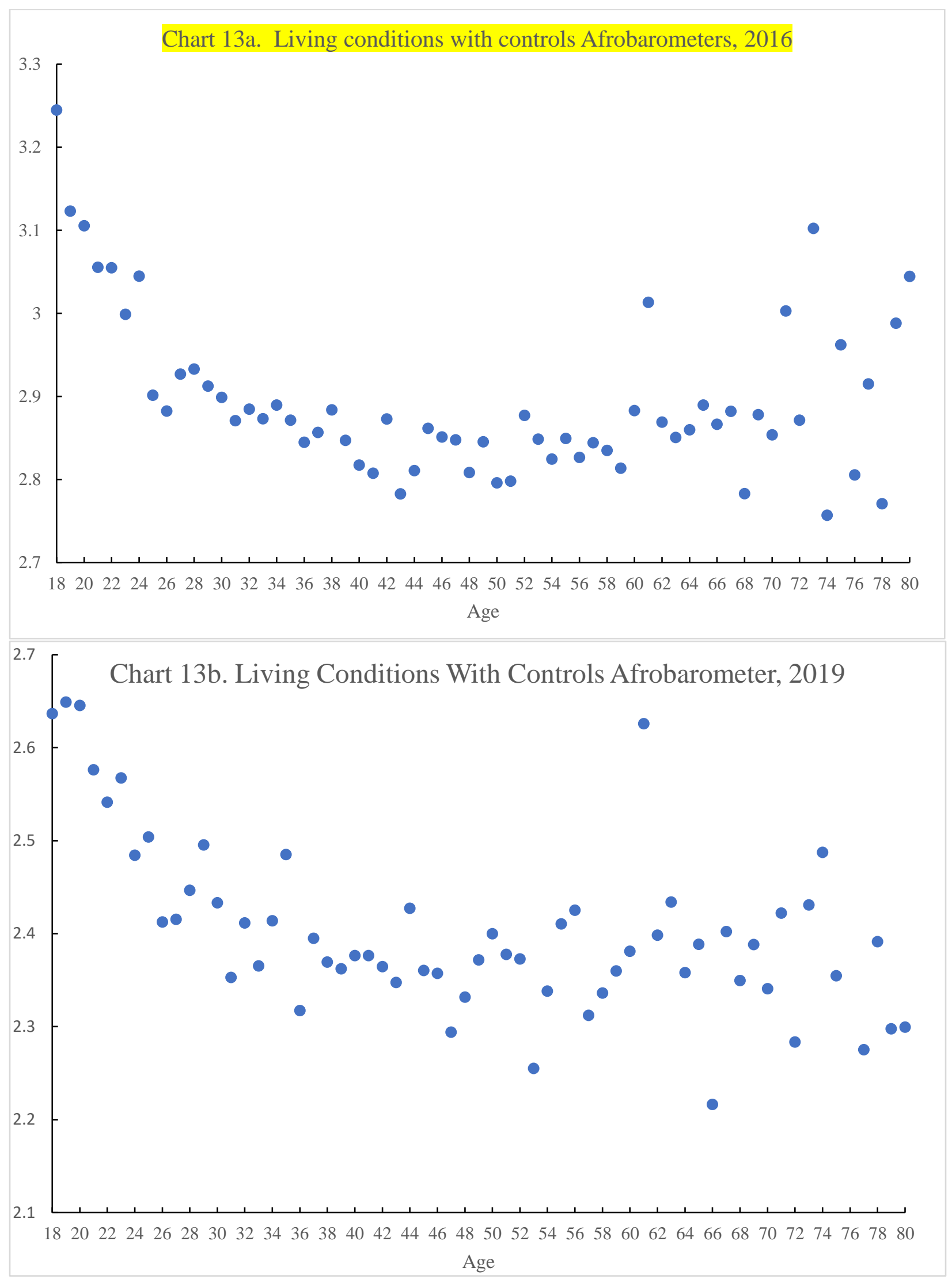


Appendix 1. Developing countries by data set

a) World Values Survey

Wave 6 (2010-2014)

Algeria; Azerbaijan; Argentina; Armenia; Brazil; Belarus; Chile; China; Taiwan; Colombia; Ecuador; Georgia; Palestine; Ghana; Haiti; Hong Kong; India; Iraq; Kazakhstan; Jordan; South Korea; Kuwait; Kyrgyzstan; Lebanon; Libya; Malaysia; Mexico; Morocco; Nigeria; Pakistan; Peru; Philippines; Qatar; Russia; Rwanda; Singapore; South Africa; Zimbabwe; Thailand; Trinidad and Tobago; Tunisia; Turkey; Ukraine; Egypt; Uruguay; Uzbekistan and Yemen.

Wave 5 (2005-2009)

Andorra; Argentina; Brazil; Chile; China; Taiwan; Colombia; Ethiopia; Georgia; Ghana; Guatemala; Hong Kong; India; Indonesia; Iran; Iraq; Jordan; South Korea; Malaysia; Mali; Mexico; Moldova; Morocco; Peru; Russia; Rwanda; Serbia; Vietnam; South Africa; Thailand; Trinidad and Tobago; Turkey; Ukraine; Egypt; Burkina Faso; Uruguay and Zambia.

Wave 4 (1999-2004)

Albania; Algeria; Argentina; Bangladesh; Chile; China; India; Indonesia; Iran; Iraq; Israel; Jordan; South Korea; Kyrgyzstan; Mexico; Moldova; Morocco; Nigeria; Pakistan; Peru; Philippines; Puerto Rico; Saudi Arabia; Singapore; Vietnam; South Africa; Zimbabwe; Turkey; Uganda; Macedonia; Egypt; Tanzania; Venezuela; Serbia and Montenegro.

Wave 3 (1995-1998)

Albania; Azerbaijan; Argentina; Bangladesh; Armenia; Brazil; SrpSka Republic; Belarus; Chile; China; Taiwan; Colombia; Dominican Rep.; El Salvador; Georgia; India; South Korea; Mexico; Moldova; Nigeria; Pakistan; Peru; Philippines; Puerto Rico; Russia; South Africa; Turkey; Macedonia; Uruguay; Venezuela; Serbia; Montenegro and Bosnia.

Wave 2 (1990-1994)

Argentina; Brazil; Belarus; Chile; China; India; South Korea; Mexico; Nigeria; Russia; South Africa and Turkey.

\section{b) International Social Survey Programme 2017}

China; Taiwan; India; Israel; Mexico; Philippines; Russia; South Africa; Surinam; Thailand

2012

Argentina; Chile; China; Taiwan; India; Israel; South Korea; -Mexico; Philippines; Russia; South Africa; Turkey; Venezuela

\section{c) Asiabarometers}

2007

Malaysia; Indonesia; Philippines; Thailand; Myanmar; Cambodia and Laos

2006

China; Hong Kong; Japan; Singapore; South Korea; Taiwan and Vietnam 
Afghanistan; Bangladesh; Bhutan; India; Kazakhstan; Kyrgyzstan; Maldives; Mongolia; Nepal; Pakistan; Sri Lanka; Tajikistan; Turkmenistan and Uzbekistan

\section{d) Latinobarometers}

2017 and 2018

Argentina; Bolivia; Brazil; Chile; Colombia; Costa Rica; Dominican Rep of; Ecuador; El Salvador; Guatemala; Honduras; Mexico; Nicaragua; Panama; Paraguay; Peru; Uruguay and Venezuela 
Appendix B. Raw Plots of data from MO's Eurobarometer Data Series, 1973-2016
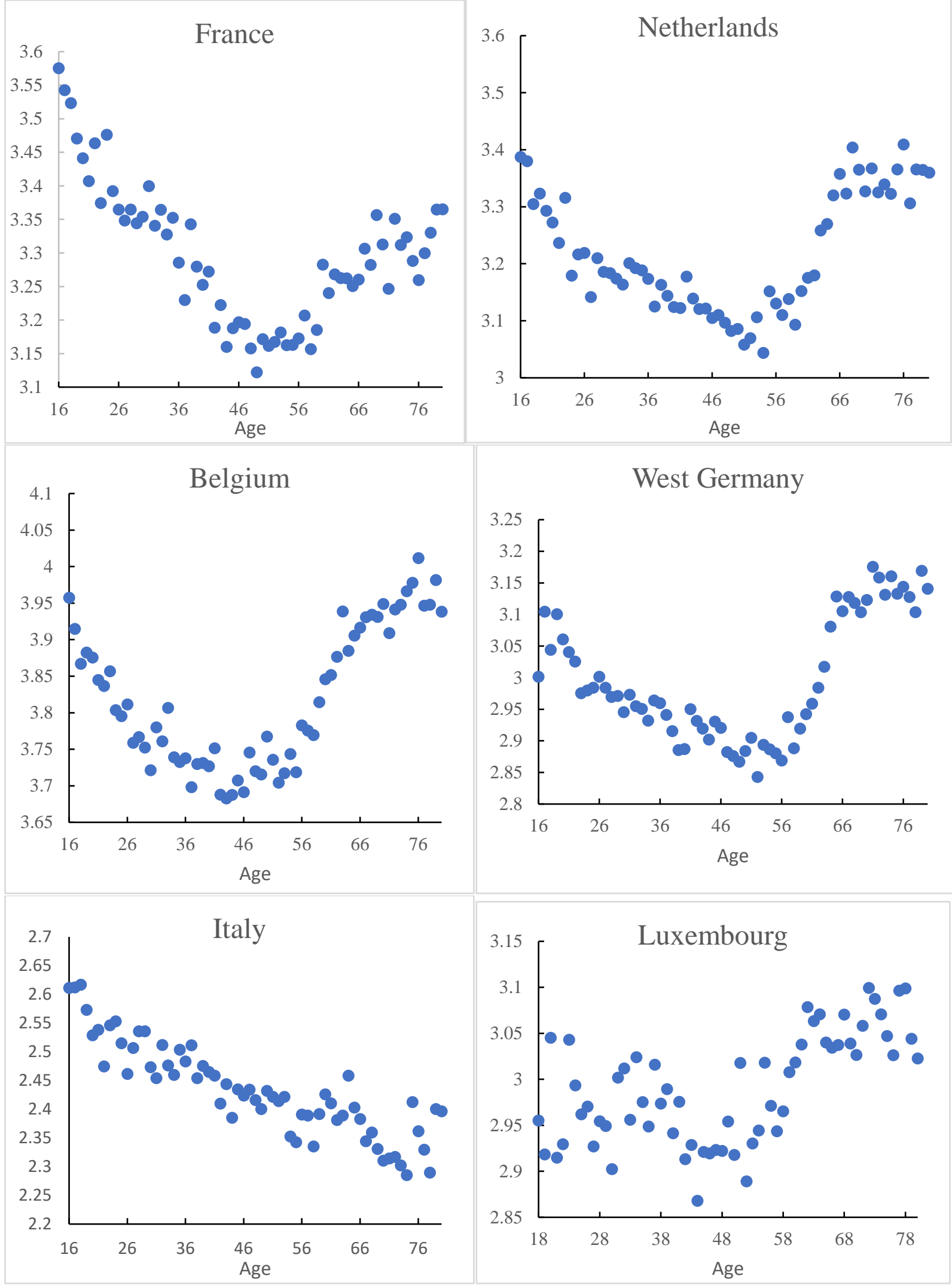


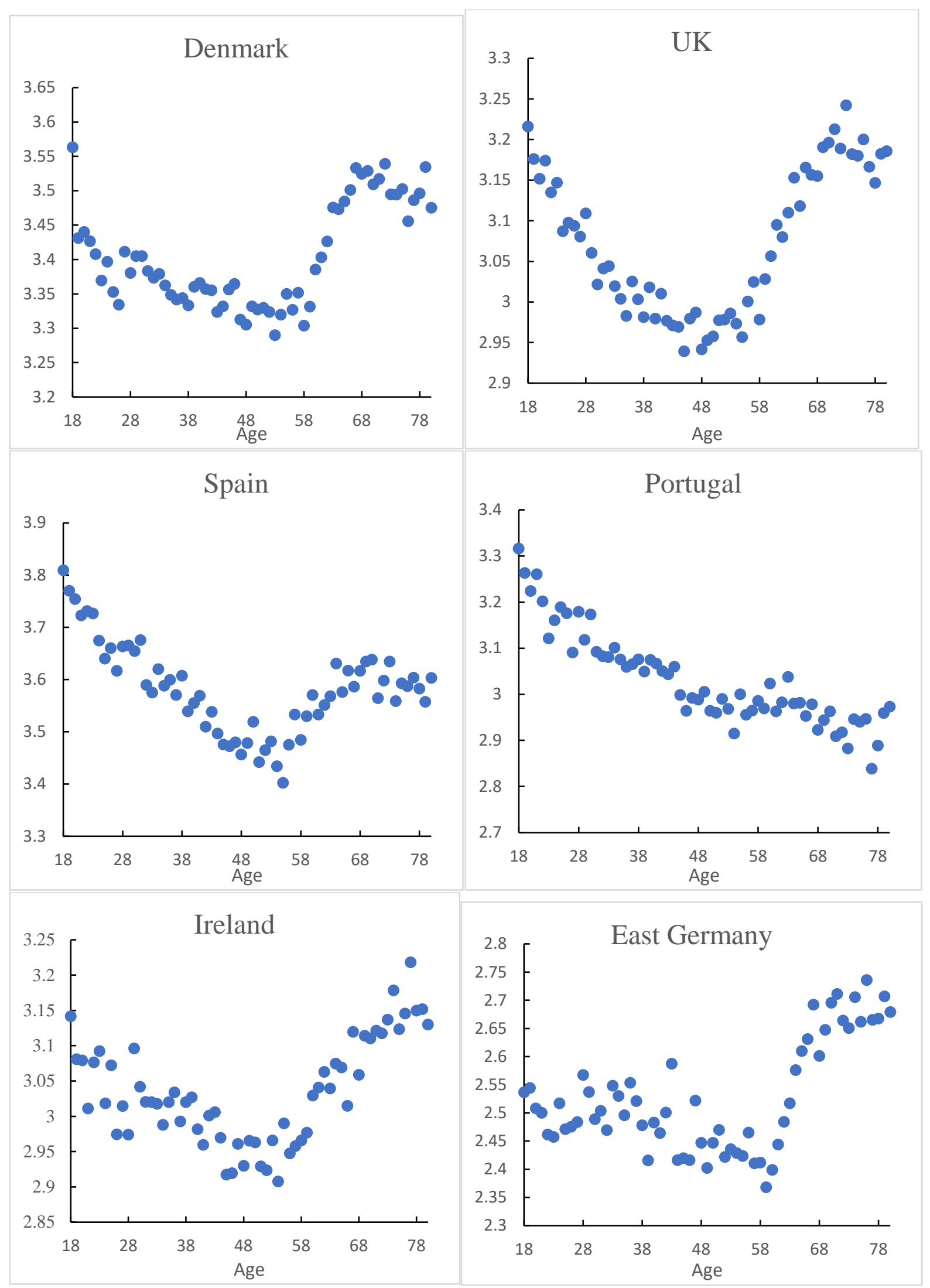




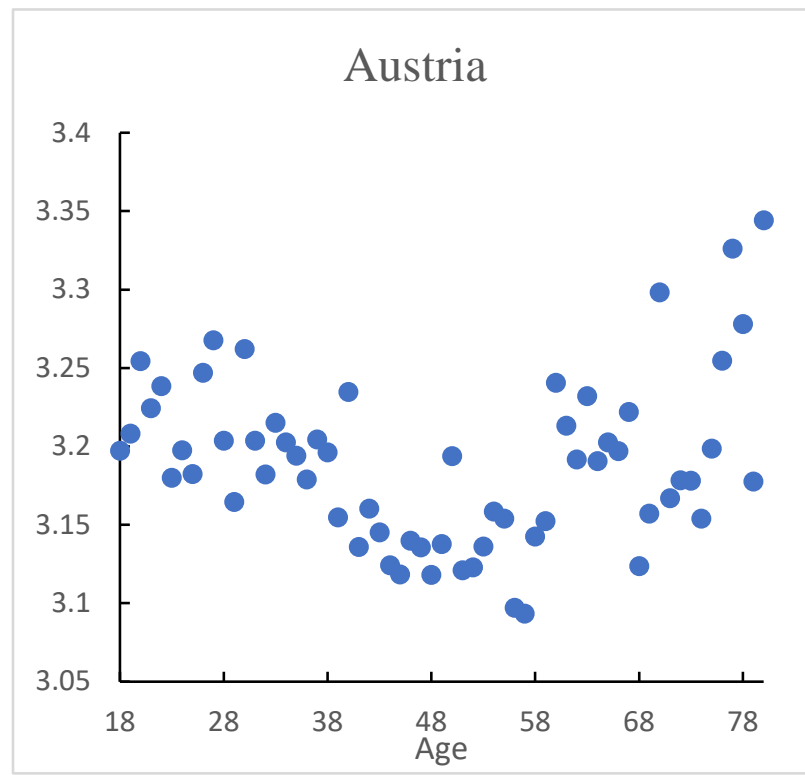

Finland

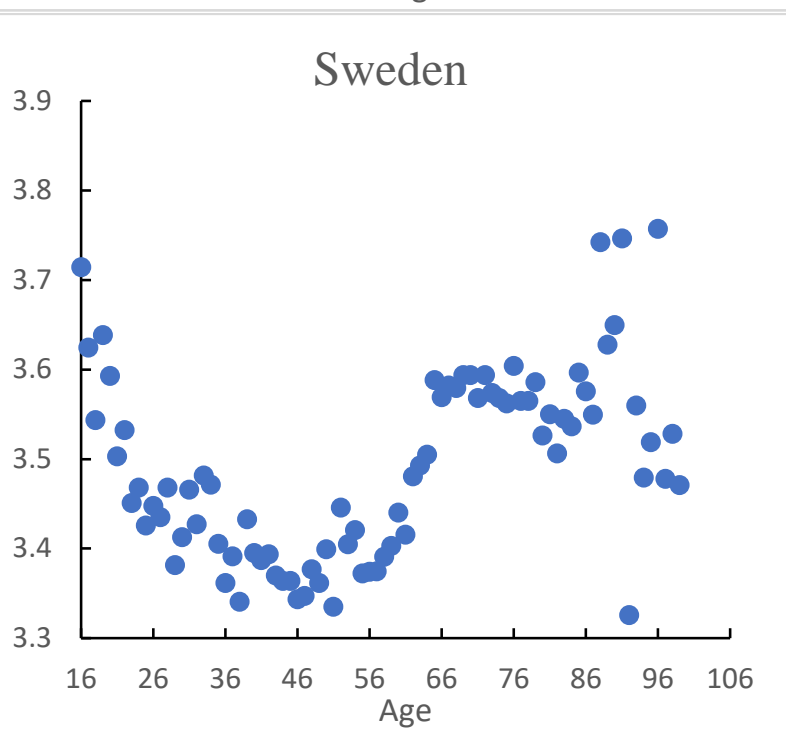

